\author{
UNIVERSIDADE DE SÃO PAULO \\ Faculdade de Filosofia, Ciências e Letras de Ribeirão Preto \\ Departamento de Psicologia \\ Programa de Pós-Graduação em Psicobiologia
}

\title{
EQUIVALÊNCIA DE ESTÍMULOS E RESPONDER POR EXCLUSÃO EM IDOSOS COM E SEM COMPROMETIMENTO COGNITIVO
}

Mariana Ducatti Almeida

Ribeirão Preto

2014 


\author{
UNIVERSIDADE DE SÃO PAULO \\ Faculdade de Filosofia, Ciências e Letras de Ribeirão Preto \\ Departamento de Psicologia \\ Programa de Pós-Graduação em Psicobiologia
}

\title{
EQUIVALÊNCIA DE ESTÍMULOS E RESPONDER POR EXCLUSÃO EM IDOSOS COM E SEM COMPROMETIMENTO COGNITIVO
}

\author{
Mariana Ducatti Almeida
}

Dissertação apresentada à Faculdade de Filosofia, Ciências e Letras de Ribeirão Preto, como parte das exigências para obtenção do título de Mestre em Ciências, área de Psicobiologia.

Orientadora: $\operatorname{Prof}^{a} \operatorname{Dr}^{\mathrm{a}}$ Andréia Schmidt

Ribeirão Preto 
Autorizo a reprodução e divulgação total ou parcial deste trabalho, por qualquer meio convencional ou eletrônico, para fins de estudo e pesquisa, desde que citada a fonte.

FICHA CATALOGRÁFICA

Ducatti, Mariana.

Equivalência de Estímulos e Responder por Exclusão em Idosos com e sem Comprometimento Cognitivo. Ribeirão Preto, 2014.

145 p. : il. ; $30 \mathrm{~cm}$

Dissertação de Mestrado, apresentada à Faculdade de Filosofia, Ciências e Letras de Ribeirão Preto/USP. Área de concentração: Psicobiologia.

Orientadora: Schmidt, Andréia.

1. Equivalência de Estímulos. 2. Responder por Exclusão. 3. Idoso. 4. Comprometimento Cognitivo Leve. 5. Doença de Alzheimer. 6. Instituição de Longa Permanência para Idosos. 


\section{FOLHA DE APROVAÇÃO}

Nome: Mariana Ducatti Almeida

Título: Equivalência de Estímulos e Responder por Exclusão em Idosos com e sem Comprometimento Cognitivo

Dissertação apresentada à Faculdade de Filosofia, Ciências e Letras de Ribeirão Preto da USP, como parte das exigências para a obtenção do título de Mestre em Ciências. Área: Psicobiologia.

Aprovado em: / 2014

\section{Banca Examinadora}

Prof ${ }^{\text {. Dra }}$. Andréia Schmidt (orientadora)

Instituição: Universidade de São Paulo

Assinatura:

Prof ${ }^{\mathrm{a}}$. Dr ${ }^{\mathrm{a}}$ Camila Domeniconi

Instituição: Universidade de São Carlos

Assinatura:

\section{Prof $^{0}$ Dr$^{\circ}$ Cesar Alexis Galera}

Instituição: Universidade de São Paulo

Assinatura: 


\section{Dedicatória}

Dedico meu trabalho...

À minha mãe, Rosana, que foi a primeira da família a entrar no mundo acadêmico e mostrar as possibilidades que vão além da graduação.

Ao meu pai, Alberto, que é o porto seguro da família. Obrigada pelo carinho e preocupação constante.

Ao Everton, meu namorado. Obrigada pelas risadas, compreensão, e principalmente, pelo cuidado diário. Amo você a cada dia mais.

Obrigada.

Amos rocês! 


\section{Agradecimentos}

A Deus, pela força.

À minha irmã Juliana, pelo apoio e companheirismo.

À amiga-irmã Danielle Nishida e as professora-amigas Camila e Denise, por acompanharem todo o processo de estudo antecedente à entrada no mestrado e pelas constantes palavras de apoio.

À professora e orientadora Andréia Schmidt, por me dar uma oportunidade, por me ensinar conceitos da análise do comportamento e por confiar a mim o trabalho com a população idosa. Andréia, obrigada por este presente.

Às professoras $\operatorname{Dr}^{\mathrm{a}}$ Camila Domeniconi e Dr ${ }^{\mathrm{a}}$ Deisy das Graças de Souza, pelas contribuições durante a qualificação.

Aos amigos de laboratório, Alana Brunini, pela palavra sábia no meio da dúvida; Camila Bonagamba, pelo apoio; Julia Fonseca, pelo carinho; Matheus Felipe de Souza, pela ajuda inicial, que foi importante para essa conquista; Melina Vaz, por dividir comigo a ansiedade da qualificação; Sabrina Oliveira, pelas opiniões científicas sempre sensatas; Sara Cirilo, pelas conversas referentes a pós-graduação e vida pessoal (Sim, há vida fora do mestrado!); e Vinícius Warisaia, pela animação diária. Vinni, sem você o laboratório não teria graça! Pessoal, agradeço as colaborações e momentos de bolo após a reunião do Catania.

À Iara, Eliane e Igor, por permitirem que eu realizasse meu trabalho em suas instituições e apoiarem a pesquisa. $\mathrm{E}$ aos participantes, não apenas por terem contribuído com os resultados do trabalho, mas por terem permitido que eu, tão cedo, conhecesse as dádivas e dores da velhice.

À Renata Del Moro, secretária do programa de PG em Psicobiologia, por sempre resolver as dúvidas e problemas burocráticos. À Coordenação de Aperfeiçoamento de Pessoal de Nível Superior (CAPES) pelo apoio na pesquisa e concessão da bolsa de mestrado.

Ao Leo Escarpellin por me socorrer tecnologicamente. Obrigada pela atenção e paciência. E ao amigo Fernando Henrique, por sempre estar tão perto, mesmo que longe.

Muito obrigiada! 


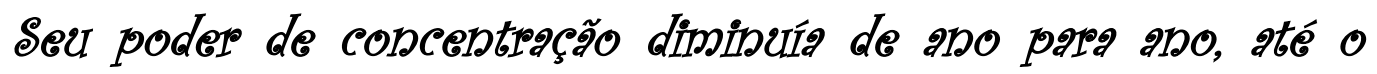

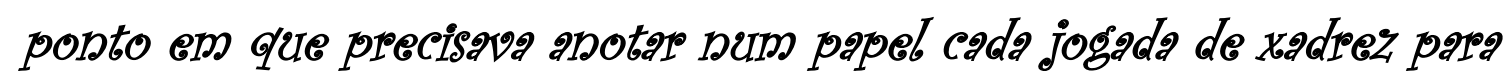
saber por onde ia (Gasprél Garecia Marequez. $O$ amor pos tempos do Cóbera).

Ele extra pa idade em que pão se recomeça mais, a idade em que se começa a ebrelhecer, em que é preciso aceitar ocupar pa sociedade um lutgar que bos fare axistip como um Outro entre os Outros. Bem antes de ser um destino biológico, o envelhecimento é

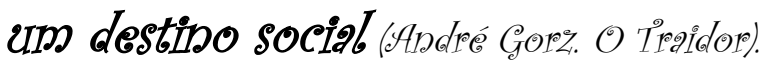




\section{Sumário}

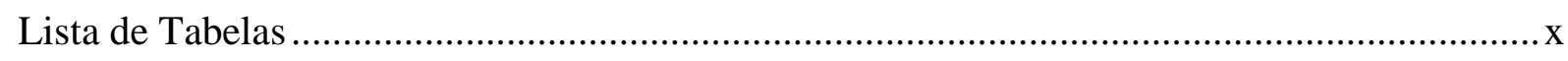

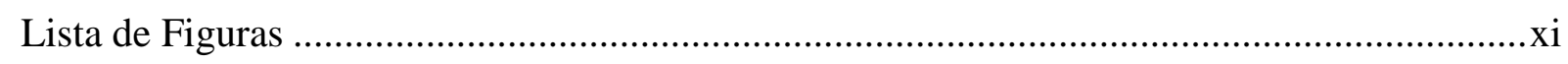

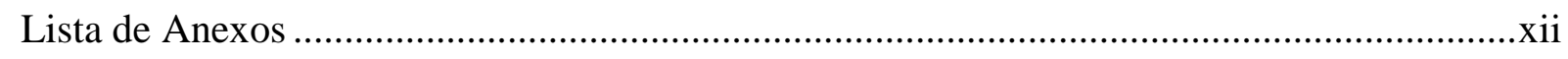

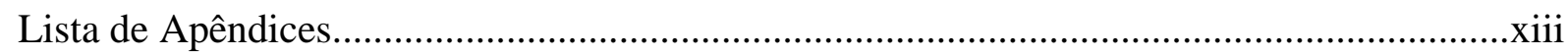

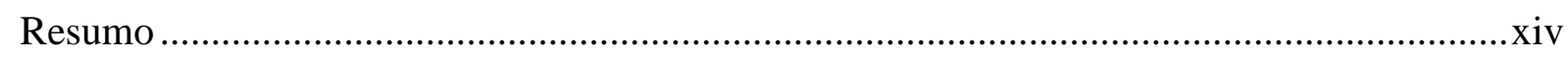

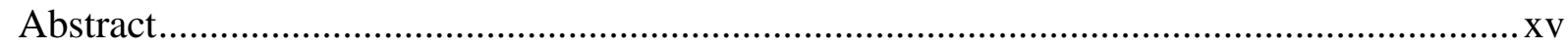

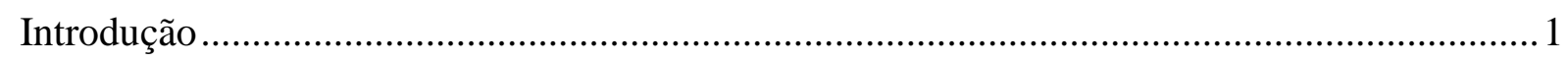

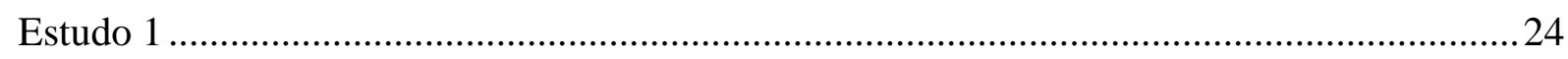

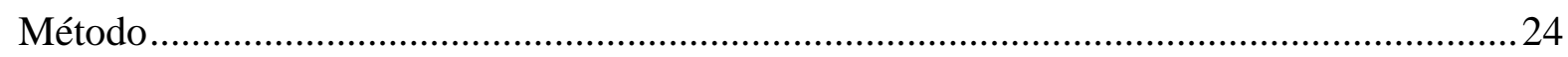

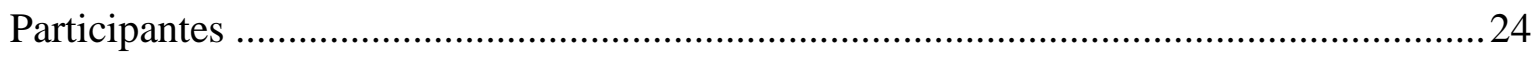

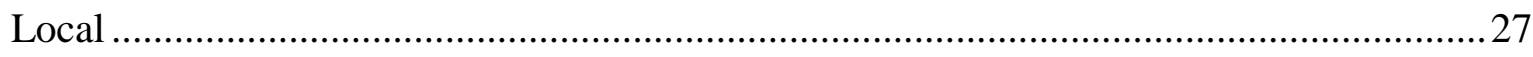

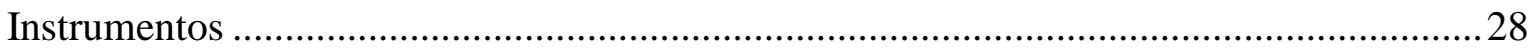

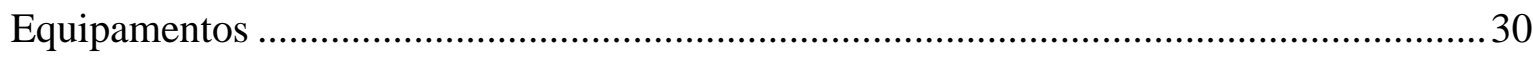

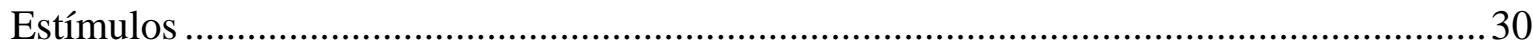

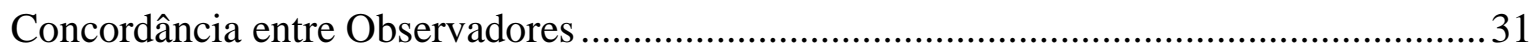

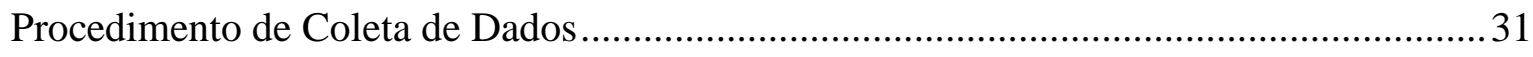

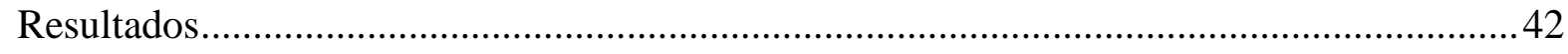

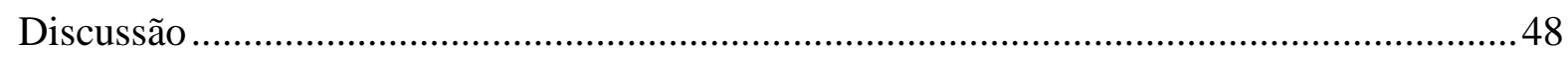

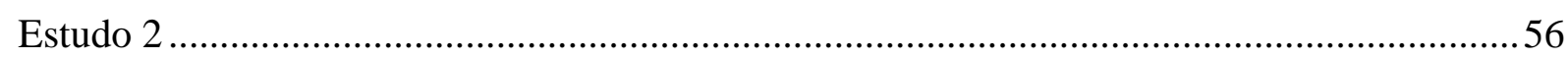

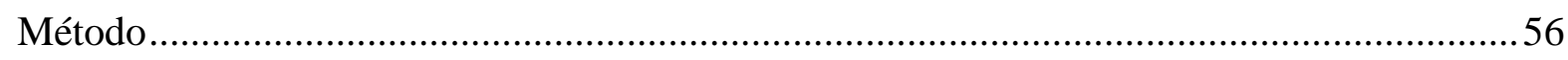

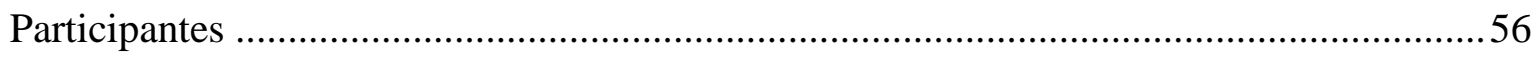




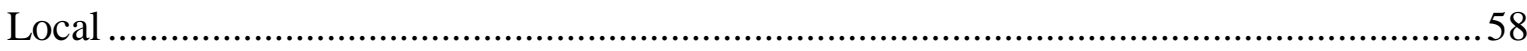

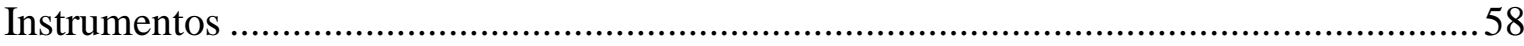

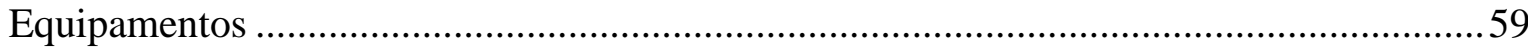

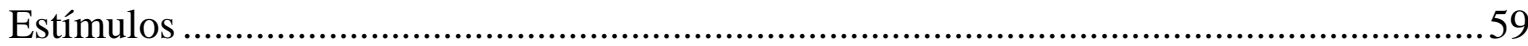

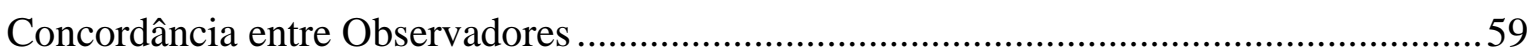

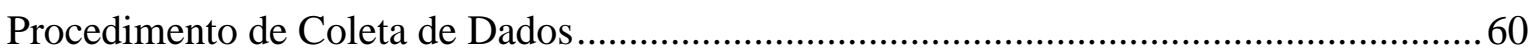

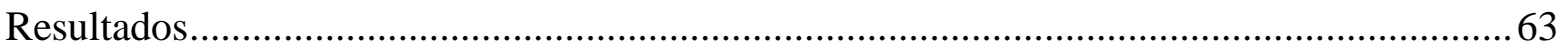

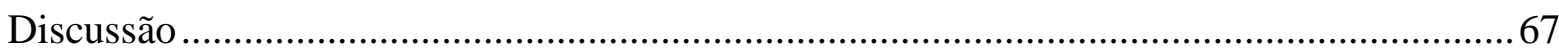

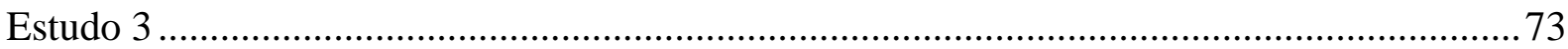

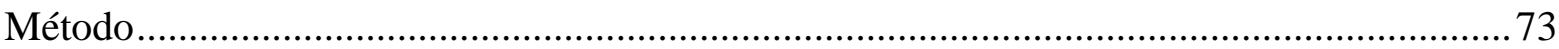

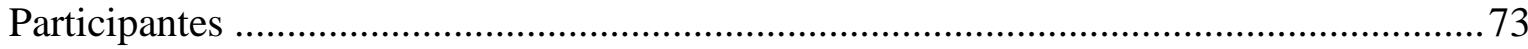

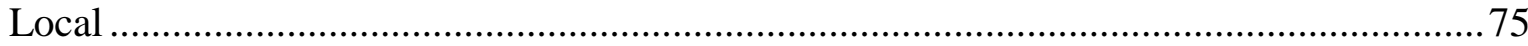

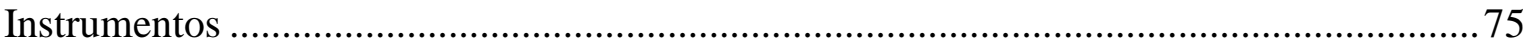

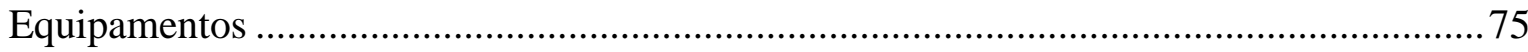

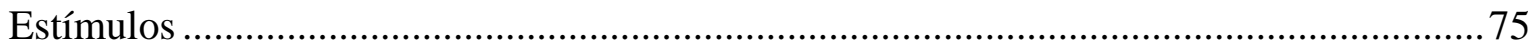

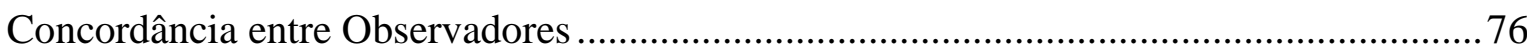

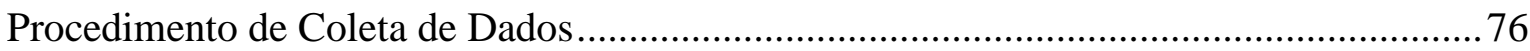

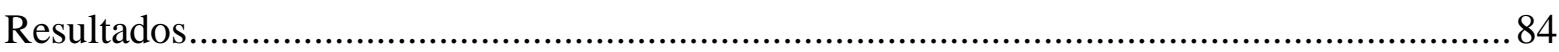

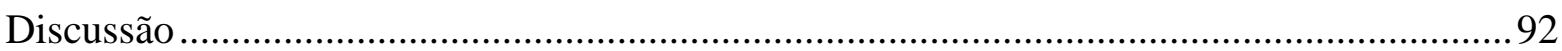

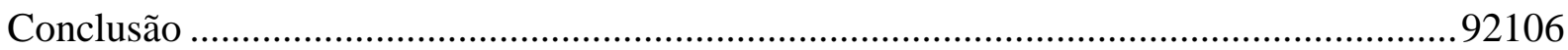

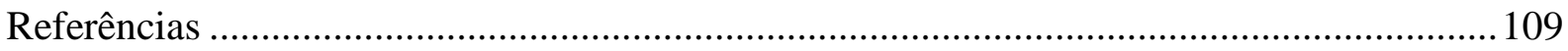

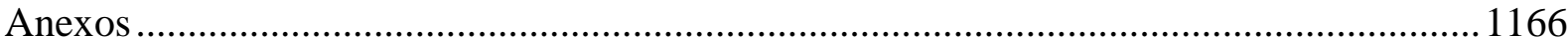

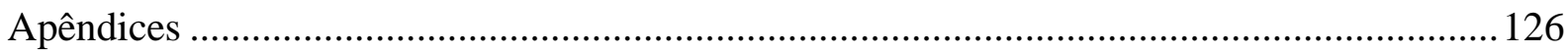




\section{Lista de Tabelas}

Tabela 1. Caracterização dos Participantes do Estudo 1.

Tabela 2. Resultados dos instrumentos aplicados para seleção dos participantes do Estudo 1.

Tabela 3. Estímulos empregados no procedimento do Estudo 1.

Tabela 4. Descrição das Fases do Procedimento de Ensino de Relações Arbitrárias do Estudo 1.

Tabela 5. Descrição dos blocos de Ensino das Relações e Testes de Equivalência.

Tabela 6. Caracterização dos Participantes do Estudo 2.

Tabela 7. Resultados dos instrumentos aplicados para seleção dos participantes do Estudo 2.

Tabela 8. Estímulos empregados no Estudo 2

Tabela 9. Composição dos blocos de ensino de discriminações condicionais AB.

Tabela 10. Caracterização dos Participantes do Estudo 3.

Tabela 11. Estímulos empregados no procedimento do Estudo 3.

Tabela 12. Fases e Etapas do procedimento de ensino e teste de relações condicionais do Estudo 3.

Tabela 13. Resultados dos Testes de Nomeação do Estudo 3. 


\section{Lista de Figuras}

Figura 1. Porcentagem de acertos dos participantes do Estudo 1 no ensino e teste das relações condicionais, bem como nos Testes de Manutenção.

Figura 2. Desempenho das idosas do Estudo 2 nas tentativas de exclusão e ensino das relações $\mathrm{AB}$.

Figura 3. Desempenho das idosas do Estudo 2 no ensino das relações AB

Figura 4. Resultados das participantes do Estudo 3 no ensino das relações condicionais e testes de equivalência

Figura 5. Resultados das participantes no Estudo 3 em cada LBCE.

Figura 6. Resultados das participantes do Estudo 3 em cada relação de equivalência. 


\section{Lista de Anexos}

Anexo 1. Parecer de Aprovação do Comitê de Ética.

Anexo 2. Mini-Exame do Estado Mental.

Anexo 3. Montreal Cognitive Assessment.

Anexo 4. Protocolo Montreal-Toulouse de Exame Linguístico da Afasia, versão M1Alpha

Anexo 5. Escala de Depressão Geriátrica

Anexo 6. Escala Hospitalar de Avaliação do Nível de Ansiedade e Depressão. 


\section{Lista de Apêndices}

Apêndice 1. Termo de Autorização da Instituição de Longa Permanência para Idosos Apêndice 2. Termo de Consentimento Livre e Esclarecido

Apêndice 3. Entrevista Semi-Estruturada. 
Ducatti, M. (2014). Equivalência de Estímulos e Responder por Exclusão em idosos com e sem Comprometimento Cognitivo. Dissertação de Mestrado, Programa de PósGraduação em Psicobiologia, Universidade de São Paulo, Ribeirão Preto-SP.

\section{Resumo}

O processo de envelhecimento pode gerar perdas cognitivas que, se agravadas, podem acarretar o diagnóstico de demência, sendo a Demência de Alzheimer (DA) a mais comum. A DA é uma doença neurodegenerativas que afeta principalmente a memória e a linguagem. Procedimentos de ensino baseados no paradigma de equivalência de estímulos e no ensino por exclusão, apesar de testados com sucesso em diferentes populações com problemas de desenvolvimento, têm gerado poucas pesquisas com idosos com perdas cognitivas. Esta pesquisa apresenta três estudos, com objetivos distintos, mas complementares. O Estudo 1 teve como objetivo avaliar se idosos institucionalizados sem DA formariam classes de estímulos equivalente a partir de um procedimento de ensino de relações condicionais entre palavras ditadas, fotos, nomes impressos de profissões e de graus de parentesco; adicionalmente, pretendia-se verificar que essas relações se mantinham ao longo de um mês, em três testes de manutenção. Cinco idosos institucionalizados passaram pelo ensino de relações arbitrárias, em uma estrutura de treino linear com ensino de novas relações por exclusão. Testes de equivalência foram conduzidos em seguida à Fase de Ensino, e após cinco, 15 e 30 dias. Todos os idosos demonstraram desempenho por exclusão na Fase de Ensino e aprenderam todas as relações com o número mínimo de blocos de ensino programados (exceto uma participante). Todos os idosos apresentaram formação de classes de equivalência. Quatro dos idosos apresentaram manutenção dessas classes em todos os testes de manutenção. O procedimento, portanto, mostrou-se efetivo para esses idosos e gerou formação de equivalência, apesar da sua condição de institucionalização. $O$ Estudo 2 teve como objetivo avaliar se idosos com DA, também institucionalizados, demonstrariam desempenho por exclusão e aprenderiam relações condicionais entre quatro nomes ditados e quatro fotos, em um procedimento de ensino por exclusão. Seis idosas com diagnóstico de DA passaram por tarefas de emparelhamento ao modelo, em que as relações entre modelos ditados e fotos foram ensinadas por exclusão. Apesar de todas as idosas terem respondido por exclusão na primeira apresentação de um estímulo modelo novo e seu comparação correspondente em pelo menos duas das três tentativas em que tal desempenho era possível, apenas duas mantiveram essa relação ao longo das demais tentativas e aprenderam as relações ensinadas. Possíveis motivos para esse desempenho são discutidos. O Estudo 3 avaliou se idosos institucionalizados, com DA e comprometimento cognitivo, formariam classes de equivalência a partir de um ensino de relações arbitrárias com estrutura de treino um-para-muitos, procedimento de dica atrasada e ensino por exclusão. Quatro idosas passaram pelo ensino de relações condicionais entre estímulos visuais (nomes escritos, fotos e nomes de profissões). Todas aprenderam as relações ensinadas com o número mínimo de blocos programados, porém apresentaram dificuldade em formar classes de equivalência e manter tais relações nos testes de manutenção após cinco e oito dias. Os procedimentos de ensino empregados foram eficientes em gerar a aprendizagem das relações, mas tal aprendizagem, nessas idosas, não sustentou a formação e manutenção de classes de equivalência.

Palavras-chave: Responder por Exclusão; Equivalência de Estímulos; Idosos; Comprometimento Cognitivo Leve; Demência de Alzheimer. 
Ducatti, M. (2014). Stimulus equivalence and responding by exclusion in elderly subjects with and without cognitive impairment. Master's Dissertation, Graduate Program in Psychobiology, University of São Paulo, Ribeirão Preto-SP.

\begin{abstract}
The aging process can cause cognitive impairments that, if aggravated, may lead to the diagnosis of dementia, with Alzheimer's Dementia (AD) being the most common. Alzheimer's Dementia is a neurodegenerative disease that primarily affects memory and language. Teaching procedures based on the paradigm of stimulus equivalence and on teaching by exclusion, although successfully tested in different populations with developmental problems, have generated little research with elderly people with cognitive impairments. This paper presents three studies, with different but complementary aims. Study 1 aimed to assess whether institutionalized elderly people without $\mathrm{AD}$ would form classes of equivalent stimuli from a procedure of teaching conditional relationships among dictated words, photos, printed names of professions and degrees of relatedness; additionally, it aimed to verify whether these relationships would be maintained over a month, using three maintenance tests. Five hospitalized elderly subjects underwent teaching of arbitrary relationships in a linear training structure with the teaching of new relationships by exclusion. Equivalence tests were conducted following the teaching phase, and after five, 15 and 30 days. All the elderly subjects demonstrated performance by exclusion in the teaching phase and learned all the relationships within the minimum number of programmed teaching blocks (except for one participant). All the subjects presented the formation of equivalence classes. Four of the elderly subjects presented maintenance of these classes in all the maintenance tests. The procedure, therefore, was effective for these elderly subjects and generated equivalence formation, despite their hospitalization condition. Study 2 aimed to assess whether institutionalized $\mathrm{AD}$ patients would demonstrate performance by exclusion and learn the conditional relationships between four dictated names and four photos, in a teaching by exclusion procedure. Six elderly women diagnosed with AD underwent pairing to the sample tasks, in which the relationships between dictated sample and photos were taught by exclusion. Despite all the elderly women responding by exclusion in the first presentation of a new sample stimulus and its corresponding comparison in at least two of the three trials in which this performance was possible, only two maintained this relationship throughout the other trials and learned the relationships taught. Possible reasons for this behavior are discussed. Study 3 evaluated whether hospitalized elderly subjects, with AD and cognitive impairments, would form equivalence classes from the teaching of arbitrary relationships using a one-to-many training structure, a procedure of delayed hints and teaching by exclusion. Four elderly subjects underwent the teaching of conditional relationships among visual stimuli (written names, photos and names of professions). All learned the relationships taught within the minimum number of programmed blocks, however, they presented difficulty forming equivalence classes and maintaining such relationships in the maintenance tests at five and eight days. The teaching procedures employed were efficient in generating the learning of relationships, however, such learning, in these elderly subjects, did not support the formation and maintenance of equivalence classes.
\end{abstract}

Keywords: Responding by Exclusion; Stimulus Equivalence; Elderly; Mild Cognitive Impairment; Alzheimer's Dementia. 


\section{Caracterização do Idoso}

O número crescente de idosos é um fenômeno mundial, justificado pelo aumento na expectativa de vida e a queda de natalidade (IBGE, 2000). Dados da United Nations Population Fund indicavam que no ano 2000 já havia 15 países com mais de 10 milhões de idosos, e que até 2050 haverá 33 países nessas condições. O número de idosos no mundo cresceu ao ano, entre 1950 e 1998, o equivalente a quase oito milhões de pessoas, o que demonstra um aumento significativo desta parcela da população. Estimativas indicam que, até 2050, haverá um milhão e 900 mil pessoas idosas (IBGE, 2000), sendo que o Brasil, neste período, será o sexto país com maior número de idosos (WHO, 2005). Para Kane, Ouslander e Abrass (2004) esse aumento no número de idosos tem como principal justificativa a evolução da medicina, que tem desenvolvido formas mais eficazes de aumentar a longevidade, sem, contudo, garantir um envelhecimento com qualidade.

Segundo a Organização Mundial da Saúde (WHO, 2005), considera-se idoso, em países em desenvolvimento, a pessoa que tem a partir de 60 anos de idade. Este corte aumenta em cinco anos para os países desenvolvidos. Porém, o processo de envelhecimento é caracterizado não só pelo aumento na idade, mas também por fenômenos físicos, psicológicos e sociais que contribuem para a percepção das mudanças causadas pelo envelhecer (Moreira, 1998).

No Brasil o idoso tem seus direitos resguardados pelo Estatuto do Idoso (2010), que garante a esta população, entre outras coisas, o direto à saúde, educação e habitação. Essa legislação afirma, por exemplo, que o idoso tem direito a morar com sua família, sozinho, quando desejar, ou em instituições de longa permanência (Lei $\mathrm{n}^{\mathrm{o}}$ 10.741, 2003). Dados do IBGE (2000) mostram que 62,4\% dos idosos brasileiros são responsáveis por suas casas, entretanto, as instituições de longa permanência para 
idosos (ILPIs) têm sido uma alternativa de moradia para muitos deles (Camarano \& Kanso, 2010).

As ILPIs são instituições que podem ser mantidas ou não pelo governo e que objetivam proporcionar ao idoso cuidado absoluto em caráter residencial. Tais instituições podem acolher idosos independentes, com dependências funcionais, ou totalmente dependentes e deve proporcionar a estes o cuidado pautado na intervenção de uma equipe multiprofissional (ANVISA, 2004).

Segundo Santos, Feliciani e da Silva (2007), que entrevistaram 55 idosos residentes em ILPI's na cidade do Rio Grande (RS/Brasil), e constataram que estas instituições abrigavam, principalmente, mulheres, viúvos e idosos com baixa escolaridade. Os residentes destas instituições afirmaram gostar de morar nas instituições e realizar atividades como artesanato, participar de grupos religiosos e assistir televisão. Os autores (2007) relataram, também, a prevalência de doenças físicas (como alteração da visão), doenças crônicas, sintomas emocionais (como tristeza) e idosos parcialmente dependentes. Entretanto, tais sintomas não são característicos apenas dos idosos morados de ILPI's, pois são sintomas atrelados ao processo de envelhecimento de forma mais ampla.

Outras doenças comuns no envelhecimento são a hipertensão, a doença osteoarticular, a osteoporose, a diabetes mellitus, as doenças cardíacas e respiratórias, a dor crônica, as quedas e as demências (Jorm, Korten \& Henderson, 1987; Lebrão, Duarte, Santos, \& Laurenti, 2008).

De acordo com Lebrão et al, (2008), cerca de 44\% dos idosos do Município de São Paulo apresentam declínio cognitivo. Nesse sentido, Kane et al. (2004) afirmam que a Demência de Alzheimer (DA) se tornará um problema de saúde pública não apenas no Brasil, já que no ano 2000 essa doença já ocupava a oitava posição entre as 
causas de morte. Jorm et al. (1987), descrevem que, a partir dos 60 anos, a prevalência de demência segundo a faixa etária dobra a cada cinco anos. Papaléo Netto (2007) afirma que há estudos que mostram que a prevalência da DA é maior do que a somatória das demais demências.

\section{Comprometimento Cognitivo Leve e Demência}

Caxieta (2012) afirma que o processo de envelhecimento faz parte de um continuum, que se inicia com o envelhecimento normal, podendo passar pelo comprometimento cognitivo leve (CCL) e podendo se encerrar na DA. De acordo com Peterson, Stevens e Ganguli (2001) o CCL é definido como a transição entre um processo de envelhecimento normal e uma demência severa, no qual o prejuízo da memória, apesar de presente, não ocorre de modo severo.

Para Petersen et al (1997), Petersen et al. (2011) e Stella (2012) os critérios de definição do CCL são queixa da memória, confirmação das queixas pelos familiares dos pacientes, função cognitiva preservada e ausência de demência. No entanto, Bischkopf, Busse e Angermeyer (2002), baseando-se em pesquisas sobre CCL, afirmam que este pode ser considerado um risco para a demência.

Segundo o DSM-IV, o Manual de Diagnóstico e Estatístico de Transtornos Mentais (2008), a demência é uma síndrome com etiologias diversas e pode ser compreendida como a perda de funções cognitivas de modo contínuo, sendo que o paciente diagnosticado por DA tem perda de três ou quatro pontos por ano no MiniExame do Estado Mental (MEEM), segundo os critérios de instrumentos para avaliação. Além da perda cognitiva, o paciente diagnosticado com essa demência pode também apresentar alteração da personalidade durante os primeiros estágios da doença e, com o agravamento dos estágios, ocorre o aparecimento de perturbações motoras. Alguns dos 
sintomas que caracterizam tal demência são: comprometimento da memória, perturbações cognitivas, tais como alteração na linguagem (afasia), dificuldades motoras (apraxia), falta de capacidade de reconhecimento de objetos (agnosia) e dificuldade em organização (no funcionamento executivo).

O diagnóstico de DA é clínico e feito pela exclusão das demais manifestações de demência, já que é difícil classificar as características vinculadas diretamente ao Alzheimer. Apesar de o diagnóstico ser clínico, o DSM-IV (2008) descreve a importância do MEEM como instrumento indicado para rastrear comprometimento cognitivo, uma vez que ele diferencia os pacientes com sintomas psiquiátricos daqueles que apresentam quadros orgânicos funcionais e determina o estado cognitivo atual.

Jackson (2011) descreve que a DA pode ser dividida em Fases Progressivas. Na primeira fase de definição do diagnóstico, as reações e captações de informações são mais lentas, aparecendo, também, a dificuldade de pensar em palavras ou o esquecimento de dados habituais. A segunda fase, que parece durar do segundo ano da doença até o décimo, é caracterizada, entre outros fatores, pela dificuldade na coordenação motora e o reconhecimento de familiares, o costume de conceber histórias para descrever aquilo de que não se lembra e a perda da capacidade de exercer atividades do dia-a-dia. Na terceira fase, definida como fase terminal, os sintomas mais comuns são a apatia e o não reconhecimento de si mesmo e de ambientes conhecidos. No entanto, Jackson (2011) observa que na última fase o paciente é capaz de entender a emoção e o tom de voz, como também responder ao tratamento físico.

Engelhardt, et al. (2005) descrevem que o tratamento recomendado para os pacientes que possuem a DA é dividido em intervenções farmacológicas e intervenções não farmacológicas. Tais intervenções têm por objetivo retardar o começo da demência 
ou reverter, parcialmente ou por um período determinado, os danos neurais da mesma (Forlenza, 2005).

\section{Formas de Tratamento}

O tratamento farmacológico para pacientes com DA pode visar à reversão dos processos que causam a morte neuoronal e a demência, o retardamento do início da demência ou a prevenção da perda cognitiva, a restauração parcial ou temporária das funções cognitivas e o tratamento de sintomas decorrentes da demência, como depressão, psicose e agressividade, por exemplo (Forlenza, 2005). Essas intervenções podem ser associadas aos treinos cognitivos, entretanto tais treinos se esbarram com problemas como, a diversidade dos pacientes, as alterações cognitivas, o avanço da doença e o auxílio da família (Engelhardt, 2005).

A reabilitação cognitiva engloba técnicas tais como: orientação para realidade, que mostra bons resultados na memória pessoal e orientação, porém quase nenhuma melhoria nas atividades cotidianas; terapia de reminiscência, que ainda não apresenta dados relevantes sobre seu efeito; técnicas de facilitação da memória explícita, que mostra eficácia quando utilizada com estímulos multimodais e criação de códigos semânticos; e estratégias compensatórias ou auxílios mnemônicos externos, como diários e calendários ou ajudas verbais vinculados à aprendizagem (Da Silva, et al., 2011; Engelhardt, et al., 2005). Olchick et al. (2012) realizaram um levantamento de pesquisas publicadas entre 1995 e 2011 sobre treino de memória em idosos com e sem CCL e constaram que há poucas publicações sobre estes tema no Brasil, além de existir muita heterogeneidade quanto ao tipo de treino utilizado. Porém, os dados publicados mostram que os treinos resultam em dados variados, uma vez que em alguns estudos com idosos com comprometimento cognitivo, foi possível notar, após a intervenção, uma melhora significativa da memória, enquanto que em outro não. O mesmo foi 
observado nos dados de manutenção. Bottino et al. (2002), por exemplo, selecionaram seis pacientes com DA leve que faziam uso de Rivastigmina e os submeteram, por cinco meses, a uma intervenção cognitiva em grupo, semanal, com duração de uma hora. Estas intervenções eram compostas por técnicas de orientação para realidade (com o auxílio de calendários e agendas associados a datas comemorativas ou estações do ano, por exemplo), apoio externo, recursos mnemônicos (como associações verbais, rimas e histórias), facilitação da aprendizagem, terapia por reminiscência (cuja atividade tinha como objetivo o relato de lembranças emocionais) e adaptação ambiental (no qual era realizado um treino para atividades diárias, como tomar remédio e atender ao telefone). Em paralelo, os cuidadores destes idosos participaram de um grupo de apoio e orientação, que objetivou elucidar dúvidas sobre a DA e a troca de experiências. Os resultados mostraram que a associação de tais técnicas com o medicamento auxiliou na estabilização da perda cognitiva, proporcionando uma leve melhora aos pacientes e diminuição dos sintomas psiquiátricos dos cuidadores.

Mesmo com o aumento das propostas de técnicas de Reabilitação Cognitiva, pesquisas de diferentes áreas do conhecimento que buscam compreender a dinâmica da DA e as maneiras de retardar seus efeitos ainda são muito importantes, dados os resultados ainda variados relatados pela literatura sobre os efeitos dessas intervenções.

A Análise do Comportamento, ao longo das últimas décadas, tem se dedicado ao estudo sistemático da aprendizagem (Catania, 1999). Inicialmente, nas décadas de 1930 a 1950, os estudos dessa corrente teórica se concentraram na compreensão de processos de aprendizagem em organismos simples (como ratos e pombos). Com o avanço das pesquisas, os estudos se estenderam a processos complexos de aprendizagem em humanos, o que tem sido a tônica das pesquisas a partir dos anos de 1970. As pesquisas realizadas sobre controle de estímulos, principalmente, tem permitido o 
desenvolvimento de modelos experimentais para o estudo da linguagem e da cognição (de Rose, 1993), e o desenvolvimento de estratégias de intervenção com diferentes populações (crianças, adultos e idosos) com os mais diferentes quadros, que vão desde quadros psiquiátricos até problemas de desenvolvimento (e.g., Aggio \& Domeniconi, 2011; Melchiori, de Souza, \& de Rose, 2000; de Rose, de Souza, \& Hanna, 1996; Saunders, Saunders, Kirby, \& Spradlin, 1988; Saunders, Wachter, \& Spradlin, 1988; Sidman, 1971; Sidman \& Cresson, 1973).

Trabalhos dirigidos aos idosos, apesar de existentes, ainda são em número reduzido nessa área. Goyos et al. (2009) realizaram a análise de 16 artigos científicos que propunham intervenções analítico-comportamentais para problemas da população idosa. Os pesquisadores notaram que as pesquisam tinham basicamente o foco em processo de memória e déficits do comportamento verbal (como o ensino do comportamento de falante e de ouvinte), mas que, apesar disto, os analistas do comportamento pouco têm feito pela população idosa. Os autores ainda afirmam que isto ocorre porque a ciência analítico-comportamental não está desenvolvida ao ponto de trabalhar com tal assunto e que muitos analistas acreditam que intervenções ambientais não podem alterar os processos de neurodegeneração causados pelo envelhecimento. No entanto, Ponte e Hübner (2008) propõem que intervenções neuropsicológicas pautadas na Análise do Comportamento podem contribuir para a aquisição de processo de aprendizagem e alterações comportamentais a partir da análise das contingências.

Um exemplo de pesquisa em análise do comportamento com a população idosa é o trabalho de Dixon, Baker e Sadowski (2011) que submeteram três idosas, com DA, residentes em uma ILPI, a um experimento cujo objetivo era realizar uma intervenção de recuperação de lembranças de objetos com base nos conceitos de comportamento 
verbal de Skinner (1957). As idosas deveriam, primeiramente, olhar para 40 figuras classificadas em grupo de roupas, formas, ferramentas e comidas. No segundo momento, as fotos mostradas por um computador, poderiam ser apresentadas sobre um fundo azul ou vermelho. Caso estivessem em um fundo azul, o experimentador iria falar "Diga [nome do objeto]" e o participante deveria repetir o nome e, em seguida, o pesquisador fazia uma pergunta sobre o objeto; caso estivesse sobre um fundo vermelho, ele nada falaria. No final do experimento, foi realizado um teste, com duração de 15 segundos, cuja tarefa das participantes era dizer o nome das figuras que elas lembravam. Após uma semana da finalização do procedimento, foi perguntado novamente as participantes se elas lembravam as figuras vistas na tela do computador, com o intuito de avaliar a manutenção daquilo que foi ensinado. As idosas tinham 30 segundos para responder. Os resultados mostraram que as idosas conseguiram lembrar com maior facilidade dos objetos que foram apresentados sobre o fundo azul, ou seja, cuja apresentação era acompanhada de um comportamento intraverbal (pergunta do experimentador). No Teste de Manutenção, apesar das idosas não terem ido tão bem quanto no teste após o treino, elas continuaram apresentando maior facilidade para lembrar os objetos que foram acompanhados do intraverbal. Os resultados sugerem, portanto, que intervenções pautadas nos princípios funcionais da compreensão do comportamento verbal podem auxiliar em intervenções voltadas à recuperação de linguagem de idosos diagnosticados com demência.

Esse e outros estudos conduzidos com idosos têm se baseado em trabalhos voltados para a compreensão de processos simbólicos. De acordo com de Rose e Bortoloti (20017), o ser humano tem habilidade para construir símbolos sociais e o uso desses símbolos serve para referenciar aquilo que está ausente. A relação entre o símbolo e o objeto é arbitrariamente convencionada, ou seja, a palavra não tem relação 
com o objeto porque apresente alguma semelhança com este, mas porque a relação entre esses estímulos foi estabelecida por processos naturais de ensino engendrados pelo ambiente social.

Nessa perspectiva, Gallagher e Keenan (2009) propuseram o ensino de discriminações condicionais, via tarefa de emparelhamento ao modelo (matching to sample - MTS) a 18 idosos, residentes de uma ILPI, cujo objetivo era relacionar símbolos com sílabas sem sentido. O treino linear consistiu em ensinar a relação A (sílaba) - B (símbolo) - C (símbolo), sendo o estímulo A1 a palavra "Paf" e A2 a palavra "Zid”; B1 o símbolo “\&” e B2 o símbolo “@”; e C1 a imagem de um círculo e C2 a imagem de um quadrado. Os estímulos foram impressos em cartões e, durante o procedimento, o estímulo modelo era colocado ao centro da mesa e os estímulos de comparação abaixo deste, um a esquerda e o outro a direita. Assim, se em uma tentativa de treino fosse apresentado o estímulo modelo A1 e os estímulos de comparação B1 e B2, a escolha do participante pelo estímulo de comparação B1 seria considerada correta e reforçada pelo experimentador com a palavra "Certo", enquanto a escolha do estímulo de comparação B2 nesta condição seria incorreta e não teria consequências. Posteriormente ao ensino de cada relação, era testada a relação de simetria e ao final do ensino de todas as relações, foram realizados testes de transitividade e equivalência. Os resultados mostraram que 11 dos participantes demostraram equivalência, seis falharam em demonstrar simetria e um participante não atingiu critério nos treinos.

Independe do resultado de cada participante e das condições biológicas (como o diagnóstico de DA e Parkinson) que podem ter interferido no baixo desempenho de alguns participantes, o procedimento exemplifica como relações arbitrárias podem ser construídas. As sílabas não tinham, antes do treino, nenhuma relação com os símbolos, mas passaram a ter depois que a comunidade verbal reforçou ou extinguiu determinadas 
respostas, favorecendo assim a formação dessas relações simbólicas. O mesmo ocorre quando se aprende a chamar determinada pessoa pelo seu nome e não por outro nome qualquer, ou quando se aprende que o pedaço de papel com a imagem do número dez é dinheiro, tendo assim um valor e propiciando a compra de objetos.

A partir da perspectiva da Análise do Comportamento o estudo da constituição das relações entre estímulos arbitrários (palavras e objetos, por exemplo), com a formação de classes de estímulos, tem sido um campo vastamente explorado, especialmente a partir da proposta de Sidman e Tailby (1982) do modelo de equivalência de estímulos, a partir da qual é possível estudar de que maneira são constituídos os "significados" dos estímulos e de que maneira ocorre a substituição recíproca entre eles (por exemplo, como uma palavra pode substituir um objeto na sua ausência, em determinados contextos discursivos) (de Rose \& Bortoloti, 2007).

A proposta de intervenções baseadas em pressupostos teóricos que tenham tradição no estabelecimento de procedimentos de aprendizagem e o uso de tecnologias recentes (como o emprego de computador, por exemplo) pode ser um meio de encontrar estratégias para a estabilização dos sintomas cognitivos da DA e do CCL.

\section{Equivalência de Estímulos}

Os sistemas de pensamento e linguagem são inerentes à espécie humana e permitem ao homem a capacidade de manipulação de símbolos (ou estímulos), que por sua vez, permitem a formação de conceitos. Isso só ocorre porque tais sistemas admitem que estes símbolos (ou estímulos), mesmo que de diferentes ordens, sejam agrupadas em classes, definidas como classes de estímulos (de Rose, 1993; de Rose \& Bortoloti, 2007). 
Classes de estímulos podem ser entendidas como redes de relações que se estabelecem entre estímulos por meio de procedimentos de reforço, extinção ou punição. Classes de estímulos podem ser formadas a partir da relação de similaridade física entre eles, ou seja, quando um estímulo compartilha atributos comuns com outros estímulos, podendo, então, fazer parte do mesmo conjunto (classe). Porém, também é possível a formação de uma classe em função de relações arbitrárias estabelecidas entre estímulos, mediadas por uma resposta comum. Esse tipo de classe é formada quando os estímulos que a compõem são diferentes, mas evocam uma mesma resposta como, por exemplo, uma bola e uma boneca que, apesar de não se parecerem fisicamente, evocam a resposta de brincar. Além disso, classes podem ser formadas por relações arbitrárias entre estímulos, que ocorre quando estímulos que não possuem similaridade física se relacionam em função de contingências sociais (de Rose, 1993).

A formação de classes de estímulos pode favorecer a ocorrência de relações de equivalência, que são desempenho emergentes demonstrados a partir de relações previamente ensinadas. De acordo com Sidman e Tailby (1982), a relação de equivalência entre estímulos pode ser verificada a partir da presença das propriedades de reflexividade, simetria e transitividade. A primeira diz respeito à relação de um elemento consigo mesmo, propondo que, para haver reflexidade, um estímulo (A) obrigatoriamente deve ser igual a si mesmo (de Rose, 1993).

A propriedade de simetria pode ser verificada quando, ao se estabelecer uma dada relação entre os estímulos A e B (por exemplo, A=B), a mesma relação continua válida quando a ordem dos termos é invertida, ou seja, B=A (de Rose, 1993). Por exemplo, ao ensinar uma pessoa a relacionar a foto de uma pessoa (estímulo modelo) com um nome próprio (estímulo de comparação), verifica-se simetria caso o 
participante seja capaz de selecionar a foto diante do nome apresentado, agora, como estímulo modelo (Haydu \& Morais, 2009).

Finalmente, de Rose (1993) afirma que a relação transitiva entre os estímulos é verificada a partir do estabelecimento de relações entre pares de estímulos. Por exemplo, se $\mathrm{A}=\mathrm{B}$, e $\mathrm{B}=\mathrm{C}$, a transitividade é demonstrada caso a relação entre $\mathrm{A}$ e $\mathrm{C}$ seja estabelecida sem a necessidade de ensino direto dessa relação. De Rose (1993) exemplifica esta relação mostrando que se é ensinado que Fulano tem Beltrano como irmão, e Beltrano tem Cicrano como irmão, a propriedade de transitividade pode ser verificada se a relação entre Fulano ser irmão de Cicrano for apresentada.

Muitos experimentos baseados no paradigma de equivalência têm sido realizados para estudar relações simbólicas. O procedimento mais comum empregado nesses estudos é o de matching to sample (MTS) ou emparelhamento ao modelo. Nas tarefas de MTS é apresentado para o participante um estímulo modelo e dois ou mais estímulos de comparação, sendo que cada estímulo modelo é relacionado a apenas um estímulo de comparação. Os estímulos são referenciados por letras, que indicam o conjunto do qual o estímulo faz parte, e números, que indicam quais estímulos de cada conjunto serão relacionados entre si (Sidman \& Tailby, 1982; de Rose, 1993). Assim, se o conjunto A referir-se a figuras, todos os estímulos que comporão este conjunto serão figuras, sendo o primeiro estímulo (figura) indicado por A1, o segundo por A2, o terceiro por A3 e assim sucessivamente; se o conjunto B for composto por nomes de objetos, o primeiro estímulo será denominado B1, o segundo B2 e o terceiro B3; e, se o conjunto $\mathrm{C}$ referir-se a nomes de pessoas, todos os estímulos deste conjunto devem necessariamente ser nomes de pessoas (C1, C2 e C3). Com isso, a figura A1 deve se relacionar apenas com o nome de objeto B1 e com o nome de pessoa C1 (Haydu \& Miura, 2010). 
Muitos dos estudos conduzidos têm como preocupação central com a elucidação das variáveis que podem influenciar no processo de formação e manutenção das classes, como o número de estímulos que a compõem (e.g., Aggio, \& Domeniconi 2012), o tipo de estímulo utilizado (e.g., McIlvane \& Dube, 1992) e a estrutura do treino (e.g., Arntzen, 2006). A estrutura do treino, em especial, pode ser uma variável importante no processo de formação e manutenção de classes de estímulos equivalentes. A estrutura pode ser linear, na qual se ensinam as relações entre um conjunto de estímulos em relação ao próximo previamente determinado, ou seja: $\mathrm{AB}-\mathrm{BC}-\mathrm{CD}$ etc.; a estrutura é chamada de "um para muitos", quando há um conjunto de estímulos base que é usado como referência (modelo) para o ensino de todas as relações, como, por exemplo, AB AC - AD; e a estrutura pode ser chamada de "muitos para um", quando os diferentes conjuntos de estímulos - B, C, D - são relacionados como modelo a um mesmo conjunto de estímulo - A, que serve sempre como base para a apresentação dos estímulos de comparação: BA, CA, DA (Saunders, Chaney \& Marquis, 2005). De Rose, Kato, Thé e Kledaras (1997) afirmam, com base na análise dados de pesquisas de outros autores, que, para pessoas com deficiência intelectual, o arranjo "muitos-para-um" mostra-se mais eficaz. Porém, para pessoas com desenvolvimento típico, não parece haver diferença entre este arranjo e o arranjo "um-para-muitos". Sobre o arranjo linear, De Rose et al. (1997) afirmam que quando a classe de estímulos equivalentes a ser formada possui mais de três membros, a formação da classe ocorre de modo mais lento devido ao aumento no número de nódulos.

Rehfeldt e Hayes (2000) ressaltam a importância de estudar não apenas a aquisição de classes de equivalência, mas também a manutenção dessas classes. Spradlin, Saunders e Saunders (1992) afirmam que a manutenção das classes de equivalência pode estar vinculada ao tamanho dessa classe, ou seja, à quantidade de 
estímulos que compõem cada classe. O número de estímulos da classe parece ser uma variável importante na sua manutenção dado confirmado por outros estudos que serão discutidos na sequência.

Todos esses estudos que investigam aspectos básicos sobre a formação e a manutenção de classes de equivalência têm servido como base para a condução de pesquisas que se preocupam em propor procedimentos que auxiliam a aprendizagem de crianças e adolescentes com desenvolvimento típico e atípico (e.g., Almeida-Verdu, 2009; de Souza \& de Rose, 2006; Oliveira, 2013). Estudos que objetivam investigar a formação e manutenção de classes de estímulos equivalentes em idosos, apesar de existentes, têm sido conduzidos com objetivos mais voltados à pesquisa básica e ainda são em número reduzido.

Um exemplo de pesquisa com idosos é o trabalho de Haydu e Morais (2009) que estudaram o processo de formação, manutenção e recuperação de classes de estímulos em idosos, com o objetivo de averiguar a influência do tamanho da classe nesse processo. Participaram 18 senhoras que foram divididas aleatoriamente em dois grupos. Ambos os grupos aprenderam discriminações condicionais via procedimento de MTS, com uma estrutura de treino linear, porém um grupo foi exposto primeiro ao ensino de seis classes com seis membros e em seguida do ao ensino de seis classes com quatro membros de estímulos e o outro grupo foi exposto às mesmas condições, porém na ordem contrária. Os conjuntos de estímulos utilizados em ambas as condições foram fotografias, nomes próprios ditados, palavras impressas referentes à profissão e palavras impressas referentes a hobbies. O procedimento que ensinou classes de seis membros empregou, também, palavras impressas referentes a figuras de objetos e palavras impressas referentes a animais. Assim, cada classe seria formada pela imagem de uma pessoa (A), o nome impresso de uma pessoa (B), uma palavra impressa de uma 
profissão (C), uma palavra impressa referente a uma atividade (D), uma palavra impressa referente a um objeto (E), e uma palavra impressa de um animal (F). Todas as idosas dos dois grupos aprenderam a tarefa ensinada, e o tamanho da classe (com quatro ou seis estímulos) não influenciou o processo de aprendizagem das discriminações condicionais e formação de equivalência. Porém, as classes com um número maior de membros foram mais facilmente lembradas mais tarde, em sondas de recuperação realizadas seis semanas depois do término do procedimento.

Saunders, Chaney e Marquis (2005) também pesquisaram se o estabelecimento das classes de equivalência poderia ter relação com o número de estímulos de cada classe e a estrutura usada para o treino. Para tanto, os pesquisadores contaram com a participação de 12 idosos (de 59 a 89 anos) que aprenderam seis conjuntos de estímulos divididos igualmente entre as estruturas de treino linear, um-para-muitos ou muitospara-um, totalizando, assim, um total de 18 classes. Foi manipulada a quantidade de estímulos por classe e o número de estímulos de comparação em cada tentativa. Os resultados mostraram que os participantes formaram classes de equivalência em todos os tipos de treinos, porém precisaram de um número maior de blocos de treino para atingir os critérios de aprendizagem na estrutura muitos-para-um, em comparação com as demais estruturas, quando havia disponíveis três ou quatro estímulos de comparação. Apesar disto, não houve diferença significativa entre o uso de dois, três ou quatro estímulos de comparação para a formação de classes de equivalência.

Aggio e Domeniconi (2012) desenvolveram um trabalho com oito idosos que não apresentavam comprometimento cognitivo, com o objetivo de avaliar a formação de classes de estímulos equivalentes em procedimentos cujas classes apresentavam números distintos de estímulos e verificar se o tamanho das classes poderia influenciar na sua manutenção. Os participantes foram divididos em dois grupos. O primeiro grupo 
foi submetido a um procedimento de ensino de três classes com três estímulos cada e o outro grupo a um procedimento de ensino de três classes com seis estímulos. Os participantes foram submetidos a uma fase de treino e teste com figuras abstratas. A estrutura do treino empregada foi muitos-para-um, e os estímulos de comparação eram introduzidos gradualmente ao longo das tentativas.

Todos os idosos formaram classes de equivalência, porém para cinco deles a emergência da classe foi atrasada. Os resultados de manutenção mostraram que os participantes que foram submetidos ao treino com maior número de estímulos por classes apresentaram um desempenho superior a $90 \%$ de acerto, enquanto o outro grupo demonstrou um desempenho inferior a $90 \%$ de acerto, confirmando dados anteriores de que classes de equivalência com um número maior de estímulos tendem a se manter melhor em comparação com classes formadas por um número menor de estímulos (Aggio \& Domeniconi, 2012).

Além dos trabalhos com idosos sem comprometimento cognitivo, há estudos com idosos com DA. Steingrimsdottir e Arntzen (2011), por exemplo, trabalharam com uma paciente com diagnóstico de DA de 84 anos, com o objetivo de verificar o seu desempenho na aprendizagem de relações condicionais (um estágio anterior à formação de classes de equivalência). Também avaliaram a implicação do atraso entre a apresentação do modelo e a disponibilização dos estímulos de comparação para a aprendizagem das discriminações. Foram empregados atrasos de 0, 3, 6 e 9 segundos. Observou-se que a participante teve dificuldade de responder na tarefa de MTS quando os atrasos eram mais longos, mas conseguiu aprender a tarefa quando a apresentação do estímulo modelo era simultânea à apresentação dos estímulos de comparação.

Souza (2011) conduziu quatro estudos com idosos diagnosticados com DA. Os três primeiros tinham como objetivo verificar se procedimentos de ensino de relações 
condicionais seriam condição antecedente para o comportamento de lembrar nomes e o quarto tinha como objetivo verificar a ocorrência da formação de classes de equivalência. Do primeiro estudo, participaram três idosas com idade entre 82 e 89 anos, que já haviam passado por procedimentos de estimulação cognitiva. As participantes passaram por um procedimento de ensino de relações condicionais (ou recuperação dessas relações, uma vez que os estímulos empregados eram bastante comuns), em 24 passos. Em cada passo, trabalhava-se com três conjuntos de estímulos, palavras ditadas (A), figuras correspondentes (B) e palavras impressas (C). Em cada passo, os conjuntos de estímulos poderiam referir-se a objetos pessoais, itens de alimentação, de vestuário ou animais. Assim, foram ensinadas (ou recuperadas), no total, 72 relações entre palavra ditada/figura/palavra impressa.

As relações ensinadas foram, sempre, $\mathrm{AC}$ e $\mathrm{CB}$, e foram testadas simetria (BC), transitividade $(\mathrm{AB})$ e nomeação $(\mathrm{BD})$. As tarefas de MTS ocorreram de três modos: simultâneo, com atraso zero e com atraso de 5 segundos.

De modo geral, todas as participantes demonstram um desempenho pior no treino e nos testes quando a tarefa envolvia atraso, demonstrando um desempenho melhor nos treinos e testes em que os estímulos modelo eram apresentados simultaneamente aos estímulos de comparação. A reaplicação dos instrumentos usados na avaliação inicial mostrou que, após o ensino de relações condicionais, uma idosa teve um resultado superior no MEEM quando comparado ao seu próprio resultado do MEEM realizado na avaliação inicial, todas as idosas demonstraram uma melhora nos testes de nomeação de figuras de animas e alimentos e duas idosas melhoram seus resultados no teste de fluência verbal (Souza, 2011).

No segundo estudo, Souza (2011) trabalhou com uma idosa de 73 anos com comprometimento cognitivo moderado. As 17 relações condicionais foram ensinadas 
por exclusão, com apenas dois estímulos de comparação, em um procedimento de pareamento simultâneo. Os estímulos, assim como no Estudo 1, eram palavras ditadas, palavras impressas e figuras, mas foram empregados apenas estímulos referentes a “objetos pessoais". Foi realizado o ensino das relações $\mathrm{AC}$ e $\mathrm{CB}$, e testadas as relações $\mathrm{AB}, \mathrm{BC}$ e $\mathrm{BD}$. A participante demonstrou um desempenho melhor nas relações de treino AC (palavra ditada - palavra impressa), do que nas relações de treino CB (palavra impressa - imagem), e apresentou baixo desempenho nos testes AB (palavra ditada-imagem), BC (imagem-palavra impressa) e BD (imagem-nomeação).

O terceiro estudo teve como objetivo verificar se um treino mais extenso diminuiria o número de erros nos testes. As participantes foram as duas idosas que já haviam participado do Estudo 1. O Estudo 3 manteve os mesmos conjuntos de estímulos, consequências e critérios do Estudo 1, diferenciando-se apenas pelo maior número de tentativas de ensino e teste. Assim como no Estudo 1, as participantes tiveram um desempenho pior no treino e no teste com atraso de 5 segundos, do que no treino e teste simultâneo e com atraso 0 s (Souza, 2011).

O último estudo objetivou replicar parte do trabalho de Haydu e Morais (2009) com uma das participantes do Estudo 1. O procedimento ensinava três classes com seis estímulos cada: foto (A), nome (B), profissão (C), lazer (D), objeto (E) e animal de estimação (F). Os estímulos foram ensinados a partir de uma estrutura linear e apresentados simultaneamente. Após o ensino das relações, foi realizado o teste de equivalência. Foram verificadas diferenças no desempenho da participante em cada relação ensinada. No treino, por exemplo, a participante demonstrou um desempenho de $100 \%$ nas relações AB e EF com os dois primeiros estímulos e um escore de 69,9\% de acerto com os Estímulos 2 e 3 na relação CD. Nos testes de linha de base, os resultados da participante variaram de 50 a $100 \%$ e os de simetria de $43 \%$ a $100 \%$ de acerto. Os 
resultados não foram conclusivos sobre se a participante apresentou emergência de classes de equivalência ou não, uma vez que o desempenho da participante neste teste foi inferior aos testes realizados após o término do treino. Ainda para justificar este dado, Souza (2011) acrescenta que a dificuldade de retenção do que foi aprendido é uma característica de idosos com comprometimento cognitivo e isto dificultaria a emergência das relações equivalentes. No entanto, dado o número reduzido de estudos na área, não é possível identificar claramente variáveis que poderiam contribuir ou não com a formação ou manutenção das classes de estímulos ensinadas.

De modo geral, nos estudos sobre formação de classes de equivalência com idosos há muitas questões a serem investigadas, uma vez que os dados são controversos e certamente há uma diferença importante entre os estudos conduzidos com idosos sem compromentimento cognitivo e aqueles conduzidos com idosos com tal comprometimento. Nos estudos revisados, um ponto importante a ser considerado é a forma de ensino adotada nos procedimentos. O estudo de Saunders, Chaney e Marques (2005), por exemplo, sugere que a formação de classes de equivalência ocorre independente do número de estímulos por classe e da estrutura de treino. Em contrapartida, Aggio e Domeniconi (2012) sugerem a importância da formação de classes com um maior número de estímulos, uma vez que, quanto maior a classe, maior sua estabilidade ao longo do tempo. Além disso, é necessário considerar também que o uso da apresentação simultânea dos estímulos em procedimentos para idosos pode auxiliar em seu desempenho na formação de classes de estímulos (Steingrimsdottir \& Arntzen, 2011). O que esses estudos sugerem, então, é que talvez seja necessário propor aos idosos que tenham algum tipo de comprometimento cognitivo procedimentos em que os estímulos sejam apresentados simultaneamente, ensinando-se classes com um número maior de estímulos (mais de quatro estímulos). Além disso, ainda não foi 
investigado se o procedimento de ensino por exclusão pode ser uma boa alternativa de procedimento para ensino de relações arbitrárias, tal como tem se mostrado em estudos com crianças, por exemplo (Dixon, 1977; Medeiros, Monteiro, \& Silva, 1997; de Souza \& de Rose, 2006).

\section{Responder por Exclusão}

O responder por exclusão tem sido estudado como um desempenho emergente (ou seja, cuja ocorrência não demanda ensino direto), exibido por humanos e (até onde se conhece) alguns animais não humanos, no qual os sujeitos relacionam estímulos (modelos e comparações) novos, seja pela relação direta estabelecida entre os estímulos em função de sua dimensão de novidade (denominada de controle por $\mathrm{S}+$ ), ou pela exclusão de estímulos de comparação presentes que já tenham sido relacionados anteriormente a outros estímulos (controle por rejeição ou por S-) (McIlvane, Wilkinson, \& de Souza, 2000).

O responder por exclusão se dá a partir de uma linha de base bem estabelecida, na qual são ensinadas, primeiramente, relações condicionais entre alguns estímulos modelo e estímulos de comparação. Após isso, quando o participante é exposto a um estímulo modelo novo, é capaz de, sem ensino direto, relaciona-lo com o estímulo de comparação também novo (McIlvane, et al., 2000).

Alguns autores, não só da Análise do Comportamento, mas também da Psicolinguística, afirmam que é provável que esse desempenho seja fundamental na aquisição de vocabulário em bebês e crianças pré-escolares. Inúmeros estudos sobre o assunto têm sido desenvolvidos com crianças (e.g., Costa, McIlvane, Wilkinson, \& de Souza, 2001; Domeniconi, Costa, de Souza \& de Rose, 2007; Oshiro, de Souza, \& Costa, 2006; Wilkinson \& McIlvane, 1997) e com populações com diferentes tipos de 
problemas de desenvolvimento (e.g. Costa, et al., 2001; Wilkinson, Rosenquist, \& McIlvane, 2009), e todos confirmam a regularidade de ocorrência do fenômeno.

A pesquisa de Dixon (1977), que se tornou um estudo de referência para compreender o responder exclusão na Análise do Comportamento, tinha como objetivo propor um procedimento de ensino de repertório verbal para oito adolescentes com deficiência intelectual. Os participantes passaram por um procedimento de MTS, cujo estímulo modelo era um estímulo auditivo (nome de uma letra grega) e os estímulos de comparação eram as figuras das próprias letras gregas. Os adolescentes foram ensinados a relacionar a palavra ditada "Pi" com sua respectiva letra (além da letra Pi, o outro estímulo de comparação poderia ser a letra grega Theta ou a letra Ipsilon). Após o ensino das relações os participantes realizavam um teste, no qual era apresentado um estímulo verbal novo (que nunca havia sido ditado antes - "Theta" ou "Ipsilon") e dois estímulos de comparações, sendo um deles novo (referente a essa palavra nova) e a letra Pi. Todos os adolescentes não apenas aprenderam a relação entre a palavra Pi e a letra, como também, sem ensino adicional, relacionaram as novas palavras ditadas às suas respectivas figuras.

Dixon (1977) interpretou esses resultados dizendo que se o estímulo modelo que foi treinado for apresentado, o estímulo de comparação escolhido deve ser aquele que mais se aproxima desse estímulo verbal, mas se o estímulo modelo apresentado for uma palavra nova, a escolha pelo estímulo de comparação deve ser a mais distante possível do estímulo que já tiver sido relacionado a alguma palavra. A partir destas pesquisas, muitos outros trabalhos (e.g., Costa et al., 2001; Costa, \& Domeniconi, 2009; Domeniconi et. al. 2007; Freitas, Reis, Mizael, \& Domeniconi, 2012; Wilkinson \& Mcllvane, 1997) foram realizados com o intuito, tanto de verificar a generalidade do fenômeno, quanto a compreensão do processo. 
Stromer (1989), por exemplo, desenvolveu um estudo cujo objetivo era investigar se crianças e adultos eram capazes de responder por exclusão. Para tanto, trabalhou com duas crianças com desenvolvimento típico e idade de oito e 11 anos e quatro adultos com idade média de 21 anos. Os estímulos utilizados foram desenhos de imagens não convencionais. Foram realizadas 40 sessões em que as tentativas se iniciavam com a apresentação de um estímulo modelo, no qual os participantes deveriam tocar para que os estímulos de comparação fossem mostrados, sendo as respostas corretas consequenciadas com moedas. Após o estabelecimento da linha de base de relações visuais-visuais, foram realizadas sondas de exclusão, nas quais eram apresentados estímulos modelos novos e, entre estímulos de comparação conhecidos, um estímulo também novo. Todos os participantes responderam por exclusão, apesar de alguns terem demonstrado um desempenho baixo.

Outros estudos posteriores não apenas confirmaram a ocorrência de responder por exclusão com diferentes populações, como também investigaram outras questões relacionadas, como a aprendizagem de relações após uma única tentativa de exclusão (e.g., Domeniconi et al., 2007; Wilkinson \& McIlvane, 1997), variáveis que podem interferir no desempenho por exclusão (e.g., Antoniazzi, Domeniconi, \& Schmidt, 2014; Costa, de Rose \& de Souza, 2010) e procedimentos de ensino por exclusão (e.g., de Rose, de Souza, \& Hanna, 1996; Ferrari, de Rose \& McIlvane, 1993).

Todos esses estudos têm demonstrado a robustez do fenômeno com diferentes populações e a eficácia de métodos de ensino por exclusão. No entanto, poucos estudos verificaram se esse processo ocorre também entre idosos, com e sem declínio cognitivo. O processo de envelhecimento - intrínseco a todo ser humano - seria capaz de alterar a possibilidade do organismo responder por exclusão? Ou, o quanto doenças neurodegenerativas, como a DA, podem influenciar na ocorrência deste desempenho? 
São poucos os estudos que investiguem a ocorrência do responder por exclusão na população idosa, especialmente entre aqueles que apresentam perda de linguagem decorrente de quadros de demência (Souza, 2011). O estudo desse tópico e do conceito de equivalência de estímulos entre essa população é relevante por esclarecer se os déficits decorrentes da demência (especialmente aqueles relacionados à linguagem) afetam o desempenho por exclusão e a capacidade de formar e manter classes de estímulos equivalentes.

Assim, este trabalho está dividido em três estudos. O objetivo do primeiro estudo foi (a) investigar a ocorrência de responder por exclusão em idosos institucionalizados sem diagnóstico de comprometimento cognitivo ou de qualquer patologia que tenha como resultado déficits de linguagem, (b) investigar a viabilidade do uso de estratégias de ensino de discriminações condicionais auditivo-visual e visualvisual por exclusão; e (c) investigar a formação e manutenção de classes de equivalência com estímulos auditivos e visuais. O objetivo do segundo estudo foi (a) investigar se idosos com comprometimento cognitivo e/ou diagnóstico de Demência de Alzheimer apresentam responder por exclusão em um procedimento de ensino de discriminações condicionais. Finalmente, o objetivo do terceiro estudo foi (a) investigar o ensino de discriminações condicionais a partir da estrutura um-para-muitos para idosos com comprometimento cognitivo e (b) investigar a formação e manutenção de classes de equivalência para esta mesma amostra. 


\section{ESTUDO 1}

O Estudo 1 teve como objetivo (a) investigar a ocorrência de responder por exclusão em idosos institucionalizados sem diagnóstico de comprometimento cognitivo ou de qualquer patologia que tenha como resultado déficits de linguagem, (b) investigar a viabilidade do uso de estratégias de ensino de discriminações condicionais auditivovisuais e visual-visuais por exclusão; e (c) verificar a ocorrência (ou não) da formação e manutenção de classes de equivalência com estímulos auditivos e visuais.

\section{Método}

\section{Participantes}

Participaram deste estudo cinco idosos (quatro mulheres e um homem), com idades entre 74 e 87 anos. Nenhum dos participantes apresentava comprometimento cognitivo e todos eram residentes em Instituições de Longa Permanência para Idosos (ILPI's).

A Tabela 1 apresenta características dos participantes (com nomes fictícios): idade, escolaridade, medicação utilizada e diagnósticos fornecidos pelas ILPI's. A Tabela 2 apresenta os resultados dos participantes nos testes de comprometimento cognitivo, depressão, ansiedade e fluência verbal, que foram utilizados para verificação dos critérios de exclusão da amostra.

Os critérios de exclusão na amostra foram (1) indicativos de comprometimento cognitivo segundo o MEEM, (2) baixo nível de escolaridade ou analfabetismo (os participantes deveriam conseguir ler e compreender os estímulos visuais apresentados), (3) o uso de medicações que pudessem alterar o estado de vigília do organismo, (4) problemas de audição que pudessem comprometer a compreensão dos estímulos 
auditivos apresentados, (5) problemas visuais que impedissem o participante de observar os estímulos visuais apresentados, (6) e presença de depressão em nível moderado ou grave.

Os responsáveis pelas ILPI's assinaram o Termo de Autorização da Instituição (Apêndice 1) o termo de Consentimento Livre e Esclarecido (Apêndice 2) para cada participante, porém, também foi pedido o consentimento verbal de participação na pesquisa para os mesmos. O projeto segue a Resolução nº 466/12 do Conselho Nacional da Saúde e foi submetido e aprovado pelo Comitê de Ética em Pesquisa com Seres Humanos da Faculdade de Filosofia, Ciências e Letras de Ribeirão Preto (FFCLRPUSP), número CAAE: 12939513.8.0000.54087 (Anexo 1). 
Tabela 1.

Participantes (nomes fictícios), com suas respectivas idades, grau de escolaridade, medicação utilizada no início do procedimento e diagnósticos fornecidos pelas ILPIs. FI - Ensino Fundamenta Incompleto; SD - Sem diagnóstico.

\begin{tabular}{cccccc}
\hline Participante & Idade & Escolaridade & Institucionalização & Medicação \\
\hline Cássia & 87 & FI & 1 ano e 6 meses & Enalapril, Flutamida, AS, Insulina, Cloridrato de Verapamil, Amitriptilina & Diabetes; insuficiência renal \\
Eva & 78 & FI & 1 mês & Omeprazol, Sertralina, Clonazepam, Clortalidona \\
Flora & 73 & FI & 1 mês & (apenas medicação para dor) \\
Leila & 77 & FI & 7 anos & Marevan, Macrodantina, Sinvastatina e Cálcio \\
Vagner & 74 & FI & 3 meses & Enalapril, Aldactone, Fenazopiridina \\
\hline
\end{tabular}


Tabela 2.

Resultados dos participantes nos testes MEEM, Montreal Cognitive Assessment (MoCA), Escala Hospitalar de Ansiedade e Depressão (HAD), Escala de Depressão Geriátrica (EDG) e Protocolo Montreal-Toulouse de Exame Linguístico da Afasia (versão M1-Alpha). DL - Depressão Ligeira; DA - Depressão Ausente; AA -Afasia Ausente

\begin{tabular}{cccccc}
\hline Participantes & MEEM & MocA & HAD & EDG & M1-Alpha \\
\hline Cássia & 17 & 17 & D: possível/A: improvável & DL & AA \\
Eva & 19 & 10 & D: provável/A: provável & DL & AA \\
Flora & 25 & 20 & D/A: improvável & DA & AA \\
Leila & 29 & 19 & D/A: improvável & DA & AA \\
Vagner & 25 & 15 & D: provável/A: possível & DL & AA \\
\hline
\end{tabular}

\section{Local}

A coleta de dados ocorreu em três ILPI's da cidade de Ribeirão Preto. As responsáveis pelas instituições forneceram as salas onde a coleta aconteceu. Em uma das instituições o computador foi instalado no escritório. Este espaço era composto uma mesa, que serviu de apoio para o computador, e de duas cadeiras, uma para o participante e outra para a pesquisadora. A cadeira da participante foi colocada em frente ao computador e da pesquisadora ao lado, junto à filmadora. Este espaço garantia o sigilo da pesquisa e a privacidade do participante. Nas outras instituições, o computador era instalado diariamente na sala de refeições da instituição. Esta era composta por mesas e cadeiras de plásticos. O computador era colocado sobre uma das mesas, e as cadeiras do participante e da pesquisadora, assim como a filmadora, eram posicionadas do mesmo modo que na outra instituição. 


\section{Instrumentos}

Para a execução desta pesquisa foram utilizados os seguintes instrumentos:

- Entrevista Semi-Estruturada com Participante de Pesquisa ou Responsável pela Instituição: teve por objetivo investigar dados a respeito das atividades diárias do participante (rotina) e medicamentos utilizados. O instrumento foi aplicado para o próprio participante e/ou para o responsável pela ILPI (caso o participante não soubesse responder), e era composto por duas questões abertas e uma fechada. Tal processo justifica-se pela necessidade de avaliar os critérios de exclusão da amostra e colher dados para selecionar os estímulos a serem usados no procedimento (Apêndice 3).

- Mini-Exame do Estado Mental: o objetivo era verificar a presença ou não de declínio cognitivo. O teste contém 11 questões para avaliar a função cognitiva, que podem ser divididas em duas categorias: respostas verbais, que avaliam orientação temporal, orientação espacial, registro e recordação de três palavras, habilidades de nomeação, e atenção e cálculo; e respostas não verbais, que avaliam, seguimento de comandos, escrita e cópia da imagem de um polígono. Cada questão correta vale um (1) ponto, sendo possível fazer, no máximo, 30 pontos. Escores menores ou iguais a 24 pontos são considerados indicativos de demência; escores menores que 17 pontos são indicativos de demência nos pacientes que possuem menos de quatro anos de escolaridade (Foltein, Folstein \& McHugh, 1975) (Anexo 2).

- Montreal Cognitive Assessment (MoCA): teste considerado como rastreador de declínio cognitivo. O mesmo é composto por 11 subtestes, que se referem a “atenção, funções executivas, memória, linguagem, habilidades viso-construtivas, conceituação, cálculo e orientação" (Manual MoCA, p. 1-4). O escore máximo total 
é de 30 pontos, sendo que uma pontuação igual ou inferior a 26 pontos é considerada indicativo de demência (http://www.mocatest.org/) (Anexo 3).

- Protocolo Montreal-Toulouse de Exame Linguístico da Afasia, versão M1 Alpha (versão brasileira): aplicado com o objetivo de avaliar presença de afasias, ou seja, dificuldades de nomeação e compreensão verbal. É composto por uma entrevista e 11 testes, subdivididos em compreensão oral e escrita, expressão escrita e oral (Garcia, 2007) (Anexo 4).

- Escala de Depressão Geriátrica: objetiva verificar a presença de sintomas depressivos em idosos. A escala é composta por 30 perguntas, cuja resposta deve ser "sim" ou "não". Tais respostas têm o valor de 1 ponto ou 0 , dependendo da pergunta. Escores entre 0 e 10 indicam ausência de depressão, entre 11 e 20 indicam depressão ligeira e entre 21-30 depressão grave (Anexo 5).

- Escala Hospitalar de Avaliação do Nível de Ansiedade e Depressão: tem como objetivo avaliar ansiedade e depressão em pacientes hospitalizados. A mesma é composta por 14 afirmações, sendo sete afirmações referentes à ansiedade e as demais à depressão. Cada afirmação tem quatro respostas pré-determinadas e a cada resposta é atribuído um valor que varia de 0 a 3 . Resultados entre 0 e 7 pontos indicam ansiedade e/ou depressão improvável, entre 8 e 11 pontos indicam possível depressão e/ou ansiedade e entre 12 e 21 pontos indicam provável depressão e ansiedade. Esse instrumento foi aplicado em função da condição de institucionalização dos participantes e para seu resultado ser contraposto ao da Escala de Depressão Geriátrica (confirmar ou não diagnósticos positivos no instrumento anterior) (Anexo 6). 


\section{Equipamentos}

Os equipamentos utilizados para a apresentação dos estímulos foram: um computador HP com tela de 23 polegadas sensível ao toque (touchscreen) e um notebook HP com tela de 15 polegadas (empregado apenas para uma participante acamada). Os estímulos foram apresentados por meio do Aplicativo Power Point 2007 (Microsoft Office 2007), empregado para construir a apresentação de relações condicionais entre estímulos auditivos e visuais, ou entre estímulos visuais, e testar relações de controle entre os estímulos. O aplicativo foi empregado apenas para a apresentação dos estímulos na tela. O desempenho dos participantes em cada sessão foi registrado manualmente pela pesquisadora e gravado por meio de uma filmadora da marca SONY Handycam, CDR-SR 20, HDD 80GB.

\section{Estímulos}

Os estímulos empregados foram distribuídos em cinco conjuntos, de quatro estímulos cada. O conjunto (A) foi composto de estímulos auditivos (nomes de pessoas). Os demais conjuntos (B, C, D e E) foram compostos de estímulos visuais de diferentes categorias: B - Fotos; C - Nomes escritos; D - Grau de parentesco; E Profissão, conforme a Tabela 3. 
Tabela 3.

Estímulos empregados no procedimento do Estudo 1.

\begin{tabular}{|c|c|c|c|c|c|}
\hline $\begin{array}{l}\text { Conjunto } \\
\qquad \mathrm{de} \\
\text { estímulos }\end{array}$ & $\begin{array}{c}\text { A } \\
\text { Nome } \\
\text { (ditado) }\end{array}$ & $\begin{array}{c}\text { B } \\
\text { Foto }\end{array}$ & $\begin{array}{c}\mathrm{C} \\
\text { Nome } \\
\text { (escrito) }\end{array}$ & $\begin{array}{c}\mathrm{D} \\
\text { Parentesco } \\
\text { (palavra } \\
\text { impressa) }\end{array}$ & $\begin{array}{c}\text { E } \\
\text { Profissão } \\
\text { (palavras } \\
\text { impressas) }\end{array}$ \\
\hline 1 & "Celso" & B1 & CELSO$^{1}$ & $\mathrm{IRM}^{\mathrm{A}} \mathrm{O}^{2}$ & CONTADOR \\
\hline 2 & "Paulo" & B2 & PAULO $^{2}$ & $\mathrm{PAI}^{1}$ & PEDREIRO \\
\hline 3 & "Elza" & B3 & ELZA & PRIMA & ADVOGADA \\
\hline 4 & "RITA" & B4 & RITA & MÃE & VENDEDORA \\
\hline
\end{tabular}

\section{Concordância Entre Observadores}

Uma observadora, com conhecimento em análise do comportamento, assistiu a $20 \%$ dos vídeos que foram gravados e fez o registro de acertos e erros dos participantes. Posteriormente, os dados da observadora foram comparados com os da pesquisadora. A concordância entre acertos e erros foi dividida pelo número total de tentativas e multiplicado por 100, com o intuito de computar a porcentagem de concordância entre os observadores (Kazdin, 1982). A concordância entre os observadores foi de $98 \%$.

\section{Procedimento de coleta de dados}

O projeto foi encaminhado para o Comitê de Ética em pesquisa e, após a aprovação deste, foi realizado o contato com os responsáveis das instituições e expostos os objetivos e métodos da pesquisa, assim como apresentado o Termo de Compromisso Livre e Esclarecido (TCLE). Com o aval das responsáveis pelas instituições para a 
realização da pesquisa, foi realizada uma entrevista com os morados da casa, juntamente com a aplicação do MEEM.

Em seguida foi aplicado o MoCA, o Protocolo Montreal-Toulouse de Exame Linguístico da Afasia, versão M1 Alpha, a Escala de Depressão Geriátrica e a Escala Hospitalar de Avaliação do Nível de Ansiedade e Depressão para a classificação dos participantes nos grupos. A aplicação dos instrumentos foi realizada em dias distintos para que os participantes não se cansassem. Além disso, nessa fase inicial foram feitas as entrevistas com os funcionários a respeito dos idosos para coletar informações sobre medicamentos e rotina destes. Com a definição dos participantes, iniciou-se o procedimento propriamente dito, descrito a seguir e apresentado nas Tabelas 4 e 5 . As sessões tinham duração aproximada de 30 minutos e eram realizadas cinco vezes por semana, de acordo com a disposição dos participantes. 
Tabela 4.

Descrição das Fases do Procedimento de Ensino de Relações Arbitrárias.

\begin{tabular}{|c|c|c|c|}
\hline Fase & Etapa & Blocos/Tentativas & Objetivo \\
\hline $\begin{array}{c}1 \\
\text { Pré-teste }\end{array}$ & & & $\begin{array}{l}\text { Verificar o conhecimento dos } \\
\text { participantes sobre os estímulos } \\
\text { que a serem empregados no } \\
\text { procedimento. }\end{array}$ \\
\hline \multirow{4}{*}{$\begin{array}{l}\text { Estabelecimento } \\
\text { de Linha } \\
\text { de Base }\end{array}$} & $\begin{array}{c}1 \\
\text { Ensino } \mathrm{AB}\end{array}$ & $4 / 96$ & $\begin{array}{l}\text { Ensinar as relações auditivo- } \\
\text { visuais } \mathrm{AB} \text { (nome próprio e foto } \\
\text { de pessoas). }\end{array}$ \\
\hline & $\begin{array}{c}2 \\
\text { Ensino BC }\end{array}$ & $5 / 120$ & $\begin{array}{l}\text { Ensinar as relações visuais- } \\
\text { visuais BC, (foto e nome } \\
\text { próprio). Ao final do treino, } \\
\text { testar as relações ensinadas. }\end{array}$ \\
\hline & $\begin{array}{c}3 \\
\text { Ensino CD }\end{array}$ & $5 / 120$ & $\begin{array}{l}\text { Ensinar as relações visuais- } \\
\text { visuais CD (nome próprio } \\
\text { escrito e palavra impressa - grau } \\
\text { de parentesco/profissão). Ao } \\
\text { final do treino, testar as relações } \\
\text { ensinadas. }\end{array}$ \\
\hline & $\begin{array}{c}4 \\
\text { Ensino DE }\end{array}$ & $5 / 120$ & $\begin{array}{c}\text { Ensinar as relações visuais- } \\
\text { visuais DE (palavra impressa - } \\
\text { grau de parentesco/ profissão e } \\
\text { palavra impressa relativa a } \\
\text { profissão/hobby). Ao final do } \\
\text { treino, testar as relações } \\
\text { ensinadas. }\end{array}$ \\
\hline 3 & $\begin{array}{l}\text { Teste LBC } \\
\mathrm{AB}, \mathrm{BC}, \mathrm{CD}, \\
\mathrm{DE}\end{array}$ & $1 / 48$ & $\begin{array}{l}\text { Verificar a aprendizagem das } \\
\text { relações ensinadas. }\end{array}$ \\
\hline Testes & $\begin{array}{l}\text { Testes de } \\
\text { Equivalência }\end{array}$ & $1 / 54$ & $\begin{array}{l}\text { Testar a emergência de relações } \\
\text { não diretamente ensinadas (DB, } \\
\text { EB, EC, EB) - formação de } \\
\text { classes de equivalência. }\end{array}$ \\
\hline $\begin{array}{c}4 \\
\text { Teste de } \\
\text { Manutenção }\end{array}$ & & $2 / 102$ & $\begin{array}{c}\text { Verificar a manutenção das } \\
\text { relações ensinadas e as classes } \\
\text { de equivalência }\end{array}$ \\
\hline
\end{tabular}


Tabela 5 .

Descrição dos blocos de Ensino das Relações $A B, B C, C D$ e De e Testes de Equivalência.

\begin{tabular}{|c|c|c|c|c|c|c|}
\hline Fase & Procedimento & Relações & Modelo & Comparações & Bloco & Tentativas \\
\hline \multirow{40}{*}{2} & & & A1 & B1 & & 6 \\
\hline & Ensino & $\mathrm{AB}$ & $\mathrm{A} 2$ & B1-B2 & 1 & 6 \\
\hline & & & $\mathrm{A} 1-\mathrm{A} 2$ & B1-B2 & & 6 \\
\hline & Ensino & $\mathrm{AB}$ & A3 & B1-B2-B3 & \multirow{4}{*}{2} & 6 \\
\hline & Ensino & $\mathrm{AB}$ & A1-A2-A3 & B1-B2-B3 & & 12 \\
\hline & Ensino & $\mathrm{AB}$ & A4 & B1-B2-B3-B4 & & 8 \\
\hline & Ensino & $\mathrm{AB}$ & $\mathrm{A} 1-\mathrm{A} 2-\mathrm{A} 3-\mathrm{A} 4$ & B1-B2-B3B4 & & 8 \\
\hline & LBCR AB & $\mathrm{AB}$ & A1-A2-A3-A4 & B1-B2-B3B4 & 3 & 20 \\
\hline & LBCE AB & $\mathrm{AB}$ & A1-A2-A3-A4 & B1-B2-B3-B4 & 4 & 20 \\
\hline & Nomeação & $\mathrm{AB}$ & A1-A2-A3-A4 & B1-B2-B3-B4 & 5 & 8 \\
\hline & Ensino & $\mathrm{BC}$ & B1 & $\mathrm{C} 1$ & \multirow{3}{*}{6} & 6 \\
\hline & Ensino & $\mathrm{BC}$ & B2 & $\mathrm{C} 1-\mathrm{C} 2$ & & 6 \\
\hline & Ensino & $\mathrm{BC}$ & B1-B2 & $\mathrm{C} 1-\mathrm{C} 2$ & & 6 \\
\hline & Ensino & $\mathrm{BC}$ & B3 & $\mathrm{C} 1-\mathrm{C} 2-\mathrm{C} 3$ & \multirow{4}{*}{7} & 6 \\
\hline & Ensino & $\mathrm{BC}$ & B1-B2-B3 & $\mathrm{C} 1-\mathrm{C} 2-\mathrm{C} 3$ & & 12 \\
\hline & Ensino & $\mathrm{BC}$ & B4 & $\mathrm{C} 1-\mathrm{C} 2-\mathrm{C} 3-\mathrm{C} 4$ & & 8 \\
\hline & Ensino & $\mathrm{BC}$ & B1-B2-B3-B4 & $\mathrm{C} 1-\mathrm{C} 2-\mathrm{C} 3-\mathrm{C} 4$ & & 8 \\
\hline & LBCR BC & $\mathrm{BC}$ & B1-B2-B3-B4 & $\mathrm{C} 1-\mathrm{C} 2-\mathrm{C} 3-\mathrm{C} 4$ & 8 & 20 \\
\hline & LBCE BC & $\mathrm{BC}$ & B1-B2-B3-B4 & C1-C2-C3-C4 & 9 & 20 \\
\hline & $\begin{array}{c}\text { Teste de } \\
\text { Simetria CB }\end{array}$ & $\mathrm{CB}$ & $\mathrm{C} 1-\mathrm{C} 2-\mathrm{C} 3-\mathrm{C} 4$ & B1-B1-B3-B4 & 10 & 20 \\
\hline & Ensino & $\mathrm{CD}$ & $\mathrm{C} 1$ & D1 & \multirow{3}{*}{11} & 6 \\
\hline & Ensino & CD & $\mathrm{C} 2$ & D1-D2 & & 6 \\
\hline & Ensino & $\mathrm{CD}$ & $\mathrm{C} 1-\mathrm{C} 2$ & D1-D2 & & 6 \\
\hline & Ensino & $\mathrm{CD}$ & C3 & D1-D2-D3 & \multirow{4}{*}{12} & 6 \\
\hline & Ensino & $\mathrm{CD}$ & $\mathrm{C} 1-\mathrm{C} 2-\mathrm{C} 3$ & D1-D2-D3 & & 12 \\
\hline & Ensino & $\mathrm{CD}$ & $\mathrm{C} 4$ & D1-D2-D3-D4 & & 8 \\
\hline & Ensino & $\mathrm{CD}$ & $\mathrm{C} 1-\mathrm{C} 2-\mathrm{C} 3-\mathrm{C} 4$ & D1-D2-D3-D4 & & 8 \\
\hline & LBCR CD & $\mathrm{CD}$ & $\mathrm{C} 1-\mathrm{C} 2-\mathrm{C} 3-\mathrm{C} 4$ & D1-D2-D3-D4 & 13 & 20 \\
\hline & LBCE CD & $\mathrm{CD}$ & C1-C2-C3-C4 & D1-D2-D3-D4 & 14 & 20 \\
\hline & $\begin{array}{c}\text { Teste de } \\
\text { Simetria DC }\end{array}$ & $\mathrm{DC}$ & D1-D2-D3-D4 & $\mathrm{C} 1-\mathrm{C} 1-\mathrm{C} 3-\mathrm{C} 4$ & 15 & 20 \\
\hline & Ensino & $\mathrm{DE}$ & D1 & E1 & \multirow{3}{*}{16} & 6 \\
\hline & Ensino & $\mathrm{DE}$ & D2 & E1-E2 & & 6 \\
\hline & Ensino & $\mathrm{DE}$ & D1-D2 & E1-E2 & & 6 \\
\hline & Ensino & $\mathrm{DE}$ & D3 & E1-E2-E3 & \multirow{4}{*}{17} & 6 \\
\hline & Ensino & $\mathrm{DE}$ & D1-D2-D3 & E1-E2-E3 & & 12 \\
\hline & Ensino & $\mathrm{DE}$ & D4 & E1-E2-E3-E4 & & 8 \\
\hline & Ensino & $\mathrm{DE}$ & D4 & E1-E2-E3-E4 & & 8 \\
\hline & LBCR DE & $\mathrm{DE}$ & D1-D1-D3-D4 & E1-E2-E3-E4 & 18 & 20 \\
\hline & LBCE DE & $\mathrm{DE}$ & D1-D1-D3-D4 & E1-E2-E3-E4 & 19 & 20 \\
\hline & $\begin{array}{c}\text { Teste de } \\
\text { Simetria ED }\end{array}$ & ED & E1-E2-E3-E4 & D1-D1-D3-D4 & 20 & 20 \\
\hline
\end{tabular}




\begin{tabular}{|c|c|c|c|c|c|}
\hline Teste LBCE & $\begin{array}{l}\text { AB-BC- } \\
\text { CD-DE }\end{array}$ & $\begin{array}{l}\mathrm{A} 1-\mathrm{A} 2-\mathrm{A} 3-\mathrm{A} 4 \\
\mathrm{~B} 1-\mathrm{B} 2-\mathrm{B} 3-\mathrm{B} 4 \\
\mathrm{C} 1-\mathrm{C} 2-\mathrm{C} 3-\mathrm{C} 4 \\
\mathrm{D} 1-\mathrm{D} 2-\mathrm{D} 3-\mathrm{D} 4\end{array}$ & $\begin{array}{c}\text { B1-B1-B3-B4 } \\
\text { C1-C2-C3-C4 } \\
\text { D1-D2-D3-D4 } \\
\text { E1-E2-E3-E4 }\end{array}$ & 21 & 48 \\
\hline \multirow{7}{*}{$\begin{array}{c}\text { Testes de } \\
\text { Equivalência }\end{array}$} & $\mathrm{BD}$ & B1-B2-B3-B4 & D1-D2-D3-D4 & \multirow{7}{*}{22} & \multirow{7}{*}{56} \\
\hline & $\mathrm{CE}$ & $\mathrm{C} 1-\mathrm{C} 2-\mathrm{C} 3-\mathrm{C} 4$ & E1-E1-E3-E4 & & \\
\hline & ED & E1-E2-E3-E4 & D1-D2-D3-D4 & & \\
\hline & $\mathrm{DC}$ & D1-D2-D3-D4 & $\mathrm{C} 1-\mathrm{C} 2-\mathrm{C} 3-\mathrm{C} 4$ & & \\
\hline & $\mathrm{CB}$ & $\mathrm{C} 1-\mathrm{C} 2-\mathrm{C} 3-\mathrm{C} 4$ & B1-B1-B3-B4 & & \\
\hline & $\mathrm{EC}$ & E1-E2-E3-E4 & $\mathrm{C} 1-\mathrm{C} 2-\mathrm{C} 3-\mathrm{C} 4$ & & \\
\hline & DB & D1-D2-D3-D4 & B1-B1-B3-B4 & & \\
\hline \multirow{4}{*}{ Teste LBCE } & & A1-A2-A3-A4 & B1-B1-B3-B4 & \multirow{4}{*}{23} & \multirow{4}{*}{48} \\
\hline & AB-BC- & B1-B1-B3-B4 & $\mathrm{C} 1-\mathrm{C} 2-\mathrm{C} 3-\mathrm{C} 4$ & & \\
\hline & CD-DE & $\mathrm{C} 1-\mathrm{C} 2-\mathrm{C} 3-\mathrm{C} 4$ & D1-D2-D3-D4 & & \\
\hline & & D1-D2-D3-D4 & E1-E1-E3-E4 & & \\
\hline \multirow{7}{*}{$\begin{array}{c}\text { Testes de } \\
\text { Equivalência }\end{array}$} & $\mathrm{BD}$ & B1-B1-B3-B4 & D1-D2-D3-D4 & \multirow{7}{*}{24} & \multirow{7}{*}{56} \\
\hline & $\mathrm{CE}$ & $\mathrm{C} 1-\mathrm{C} 2-\mathrm{C} 3-\mathrm{C} 4$ & E1-E1-E3-E4 & & \\
\hline & ED & E1-E1-E3-E4 & D1-D2-D3-D4 & & \\
\hline & DC & D1-D2-D3-D4 & $\mathrm{C} 1-\mathrm{C} 2-\mathrm{C} 3-\mathrm{C} 4$ & & \\
\hline & $\mathrm{CB}$ & $\mathrm{C} 1-\mathrm{C} 2-\mathrm{C} 3-\mathrm{C} 4$ & B1-B1-B3-B4 & & \\
\hline & $\mathrm{EC}$ & E1-E1-E3-E4 & $\mathrm{C} 1-\mathrm{C} 2-\mathrm{C} 3-\mathrm{C} 4$ & & \\
\hline & DB & D1-D2-D3-D4 & B1-B1-B3-B4 & & \\
\hline
\end{tabular}

Fase 1: Pré-teste de nomeação de figuras

Nesse pré-teste foi apresentado aos participantes as fotos que seriam utilizadas no procedimento, com o objetivo de verificar se eles atribuíam algum nome às fotos sem que, contudo, esse fosse um impedimento para a realização do protocolo de pesquisa (exceto se os nomes utilizados fossem realmente de parentes dos participantes, o que não ocorreu).

Fase 2: Estabelecimento de Linha de Base

O objetivo dessa fase foi estabelecer o repertório de discriminações condicionais entre estímulos auditivos (palavras ditadas) e estímulos visuais (fotos), e entre estímulos visuais (fotos ou palavras impressas, e palavras impressas - cf. Tabela 3). A estrutura de treino empregada foi a estrutura linear (Saunders \& Green, 1999). A Fase 2 foi constituída de cinco etapas, descritas a seguir. 


\section{Etapa 1: Ensino de Discriminações Auditivo-Visuais AB}

Nesta etapa foi realizado um procedimento de emparelhamento arbitrário com modelo (arbitrary matching to sample), entre estímulos auditivos (Conjunto A) e fotos (Conjunto B). O procedimento dessa etapa foi dividido em cinco blocos. Os dois primeiros blocos foram de ensino, sendo o primeiro composto por 18 tentativas, e o segundo por 34 tentativas. Antes do início da sessão, a seguinte instrução foi dada para o participante: "Ao ouvir o nome que eu direi, você deverá apontar com o dedo a imagem que aparecerá na tela. Eu irei te falar se você apontou certo ou não”. No primeiro bloco, foi ensinada a relação A1B1 e A2B2. Nas seis primeiras tentativas, foi apresentado como modelo o estímulo A1 e como comparação apenas o estímulo B1. Nas seis tentativas seguintes, o modelo era A2 e os estímulos de comparação foram B1 e B2 (introdução gradual dos estímulos de comparação). Nas seis últimas tentativas do bloco, os estímulos A1 e A2 se alternaram como modelos e os estímulos de comparação eram sempre B1 e B2. A cada tentativa, inicialmente, a pesquisadora ditava o estímulo auditivo modelo, que foi repetido a cada três segundos até o final da tentativa. Após a apresentação inicial do estímulo, um ou dois estímulos de comparação apareciam em qualquer dos quatro cantos do monitor. A resposta esperada era que o participante colocasse o dedo sobre a figura correspondente ao estímulo modelo. Caso o participante não apresentasse essa resposta, a pesquisadora dizia "pode colocar o dedo sobre a figura" e, se necessário, era oferecida ajuda física para que o idoso realizasse a tarefa. Após a emissão da resposta, a apresentação do modelo era interrompida, e a pesquisadora dizia frases como "Você acertou” ou "Parabéns! Está certo”, sinalizando o acerto da tentativa. Respostas incorretas eram consequenciadas com a frase "Não, não é esse", e a apresentação da tentativa seguinte. O critério de passagem para o bloco seguinte era de $90 \%$ de acertos. Caso o participante não atingisse este critério, o bloco 
era retido por até três vezes. No segundo bloco eram ensinadas as relações A3B3 e A4B4. Inicialmente, foram apresentadas seis tentativas em que o estímulo modelo auditivo era A3 e os estímulos de comparação eram B1, B2 e B3. Em seguida, eram apresentadas 12 tentativas em que os estímulos A1, A2 e A3 se alternavam como modelo, e B1, B2 e B3 eram os estímulos de comparação. Na sequência, eram apresentadas oito tentativas com o estímulo A4 como modelo, tendo como estímulos de comparação B1, B2, B3 e B4, e mais oito tentativas em que as relações A1B1, A2B2, A3B3 e A4B4 eram apresentadas, de maneira alternada. Todos os estímulos de comparação eram apresentados em posições aleatórias na tela do computador. Consequências para erros e acertos, assim como o critério de aprendizagem e repetição eventual do bloco eram os mesmos descritos no primeiro bloco.

O terceiro bloco (Linha de Base Cheia Reforçada - LBCR) era formado por 20 tentativas, em que as quatro relações ensinadas nos blocos anteriores (A1B1, A2B2, A3B3 e A4B4) eram apresentadas com o objetivo de verificar a manutenção da aprendizagem das relações ensinadas até o momento. Cada relação foi apresentada por cinco vezes, em que os estímulos modelo se alternavam em uma sequência quase aleatória (não havia apresentação do mesmo estímulo modelo em mais de duas tentativas consecutivas). Os estímulos de comparação disponíveis eram todos os ensinados. Caso o participante acertasse pelo menos $90 \%$ das relações, era apresentado um novo bloco de Linha de Base Cheia, também com 20 tentativas, mas sem consequências para respostas certas ou erradas (Linha de Base Cheia em Extinção LBCE). A instrução dada para ao participante era: "Agora aparecerão quatro fotos na tela e eu direi o nome de uma pessoa. Você deve apontar com o dedo a foto da pessoa cujo nome eu disser, mas eu não direi se você acertou ou errou.". O critério de passagem para a Etapa 2 era de 90\% de acertos em um bloco. Caso esse critério não 
fosse atingido, tanto no terceiro quanto no quarto bloco, estes eram reapresentados até o máximo de 3 vezes, com uma ordem diferente de tentativas.

O último bloco da Etapa 1 consistiu em apresentar ao participante as fotos ensinadas, uma por vez, e pedir para que ele dissesse o nome da pessoa da foto (Nomeação). Cada foto foi apresentada duas vezes, assim, o bloco foi constituído por oito tentativas. Não havia critério de passagem para a Etapa 2.

Etapa 2: Ensino de Discriminações Visuais-Visuais BC

O procedimento da Etapa 2 foi dividido em cinco blocos de tentativas, de acordo com os mesmos moldes do Ensino de relações $A B$ - Etapa 1. O primeiro e o segundo blocos eram de ensino, sendo o primeiro composto por 18 tentativas e o segundo por 34 tentativas, que tinham como objetivo o ensino das relações entre fotos e nomes escritos - relações B1C1 e B2C2 (primeiro bloco), e B3C3 e B4C4 (segundo bloco). A configuração e sequência de tentativas era a mesma descrita para o ensino das relações $\mathrm{AB}$, exceto no último bloco, em que eram testadas as relações de simetria $\mathrm{CB}$. Nesta etapa as tentativas eram simultâneas, ou seja, o estímulo modelo aparecia e permanecia na tela ao mesmo tempo em que os estímulos de comparação e não havia resposta de observação. O critério de aprendizagem para o avanço de um bloco para seguinte era de $90 \%$ de acertos. Se o participante não alcançasse o critério de acertos, o bloco poderia ser repetido por até três vezes. A sequência de ensino foi: ensino de relações B1C1 e B2C2 (Bloco 1), ensino de relações B3C3 e B4C4 (Bloco 2), LBCR (Bloco 3), LBCE (Bloco 4) e Teste de Simetria CB (Bloco5). O Teste de Simetria tinha por objetivo verificar se o participante era capaz de relacionar os mesmos estímulos dos conjuntos B e C, mas com os estímulos C como modelo e os estímulos do conjunto B como estímulos de comparação, condição importante que deveria ser garantida para o 
posterior teste de equivalência. Esse teste era composto por 20 tentativas não reforçadas, em que as relações C1B1, C2B2, C3B3 e C4B4 eram apresentadas por cinco vezes não consecutivas (cada relação). O critério de aprendizagem para o avanço para a Etapa 3 era de $90 \%$ de acertos em um bloco. Caso o participante não atingisse esse critério, o teste era refeito por mais três vezes. Se o participante continuasse errando, era feito um Treino de Simetria CB, em que as tentativas apresentadas no teste eram apresentadas, mas com reforço. O critério de $90 \%$ de acertos permanecia em vigor no Treino de Simetria e, quando o participante atingisse este critério, era submetido ao Teste de Simetria novamente.

\section{Etapa 3: Ensino de Discriminações Visuais-Visuais CD}

O objetivo desta etapa era ensinar as relações CD: relações entre nome escrito de pessoas (C) e grau de parentesco (D). Para tanto, foi usada a mesma estrutura de ensino das relações $\mathrm{AB}$ e $\mathrm{BC}$ (dois blocos de ensino das relações a serem ensinados, um bloco de LBCR, um bloco de LBCE e Teste de Simetria DC). Os critérios para passagem entre os blocos, assim como as instruções e consequências, para acertos e erros, foram os mesmos da Etapa 2.

Etapa 4: Ensino de Discriminações Visuais-Visuais DE

A Etapa 4 tinha como objetivo ensinar as relações visuais-visuais DE - relações entre o grau de parentesco (D) e profissão (E). Foi seguida a mesma estrutura e sequência de ensino das etapas anteriores, bem como consequências para acertos e erros e critérios de aprendizagem. 
Fase 3: Teste Linha de Base Cheia AB, BC, CD e DE e Testes de Equivalência

O objetivo dessa Fase era verificar se as relações aprendidas na Fase anterior se mantinham e conduzir os testes de equivalência. Inicialmente, foi conduzido um Teste de $\mathrm{LBCE}$ de todas as relações $(\mathrm{AB}, \mathrm{BC}, \mathrm{CD}$ e $\mathrm{DE})$, cujo objetivo era verificar a estabilidade das relações ensinadas e preparar o participante para os testes de equivalência. Nesse teste, todas as relações ensinadas foram apresentadas em um bloco de 48 tentativas, sendo 12 tentativas de cada relação. A ordem de apresentação das relações foi quase aleatória (a mesma relação não poderia ser apresentada por mais de duas vezes consecutivas). As respostas não eram reforçadas, ou seja, o participante não era informado sobre se acertava ou não a tentativa. O critério de passagem para os testes seguintes era de $90 \%$ de acertos em um bloco. Caso o participante não atingisse o critério, o bloco era reapresentado até que o critério fosse atingido.

No Teste de Equivalência eram testadas as relações BD, CE, ED, DC, CB, EC e DB (simetria da transitividade das relações visuais-visuais), avaliando, assim, a emergência de relações que não foram ensinadas diretamente. O bloco de testes de equivalência foi composto por 56 tentativas, em que cada relação era apresentada por duas vezes não consecutivas. Para cada participante foi aplicado um único bloco de testes de equivalência, em função da extensão do teste e com o objetivo de verificar se a emergência de relações não ensinadas ocorreria de forma imediata. Essa Fase era encerrada, portanto, com a apresentação do teste de equivalência. O critério de encerramento dessa Fase foi definido pela realização do bloco, independente da porcentagem de acertos. 


\section{Fase 4: Teste de Manutenção}

O Teste de Manutenção teve por objetivo verificar se tanto as relações ensinadas na Fase 2, quanto as relações de equivalência (não diretamente ensinadas), quando presentes, se mantiveram ao longo do tempo. O Teste de Manutenção foi realizado em três momento distintos: após cinco, 15 e 30 dias da finalização da Fase 3. A Fase de Manutenção seguiu a mesma estrutura da Fase 3, ou seja, foram reapresentados os blocos de teste de $\mathrm{LBCE} \mathrm{AB}, \mathrm{BC}, \mathrm{CD}$ e $\mathrm{DE}$ e os Testes de Equivalência. A instrução inicial dada ao participante era a seguinte: "Agora será feito mais um teste e eu não irei dizer se você está acertando ou errando. Às vezes, durante o teste, eu irei dizer o nome de uma pessoa e você deverá apontar para uma das fotos mostradas pelo computador. Em outras vezes, aparecerá uma foto ou uma palavra escrita no meio da tela e você deverá escolher as alternativos dos cantos da tela que achar que combina com a informação que apareceu no centro do computador.". 


\section{Resultados}

Será apresentado, na Figura 1, o desempenho de cada participante em três das quatro Fases do procedimento: Fase 2 - ensino das relações condicionais ( $\mathrm{AB}, \mathrm{BC}, \mathrm{CD}$ e DE), Fase 3 - LBCE e equivalência, e Fase 4 - Testes de Manutenção - realizados cinco, 15 e 30 dias após a finalização da Fase 3. 

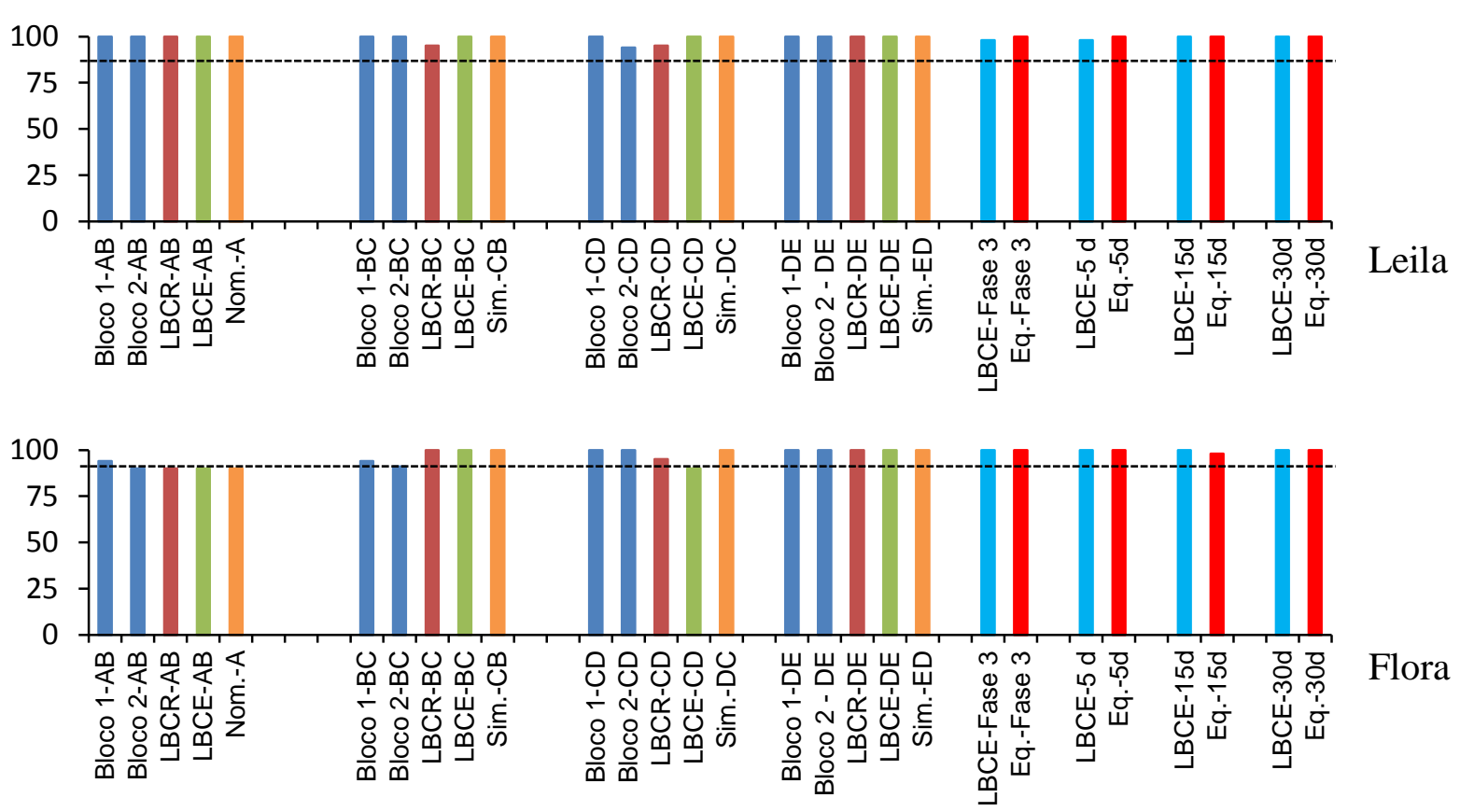

Flora

:

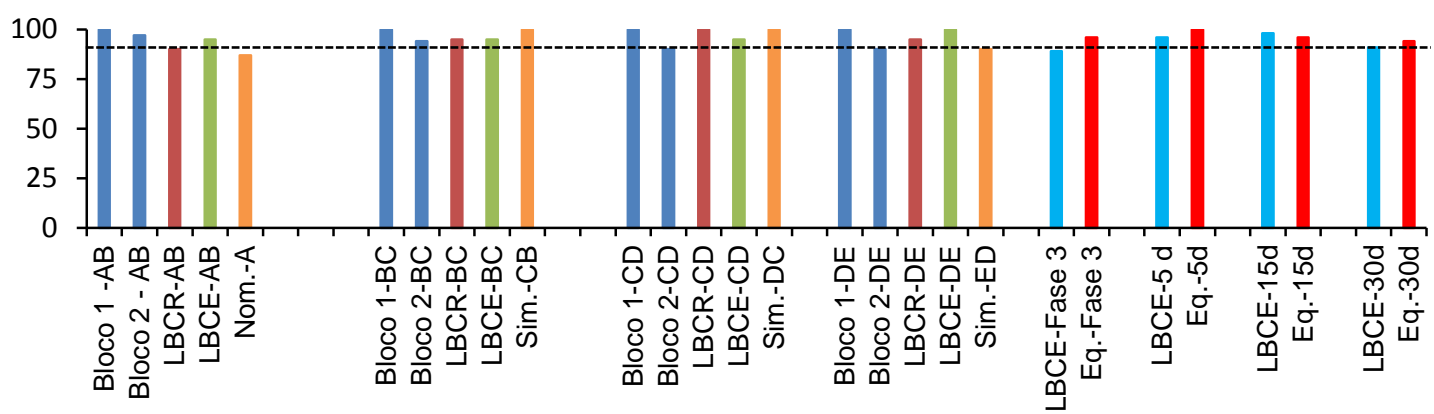

Eva

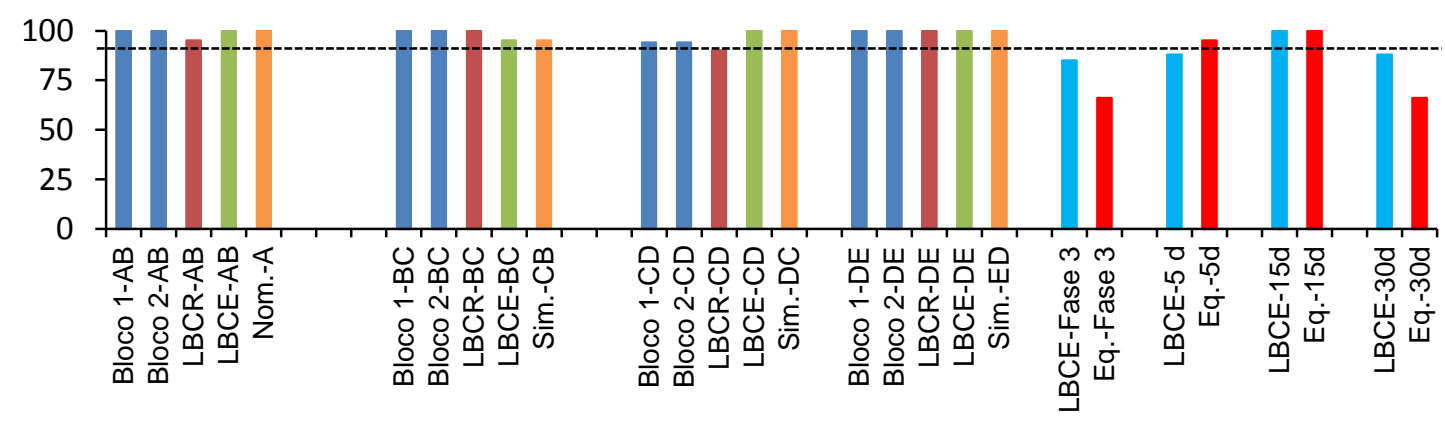

Vagner

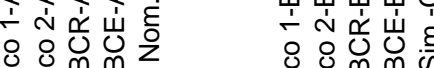

음 음

迤造品品

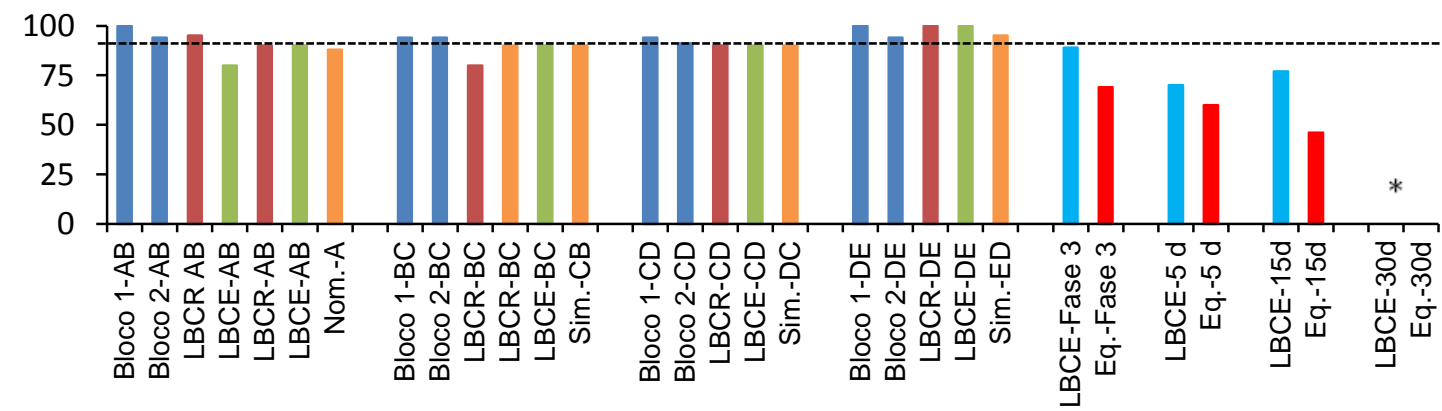

Cássia

* A participante não realizou estes testes.

Figura 1: Porcentagem de acertos dos participantes no ensino e teste das relações condicionais, bem como nos Testes de Manutenção. 
A partir da Figura 1, pode-se observar que o desempenho dos participantes Eva, Flora, Leila e Vagner foram muito semelhantes durante os procedimentos de ensino (Fase 2 - relações $\mathrm{AB}, \mathrm{BC}, \mathrm{CD}$ e $\mathrm{DE}$ ). Todos os quatro atingiram o critério de aprendizagem proposto (90\% de acertos) com uma única apresentação de cada bloco. A exceção foi a participante Cássia, cujo desempenho será descrito mais adiante, à parte dos demais participantes.

No ensino $\mathrm{AB}$, a participante Leila atingiu $100 \%$ em todos os blocos ensinados, inclusive na LBCR, LBCE e nomeação. Vagner errou uma tentativa na LBCR e acertou todas as tentativas de LBCE e nomeação. A participante Eva errou três tentativas do bloco de ensino das relações $\mathrm{AB}$, duas tentativas na $\mathrm{LBCR}$, uma tentativa no bloco de LBCE e uma tentativa no teste de nomeação. Já a participante Flora, errou quatro das tentativas nos blocos $\mathrm{AB}$, duas tentativas na $\mathrm{LBCE}$ e LBCR e uma tentativa no bloco de nomeação.

No ensino das relações BC, Leila acertou todas as tentativas do bloco de ensino, errou uma tentativa da LBCR, porém acertou todas as tentativas de LBCE e simetria. Flora errou quatro tentativas no bloco de ensino $\mathrm{BC}$ e acertou todas as tentativas de LBCR, LBCE e simetria. O participante Vagner acertou todas as tentativas de bloco de ensino BC e LBCR e errou uma tentativa da LBCE e simetria. Já a participante Eva errou duas tentativas dos blocos de ensino, uma tentativa na LBCR e LBCE e acertou todas as tentativas dos testes de simetria.

$\mathrm{Na}$ aprendizagem das relações $\mathrm{CD}$, Leila errou duas tentativas no bloco de ensino e uma tentativa na LBCR, porém acertou todas as tentativas dos blocos de LBCE e simetria. Flora acertou todas as tentativas no bloco de ensino, errou uma tentativa no bloco de LBCR, duas tentativas no bloco de LBCE e acertou todas as tentativas de simetria. Eva errou três tentativas no bloco de ensino das relações $\mathrm{CD}$, acertou todas as 
tentativas de LBCR, errou uma tentativa no bloco de LBCE e acertou todas as tentativas de simetria. Vagner errou quatro tentativas no bloco de ensino $\mathrm{CD}$, duas tentativas na LBCR e acertou todas as tentativas de LBCE e simetria.

No ensino das relações DE, Leila, Flora e Vagner acertaram todo o bloco de ensino, LBCR, LBCE e simetria. Eva errou três tentativas no bloco de ensino desta relação, uma tentativa no bloco de LBCR e acertou todas as tentativas de LBCE e simetria.

De forma geral, portanto, pode-se afirmar que os participantes Eva, Flora, Leila e Vagner passaram pela Fase 2 sem dificuldades, atingindo os critérios de aprendizagem estabelecidos com o número mínimo de apresentações de blocos de ensino e teste estabelecidos no procedimento.

Na Fase 3 - LBCE e Teste de Equivalência - que ocorreu um dia após a finalização da Fase 2, Eva, Flora e Leila apresentaram desempenhos semelhantes. Flora foi a participante que apresentou os melhores resultados: acertou todas as tentativas dos testes de LBCE e Testes de Equivalência. A participante Eva errou cinco tentativas do bloco de LBCE e duas tentativas de relações diferentes do Teste de Equivalência. Leila errou uma tentativa do bloco de LBCE e acertou todas as tentativas do Teste de Equivalência. Vagner apresentou o pior desempenho entre esses quatro participantes: errou oito tentativas de LBCE e 18 tentativas do Teste de Equivalência. Seus erros concentraram-se nas mesmas relações, pois confundiu, tanto na LBCE quanto no Teste de Equivalência a classe de estímulos A3-B3-C3-D3-E3 com A4-B4-C4-D4-E4 (por exemplo, quando o estímulo modelo era B3 e as comparações $\mathrm{C} 1, \mathrm{C} 2$, C3 e C4, Vagner escolhia a comparação C4).

A Fase 4 - Testes de Manutenção - foi conduzida em dias distintos: cinco, 15 e 30 dias após a Fase 3. Observa-se novamente, de acordo com a Figura 1, que as 
participantes Eva, Flora e Leila tiveram desempenhos semelhantes: não foi observada deterioração no desempenho dessas participantes ao longo das apresentações dos testes, tanto os de LBCE, quanto nos Testes de Equivalência.

A participante Leila errou apenas uma tentativa no bloco de LBCE da manutenção de cinco dias e, nos demais testes, a participante acertou todas as tentativas. Flora cometeu um erro apenas em uma tentativa do Teste de Equivalência de 15 dias. Nos demais testes, a participante apresentou $100 \%$ de acertos. Já Eva, no teste após cinco dias, errou duas tentativas na LBCE e acertou todas as tentativas de equivalência; errou uma tentativa na LBCE e duas tentativas no teste de equivalência de 15 dias; e errou cinco tentativas na LBCE e três tentativas no teste de equivalência de 30 dias.

O participante Vagner teve um desempenho distinto das demais participantes. Apesar de apresentar bom desempenho na Fase de Ensino das relações condicionais, desde a apresentação dos primeiros testes observou-se uma piora no seu desempenho. Vagner errou seis tentativas na LBCE de todas as relações de cinco dias e três tentativas no teste de Equivalência de cinco dias; apresentou $100 \%$ de acertos nos testes aplicados em 15 dias de manutenção e errou seis tentativas do LBCE aplicados nos 30 dias de manutenção e 18 tentativas do teste de equivalência do mesmo período. Observou-se, portanto, uma deterioração importante no desempenho de Vagner no último Teste de Manutenção conduzido.

A participante Cássia teve um desempenho bastante distinto dos demais. Observa-se que, no ensino das relações $\mathrm{AB}$, apesar de ter atingido o critério nos blocos de ensino e na LBCR com apenas dois e um erro, respectivamente, apresentou quatro erros na LBCE, pois confundiu sistematicamente as duas últimas relações ensinadas (nomes das mulheres). Diante disto, passou novamente pelo bloco de LBCR, atingindo o critério de acertos e passando mais uma vez para bloco de LBCE. Neste, apresentou 
erros em apenas duas tentativas e, no Teste de Nomeação, errou o nome de uma das fotos de mulheres.

No ensino das relações BC, Cássia atingiu o critério de aprendizagem no bloco de ensino, porém, na LBCR, Cássia errou quatro tentativas e por isso, realizou novamente este bloco. Na segunda apresentação do bloco, a participante errou apenas duas tentativas e o mesmo ocorreu no Teste de Simetria CB. Todos os erros foram referentes às profissões das mulheres.

Nas relações CD e DE, Cássia não necessitou de repetição dos blocos de ensino. Errou duas tentativas de LBCR-CD, LBCE-CD e Teste de Simetria D-E, porém apresentou $100 \%$ de acertos nos blocos de LBCR-DE, LBCE-DE e errou apenas uma tentativa no teste de simetria ED.

Na Fase 3, observou-se que o desempenho de Cássia na Fase 2 não sustentou a emergência de relações de equivalência em nenhum dos testes de manutenção que realizou. Seu desempenho nos blocos de LBCE variou entre $89 \%$ e $77 \%$ de acertos, e nos testes de equivalência, seu desempenho piorou a cada apresentação: de $69 \%$ de acertos na primeira apresentação, para $60 \%$ na segunda e $46 \%$ na terceira. Cássia foi, portanto, a única participante que não apresentou emergência de equivalência de estímulos.

Por motivos de saúde, Cássia não realizou os treinos e testes de forma contínua. O intervalo entre as sessões de ensino de cada relação variou de três a sete dias. A participante também foi a única que não realizou os testes de Equivalência e Manutenção nos dias exatos, pois muitas vezes estava com dores que a impossibilitavam de levantar da cama. A participante, inclusive, não realizou o Teste de Manutenção de 30 dias, pois estava hospitalizada. 


\section{Discussão}

Os objetivos do Estudo 1 foram (a) investigar a ocorrência de responder por exclusão em idosos institucionalizados sem comprometimento cognitivo, (b) investigar a viabilidade do uso de uma estratégia de ensino de discriminações condicionais auditivo-visuais e visuais-visuais por exclusão; e (c) testar a formação e manutenção de classes de equivalência com estímulos auditivos e visuais, a partir do procedimento de ensino conduzido. Para isso, foi implementado um procedimento de ensino de relações condicionais arbitrárias entre cinco conjuntos de quatro estímulos cada, por meio de uma estrutura de treino linear.

De modo geral, os resultados obtidos neste estudo indicam que os idosos institucionalizados investigados apresentaram responder por exclusão nas tentativas de ensino em que novos estímulos de comparação foram introduzidos. Além disso, todos os idosos aprenderam as relações condicionais ensinadas, sendo que a maioria (quatro em cinco) o fez a partir do número mínimo de blocos de ensino planejados. Também quatro, dos cinco participantes, apresentaram formação de classes de estímulos equivalentes e mantiveram essas classes nas três ocasiões em que os testes foram reapresentados. Esses resultados serão discutidos na sequência.

O responder por exclusão foi testado nos blocos de ensino das relações condicionais sempre que a tentativa apresentava pela primeira vez um estímulo modelo indefinido, juntamente com um estímulo de comparação indefinido e dois ou três estímulos de comparação definidos. O responder por exclusão, segundo McIlvane, Wilkinson, e de Souza (2000) ocorre quando um estímulo modelo indefinido é relacionado, sem ensino prévio, com um estímulo de comparação indefinido. Porém, para este fenômeno ocorrer, é necessário, primeiramente, o estabelecimento de uma linha de base consistente. No presente trabalho, esperava-se estabelecer uma linha de 
base consistente pela apresentação consecutiva (seis vezes) de um mesmo estímulo modelo. Na primeira relação ensinada, o modelo A1 era apresentado apenas com o estímulo de comparação correto (B1); com isso, esperava-se estabelecer essa relação de forma consistente, antes de introduzir a relação seguinte. Na primeira apresentação do modelo A2, os estímulos de comparação disponíveis eram B1 (já relacionado a A1) e B2, o S+ nessa relação. Essa, portanto, poderia ser considerara uma tentativa de exclusão, pois esperava-se que o participante selecionasse B2, excluindo B1. O mesmo aconteceu na introdução das relações A3B3 e A4 B4, assim como nos blocos de ensino das demais relações. Todos os participantes responderam por exclusão nas tentativas críticas, uma vez que, à medida que estímulos modelos novos eram apresentados, simultaneamente a estímulos de comparação já relacionados a outros modelos e um estímulo de comparação completamente novo, todos os idosos consistentemente selecionavam o estímulo de comparação novo, replicando dados já obtidos extensamente com outras populações (e.g., Costa et al., 2001).

Estudos que investigam a formação de relações condicionais com idosos costumam empregar outras formas de ensino, como a inserção gradual de estímulos de comparação (Aggio, \& Domeniconi, 2012), ou o procedimento de tentativa e erro (Haydu, \& Morais, 2009). Porém, o ensino por exclusão parece ter sido eficiente para a aprendizagem dos idosos, uma vez que todos eles conseguiram atingir os critérios propostos com o número mínimo de blocos de ensino programados, com exceção da participante Cássia que precisou de uma única repetição do bloco de LBCR das relações BC.

Ao se comparar os procedimento de Haydu e Morais (2009) com os do presente estudo, verifica-se que os blocos de ensino propostos pelos autores tinham um número mais elevado de tentativas em comparação com os do presente estudo (por exemplo, 
para o ensino das relações $\mathrm{AB}$, os idosos completavam 72 tentativas por bloco - mesmo no ensino de quatro conjuntos de estímulos -, em contraste com as 52 tentativas totais de ensino do presente estudo), e o número médio de repetições dos blocos foi mais elevado do que o aqui apresentado (em média, quase dois blocos por participante para a aprendizagem das relações AB no estudo de Haydu e Morais, 2009), o que exemplifica a eficácia do ensino por exclusão.

Além do procedimento de exclusão, é preciso discutir a influência da estrutura de treino no ensino das relações condicionais para idosos. A literatura de equivalência de estímulos discute extensivamente sobre a eficácia de diferentes estruturas de treino na aprendizagem de discriminações condicionais e formação de classes de equivalência (e.g., Arntzen, 2006), mas essas pesquisas de modo geral, não foram desenvolvidas com participantes idosos. No procedimento proposto por Pérez-González e Moreno-Sierra (1999) foi utilizada uma estrutura linear de ensino de relações arbitrárias (duas classes, com três estímulos cada) para oito pessoas, sendo um adolescente, um adulto jovem, dois adultos mais velhos e quatro idosos. Os estímulos utilizados foram formas geométricas impressas em cartões, que foram dispostos sobre uma mesa na frente do participante. Todos os participantes, inclusive os idosos, aprenderam as relações ensinadas e demonstraram formação de equivalência de estímulos, o que indica que a estrutura de treino não prejudicou o desempenho das relações emergentes. No entanto, é preciso reconhecer que o número de estímulos era pequeno e a estrutura de treino tinha apenas um nódulo, o que certamente facilitou a aprendizagem proposta.

Outro estudo com idosos sem comprometimento cognitivo que empregou a estrutura linear de ensino foi o de Haydu e Morais (2009). Diferente do estudo de PérezGonzález e Moreno-Sierra (1999), os idosos do estudo aprenderam a relacionar, a depender da condição a que foram designados, seis e quatro conjuntos de estímulo, e o 
ensino dessas relações ocorreu por tentativa e erro, ou seja, o modelo era apresentado, desde a primeira tentativa, junto a seis ou quatro estímulos de comparação. Assim como no estudo de Pérez-González e Moreno-Sierra (1999), a estrutura linear mostrou-se eficiente para o ensino das relações condicionais.

Diferentemente dos demais trabalhos com idosos que empregaram a estrutura linear para o ensino das relações condicionais, no estudo de Aggio e Domeniconi (2012), foi empregada a estrutura de treino "muitos-para-um", que também se mostrou eficiente, para o ensino das relações arbitrárias. Assim, já que todos os idosos aprenderam relações condicionais independente da estrutura de treino (Aggio, \& Domeniconi, 2012; Haydu \& Morais, 2009; Pérez-González, \& Moreno-Sierra, 1999), parece que a estrutura de treino não é a variável mais relevante para o ensino de relações condicionais (ou, pelo menos, não pareceu ser uma variável impeditiva para a aprendizagem das relações estudadas). No caso do presente estudo, portanto, o ensino por exclusão, aliado à estrutura de treino utilizada (linear), favoreceu a aprendizagem dos idosos participantes.

Além do ensino das relações condicionais, os participantes deste trabalho, assim, como os idosos dos demais estudos (Aggio \& Domeniconi, 2012; Haydu \& Morais, 2009; Peréz-González \& Moreno-Sierra, 1999), foram testados em relação à formação de relações emergentes. Todos os idosos, de todos os estudos, demonstraram a formação de classes de equivalência, o que demonstra, também, que a estrutura de treino empregada nos diferentes estudos não interferiu na apresentação de relações emergentes.

Porém, em relação à manutenção das relações ensinadas e das classes de equivalência formadas, observou-se no presente estudo que, pelo menos para três dos participantes deste estudo, houve manutenção das relações aprendidas e as classes de 
equivalência formadas não se deterioraram ao longo das três reapresentações dos testes. Para um dos participantes, Vagner, observou-se uma melhora no seu desempenho nos testes conduzidos após cinco e 15 dias do término do procedimento de ensino, tanto nas relações condicionais testadas na LBCE, quanto nos testes de equivalência, mas uma piora no teste conduzidos após 30 dias, com resultados iguais aos apresentados logo após o término do procedimento. Finalmente, a participante Cássia apresentou o pior desempenho, não chegando a completar os testes de manutenção em função do seu estado de saúde. Pode-se verificar, portanto, que o procedimento de ensino proposto, sendo eficaz para o ensino de relações arbitrárias, favoreceu a formação e manutenção de classes de equivalência para pelo menos quatro dos cinco idosos participantes. Esses dados são comparáveis aos obtidos nos estudos de Haydu e Morais (2009) e Aggio e Domeniconi (2012), que também testaram a manutenção de classes de equivalência em idosos sem comprometimento cognitivo.

O Teste de Manutenção das duas pesquisas (Aggio, \& Domeniconi, 2012; Haydu \& Morais, 2009) foi realizado seis semanas após a finalização do procedimento. Na pesquisa de Haydu e Morais (2009) apenas dois dos 18 participantes demonstraram um baixo desempenho de manutenção das relações aprendidas. No estudo de Aggio e Domeniconi (2012) todos os idosos da Condição 1 tiveram um desempenho inferior a $65 \%$ de acerto (provavelmente porque estes idosos aprenderam um número menor de relações condicionais), porém apenas um participante (de quatro) da Condição 2 teve um desempenho inferior a 90\% de acerto. Esses dados são compatíveis com os dados de manutenção de estudos de equivalência conduzidos com participantes de outras idades (Haydu, \& Paula, 2008; Haydu, Omote, Vicente, Aggio, \& Paula, 2009; Omote, Vicente, Aggio, \& Haydu, 2009), mostrando que os procedimentos de ensino de relações condicionais empregados em todos esses estudos não apenas favorecem a 
formação de classes de equivalência, como sua manutenção ao longo de períodos variados de tempo.

Já na análise dos erros dos participantes Cássia e Vagner, que apresentaram os piores desempenhos nos testes de manutenção, observa-se que eles confundiram os últimos estímulos ensinados (referentes às fotos, nomes, profissões e grau de parentesco das mulheres). Cássia já havia apresentado esse mesmo erro na Fase de Ensino e na LBCE com todas as relações, assim como nos testes de equivalência; Vagner apresentou esse erro apenas nos testes. Porém, no caso de Cássia, o número máximo de estímulos de comparação presentes nas tentativas finais de ensino e nas de teste (quatro) pareceu ser uma variável dificultadora, uma vez que ela necessitou que fossem repetidos os blocos de LBCR das relações $\mathrm{AB}$ e $\mathrm{BC}$, que eram blocos em que havia sempre quatro estímulos de comparação presentes.

Além disso, é importante considerar que a participante Cássia pode ter apresentado dificuldade em função da sua condição de saúde, que pode ter afetado sua disposição e sua atenção à tarefa. Por apresentar dificuldades de respiração e dificuldades de locomoção, muitas vezes a participante não levantava da cama e os dados foram coletados por meio de um notebook no quarto da participante.

Outros pontos em relação ao procedimento devem também ser discutidos. Todos os estímulos utilizados eram estímulos familiares e não figuras abstratas ou palavras sem sentido. Isto pode ter favorecido a aprendizagem das relações arbitrárias, uma vez que estímulos familiares parecem auxiliar esta aprendizagem em comparação com estímulos arbitrários ou completamente sem sentido (O’Connor, Rafferty, BarnesHolmes, \& Barnes-Holmes, 2009; Arntzen, 2012). Isso deve ser levado em consideração especialmente em estudos com idosos, pois dificuldades físicas, ligadas à audição e visão, podem interferir no seu desempenho com estímulos bidimensionais e o 
uso de estímulos "significativos" pode ser uma estratégia adequada para a condução de estudos sobre aprendizagem e manutenção de relações condicionais. No entanto, apesar dos estímulos serem familiares, a relação CD (nome escrito e grau de parentesco) foi de difícil compreensão pelos participantes. Ainda que eles respondessem por exclusão à medida que um estímulo modelo novo era ditado e um estímulo novo de comparação era apresentado na tela, juntamente com os estímulos de comparação conhecidos, os idosos faziam afirmações do tipo "o Paulo pode ser pai e irmão". Deve-se considerar que eventuais erros em tentativas de exclusão que envolvessem as relações CD poderiam ser atribuídas aos problemas de compreensão citados anteriormente (não compreensão da relação entre o grau de parentesco e o nome escrito) e que a ausência de controle desse fator pode ser considerado uma limitação do procedimento. Esse fato deve ser levado em consideração em eventuais estudos futuros que tenham como objetivo o ensino ou recuperação de relações envolvendo esse tipo de estímulo para idosos para que essas dificuldades relativas à natureza dos estímulos não interfira de forma negativa no desempenho dos participantes.

Esses dados, em conjunto, sugerem que o procedimento de ensino por exclusão foi eficiente para o ensino de relações arbitrárias em idosos sem comprometimento cognitivo, mesmo em uma estrutura de treino linear, referida pela literatura como menos eficiente em função do número de nódulos presentes no ensino (Saunders \& Green, 1999; Arntzen, 2012) favorecendo aprendizagem com um número baixo de erros, da mesma forma como em procedimentos deste tipo planejados para outras populações (e.g., Oliveira, 2012; de Souza \& de Rose, 2006). Assim, a estrutura de treino não pareceu ser uma variável dificultadora em si mesma, nem para a aprendizagem das relações e nem para a emergência de relações de equivalência entre os estímulos, devendo seus efeitos ser contrabalanceados com outras condições presentes nas 
contingências de ensino. Da mesma forma, a institucionalização em si não pareceu ser uma variável que prejudicasse o desempenho dos idosos desse estudo. Nunes, Menezes e Alchieri (2010) afirmam que idosos institucionalizados tendem a ter uma pior qualidade de vida do que idosos não institucionalizados. Entretanto, os dados obtidos com os idosos deste estudo foram bastante positivos, apesar da condição de institucionalização, o que sugere que a dinâmica da instituição não parece ter comprometido a cognição dos idosos. Por outro lado, torna-se importante ressaltar que as instituições onde o estudo foi realizado não ofereciam nenhum tipo de atividade que pudesse exercitar as funções cognitivas dos idosos, mas, por motivação própria, a participante Flora lia um livro por semana e a participante Leila realizava também, toda semana, atividades de palavras cruzadas.

Apesar destes dados obtidos com idosos institucionalizados sem comprometimento cognitivo, não se tem clareza se o responder por exclusão ocorre da mesma forma com idosos que apresentem CCL ou DA e não há evidências do desempenho destes idosos em um procedimento de ensino de relações condicionais por exclusão. Assim, antes de se propor um procedimento de ensino baseado na aprendizagem por exclusão para idosos com CCL ou DA, é necessário investigar se eles demonstram respostas por exclusão. O Estudo 2 se propõe a responder a essa questão. 


\section{ESTUDO 2}

O Estudo 2 teve como objetivo (a) investigar se idosos com CCL ou com diagnóstico de DA demonstrariam desempenho por exclusão em um procedimento de ensino de relações condicionais. Além disso, (b) buscou-se verificar se, após a tentativa de exclusão, esses idosos eram capazes de manter as relações condicionais entre os estímulos selecionados na tentativa de exclusão ao longo de um procedimento de ensino de relações $\mathrm{AB}$.

\section{Método}

\section{Participantes}

Participaram deste estudo seis mulheres, com idades entre 75 e 91 anos, residentes em duas ILPI's da cidade de Ribeirão Preto - SP. Todas apresentaram comprometimento cognitivo, segundo escores obtidos no MEEM. A Tabela 6 apresenta características gerais dos participantes (com nomes fictícios): idade, escolaridade, medicação e diagnósticos fornecidos pelas ILPI's. A Tabela 7 apresenta os resultados dos participantes nos testes de comprometimento cognitivo, depressão, ansiedade e afasia.

O critério de inclusão na amostra foi indicativo de comprometimento cognitivo, segundo o Mini Exame do Estado Mental (MEEM) e os critérios de exclusão foram: (1) o uso de medicações que pudessem alterar o estado de vigília do organismo, (2) problemas de audição que pudessem comprometer a compreensão dos estímulos auditivos apresentados e (3) problemas visuais que impedissem o participante de observar os estímulos visuais apresentados. Problemas auditivos e visuais foram investigados na entrevista feita com os responsáveis pela instituição. 
Tabela 6.

Participantes (nomes fictícios), com suas respectivas idades, grau de escolaridade, medicação utilizada no início do procedimento e diagnósticos fornecidos pelas ILPIs. FI - Ensino Fundamenta Incompleto; MC - Ensino Médio Completo; DA - Doença de Alzheimer

\section{Participantes Idade Escolaridade}

$\begin{array}{ccc}\text { Ana } & 85 & \text { FI } \\ \text { Adélia } & 84 & \text { FI } \\ \text { Bete } & 91 & \text { MC } \\ \text { Dirce } & 80 & \text { FI } \\ \text { Julia } & 75 & \text { FI } \\ \text { Paula } & 75 & \text { Fl }\end{array}$

\section{Medicação}

Micardis, Metformina, Levoid, Enalapril, Diazepam

Enalapril, Sertralina, Quetiapina, Donaren, Metformina

Enalapril, Selozok, Omeprazol, Paroxetina, Monaless, Seroquel, Sinvastatina

Enalapril, Vicog, Tapazol, Agarol, AAS, Epéz, Frontal

Rivotril, Depakote, Atenolol, Pamelor

\section{Diagnóstico}

\section{DA}

DA e Diabetes

\section{DA}

DA e Diabetes

Doença de Parkinson
Metoprolol, Sertralina, AAS, Hidralazina, Hidroclorotiazida, Amlodipina, Sinvastatina 
Tabela 7.

Resultados dos participantes nos testes Mini-Exame do Estado Mental (MEEM), Montreal Cognitive Assessment (MoCA), Escala Hospitalar de Ansiedade e Depressão (HAD), Escala de Depressão Geriátrica (EDG) e Protocolo Montreal-Toulouse de Exame Linguístico da Afasia (versão M1-Alpha). DG - depressão grave; DepA depressão ausente; AA - afasia ausente.

\begin{tabular}{cccccc}
\hline Participantes & MEEM & MocA & HAD & EDG & M1-Alpha \\
\hline Ana & 17 & 10 & D: provável/A: possível & DG & AA \\
Adélia & 12 & 6 & D/A: improvável & DepA & AA \\
Bete & 18 & 11 & D/A: improvável & DepA & AA \\
Dirce & 13 & 6 & D/A: improvável & DepA & AA \\
Julia & 17 & 16 & D/A: improvável & DepA & AA \\
Paula & 12 & 7 & D/A: improvável & DepA & AA \\
\hline
\end{tabular}

\section{Local}

A coleta de dados ocorreu em duas ILPI's da cidade de Ribeirão Preto. Em ambas as instituições o computador era instalado diariamente na sala de refeições da instituição, que continha mesas e cadeiras de plásticos. As participantes eram posicionadas frente ao computador, e a pesquisadora permanecia ao lado, juntamente com a filmadora, que era instalada sobre um tripé.

\section{Instrumentos}

Para a execução desta pesquisa foram utilizados os mesmos instrumentos descritos e usados no Estudo 1. 


\section{Equipamentos}

Os equipamentos utilizados para este procedimento foram os mesmo utilizados no Estudo 1.

\section{Estímulos}

Os estímulos usados foram distribuídos em dois conjuntos, de quatro estímulos cada. O conjunto A foi composto de estímulos auditivos (nomes ditados de pessoas correspondentes aos estímulos do conjunto B) e o conjunto B foi composto de estímulos visuais (fotos dos funcionários das instituições). Os estímulos da participante Ana foram diferentes das demais participantes, pois ela residia em outra instituição. A Tabela 8 apresenta os estímulos empregados no procedimento com as participantes Adélia, Bete, Dirce, Julia e Paula (à esquerda) e com a participante Ana (à direita).

\section{Tabela 8.}

Estímulos utilizados para as participantes Adélia, Bete, Dirce, Julia e Paula.

\begin{tabular}{cccc}
\hline Conjunto de Estímulos & \multicolumn{2}{c}{ A } & B \\
& PALAVRA DITADA & FOTO \\
\hline 1 & Vivi & Camila & B1 \\
3 & Camila & Natália & B2 \\
4 & Ge & Ge & B3 \\
& Ana & Rafael & B4 \\
\hline
\end{tabular}

\section{Concordância entre Observadores}

Duas observadores assistiram a $20 \%$ dos vídeos sob o mesmo critério descritos no Estudo 1. A concordância entre os observadores foi de $95 \%$. 


\section{Procedimento de Coleta de Dados}

Os procedimentos para coleta de dados foram realizados de forma semelhante aos adotados para ensino das discriminações condicionais $\mathrm{AB}$ no Estudo 1, com participantes sem comprometimento cognitivo. Após aprovação do Comitê de Ética em Pesquisa o estudo foi iniciado com a aplicação dos instrumentos nas participantes, sempre em dias alternados para não cansá-las. Após a avaliação inicial das participantes, foi iniciado o procedimento de ensino de discriminações auditivo-visuais, entre fotos de funcionários das instituições e seus respectivos nomes ditados. As sessões ocorreram diariamente, cinco dias por semana, e tinham duração média de 30 minutos.

Fase 1: Pré-teste de nomeação de figuras: foram apresentadas às participantes as fotos que poderiam ser utilizadas no procedimento, com o intuito de verificar se elas realmente não conseguiam nomear tais fotos. Cada imagem foi apresentada na tela do computador e permaneceu disponível por 10 segundos. A pesquisadora perguntava: “ $A$ senhora sabe o nome dessa pessoa? Qual o nome dessa pessoa que aparece na foto?". Caso a participante não soubesse nomear a pessoa da foto no tempo estipulado (10 segundos), considerava-se que a foto poderia ser utilizada. Foram selecionadas quatro fotos para o procedimento desta forma.

Fase 2: Estabelecimento de Linha de Base de Discriminações Auditivo-Visuais AB (Nome ditado - Foto): o objetivo dessa Fase foi estabelecer as relações condicionais entre estímulos auditivos (nomes ditados) e estímulos visuais (fotos). Para isso, as tentativas de ensino foram organizadas de acordo com um procedimento de ensino por exclusão, em que cada nova relação só seria introduzida após um número específico de 
tentativas da relação anterior. A Tabela 9 apresenta um resumo da composição dos blocos de ensino.

Tabela 9.

Resumo da composição dos blocos de ensino de discriminações condicionais AB.

\begin{tabular}{|c|c|c|c|c|c|}
\hline Procedimento & Relações & Modelo & Comparações & Bloco & Tentativas \\
\hline Ensino & A1B1 & A1 & B1 & \multirow{3}{*}{1} & 6 \\
\hline Ensino & $\mathrm{A} 2 \mathrm{~B} 2$ & $\mathrm{~A} 2$ & B1-B2 & & 6 \\
\hline LBCR & $\begin{array}{l}\text { A1B1, } \\
\text { A2B2, }\end{array}$ & $\mathrm{A} 1-\mathrm{A} 2$ & B1-B2 & & 6 \\
\hline Ensino & A3B3 & A3 & B1-B2-B3 & \multirow{4}{*}{2} & 6 \\
\hline LBCR & $\begin{array}{l}\text { A1B1, } \\
\text { A2B2, } \\
\text { A3B3 }\end{array}$ & A1-A2-A3 & B1-B2-B3 & & 12 \\
\hline Ensino & $\mathrm{A} 4 \mathrm{~B} 4$ & A4 & B1-B2-B3-B4 & & 8 \\
\hline LBCR & $\begin{array}{l}\text { A1B1, } \\
\text { A2B2, } \\
\text { A3B3, } \\
\text { A4B4 }\end{array}$ & $\mathrm{A} 1-\mathrm{A} 2-\mathrm{A} 3-\mathrm{A} 4$ & B1-B2-B3-B4 & & 8 \\
\hline LBCR & $\begin{array}{l}\text { A1B1, } \\
\text { A2B2, } \\
\text { A3B3, } \\
\text { A4B4 }\end{array}$ & $\mathrm{A} 1-\mathrm{A} 2-\mathrm{A} 3-\mathrm{A} 4$ & B1-B2-B3-B4 & 3 & 20 \\
\hline LBCE & $\begin{array}{l}\text { A1B1, } \\
\text { A2B2, } \\
\text { A3B3, } \\
\text { A4B4 }\end{array}$ & $\mathrm{A} 1-\mathrm{A} 2-\mathrm{A} 3-\mathrm{A} 4$ & B1-B2-B3-B4 & 4 & 20 \\
\hline Nomeação & $\begin{array}{l}\text { A1B1, } \\
\text { A2B2, } \\
\text { A3B3, } \\
\text { A4B4 }\end{array}$ & $\mathrm{A} 1-\mathrm{A} 2-\mathrm{A} 3-\mathrm{A} 4$ & ---- & 5 & 8 \\
\hline
\end{tabular}

O ensino foi dividido em cinco blocos, sendo o primeiro bloco formado por 18 tentativas, o segundo bloco por 34 tentativas, o terceiro e quarto bloco por 20 tentativas 
cada e o último bloco por oito tentativas. Inicialmente, a pesquisadora explicou às idosas que elas deveriam olhar sempre para o computador. Foi dito também que a pesquisadora diria o nome de uma pessoa e apresentaria a foto desta pessoa no computador, a idosa deveria então, ao ouvir o nome e achar a foto correspondente e colocar o dedo sobre esta foto.

Assim como no Estudo 1, o primeiro bloco se iniciou com a pesquisadora ditando o estímulo auditivo A1 e o computador apresentando uma única foto (B1), que apareceria em um dos quatro cantos do monitor. Essa tentativa foi repetida por seis vezes consecutivas, e o estímulo visual aparecia em cantos diferentes da tela a cada tentativa. Na sétima tentativa, foi realizada uma tentativa de exclusão. Assim, o estímulo A2 foi ditado como modelo e os estímulos de comparação eram B1 e B2. A relação A2B2 foi apresentada por seis tentativas consecutivas, também com alternância da posição de apresentação dos estímulos visuais na tela. O bloco se encerrava com seis tentativas em que as relações A1B1 e A2B2 que se alternavam de forma quase aleatória (não mais de duas tentativas com o mesmo modelo em sequência). Todas as respostas eram consequenciadas e o participante era submetido ao bloco seguinte caso acertasse $90 \%$ das tentativas.

Os Bloco 2 seguiu a mesma estrutura do Bloco 1: uma tentativa de exclusão e as demais para o estabelecimento de linha de base. Todas as tentativas foram reforçadas e o critério de passagem de bloco era de $90 \%$ de acerto. O bloco 3 e 4 foram de LBCR e LBCE, respectivamente. Em ambos blocos, se o participante atingisse 90\% de acerto, ele poderia fazer o bloco seguinte, caso não atingisse, cada bloco era repetido por até três vezes consecutivas. No bloco de LBCR todas as respostas eram consequenciadas, porem no bloco de LBCE não havia consequências. No bloco 5, a tarefa consistiu em teste de nomeação. 


\section{Resultados}

Na Figura 2 são apresentados os desempenhos individuais dos participantes nas tentativas de escolha forçada (tentativas da relação A1B1 - era ditado apenas o estímulo modelo A1 e havia apenas um estímulo de comparação -B1); o desempenho das idosas nas tentativas de exclusão, ou seja, quando a tentativa avaliou a resposta de exclusão, uma vez que esta tentativa consistia em apresentar o estímulo modelo (A2, A3 ou A4) pela primeira vez com seus respectivos estímulos de comparação (B2, B3 ou B4) e os estímulos de comparação já treinados; e o desempenho das idosas nas tentativas reforçadas das relações $\mathrm{A} 2 \mathrm{~B} 2, \mathrm{~A} 3 \mathrm{~B} 3$ e $\mathrm{A} 4 \mathrm{~B} 4$, que foram tentativas subsequentes à tentativa de exclusão.

Será apresentado, na Figura 3 o desempenho das participantes no ensino das relações $A B$ (blocos 1 e 2). Assim será mostrado a porcentagem de acerto das participantes sob as 52 tentativas, sendo estas seis tentativas de escolha forçada, três tentativas de exclusão, e cinco tentativas de reforçamento da relação $\mathrm{A} 2 \mathrm{~B} 2$, seis tentativas de LBCR A1B1-A2B2, cinco tentativas de reforçamento da relação A3B3, 12 tentativas de LBCR A1B1-A2B2-A3B3, sete tentativas de reforçamento da relação A4B4 e oito tentativas de LBCR A1B1-A2B2-A3B3-A4B4. 


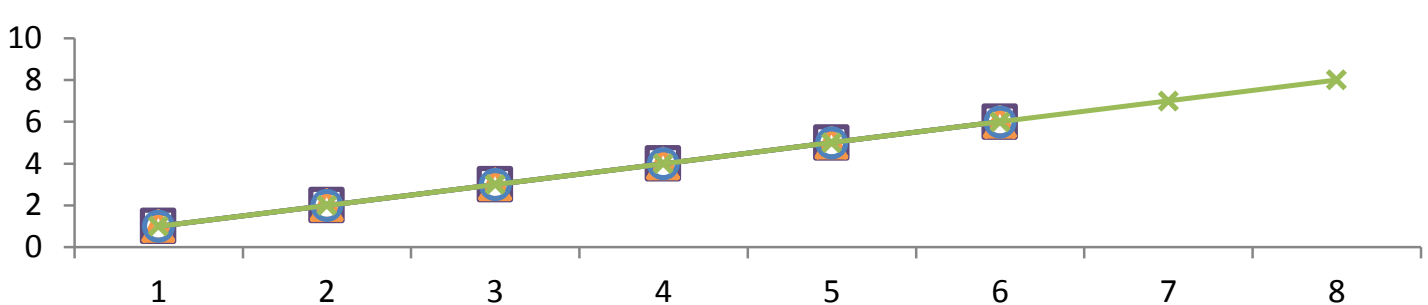

七A1B1

$\triangle \mathrm{A} 2 \mathrm{~B} 2$

- $\mathrm{A} 3 \mathrm{~B} 3$

$\because$ A4B4

Ana

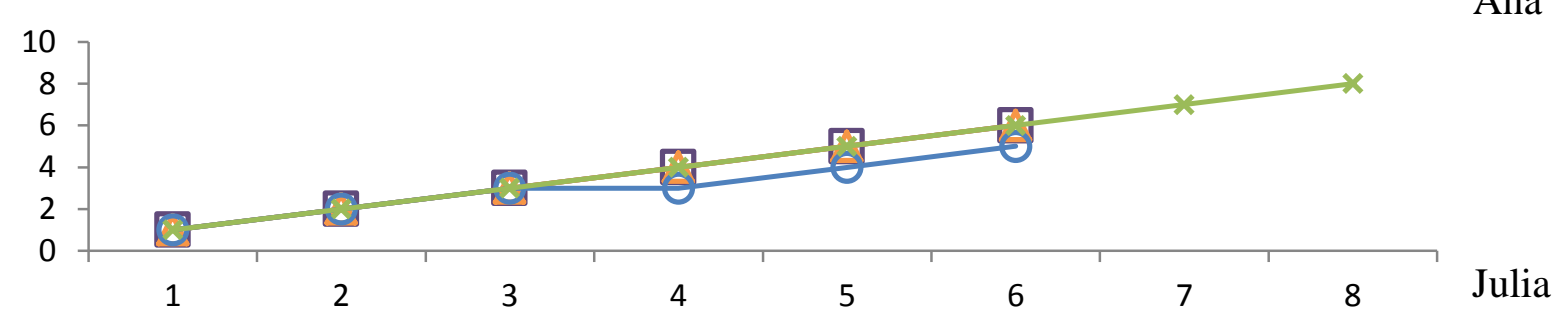

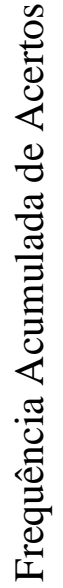
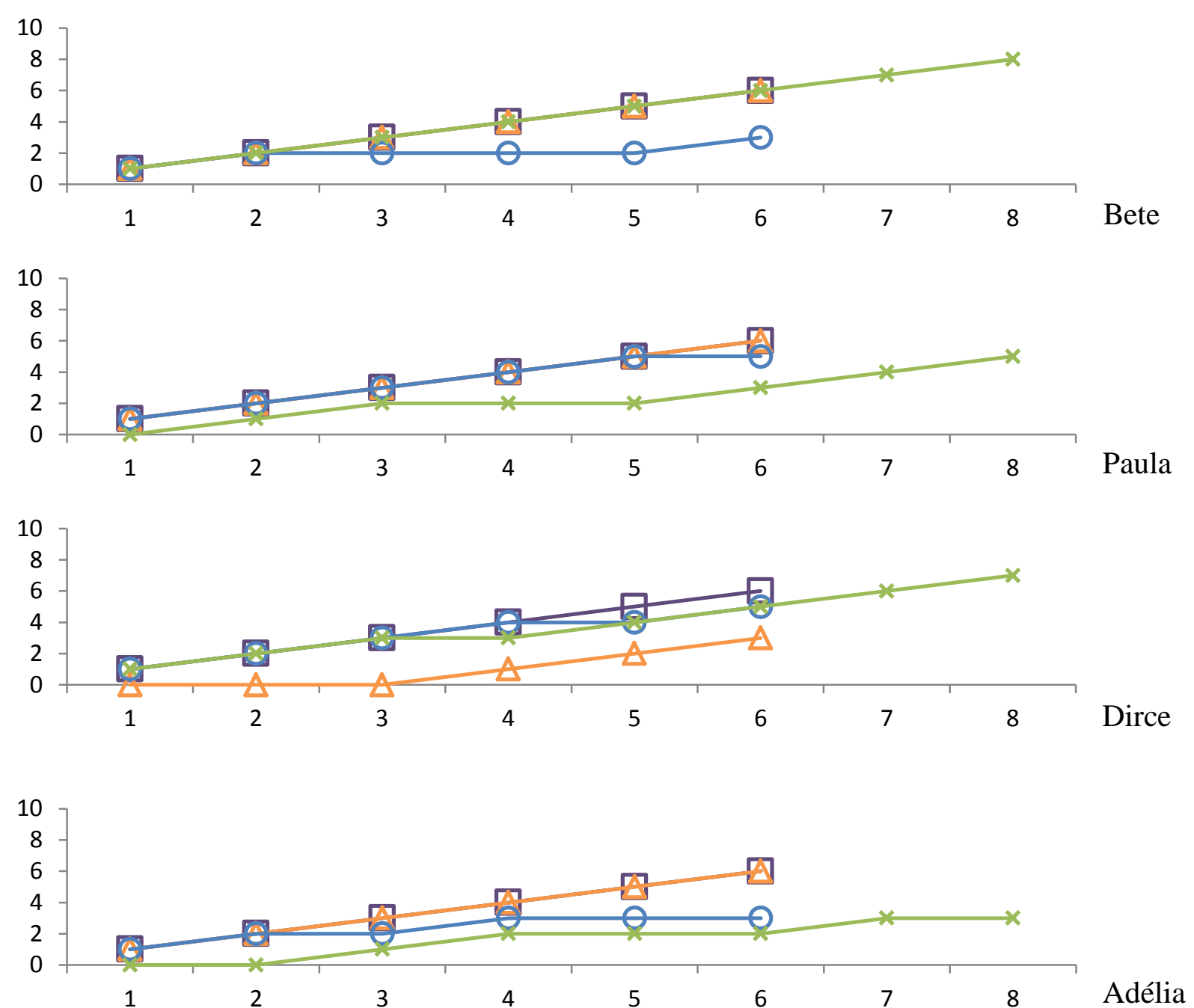

Tentativas

Figura 2: Desempenho das idosas nas tentativas de exclusão e ensino das relações AB. 
Observa-se na Figura 2 que todas as participantes, obviamente, acertaram todas as tentativas de escolha forçada (relação A1B1). De modo geral, as participantes também não apresentaram erros nas tentativas da relação A2B2, com exceção de Dirce, que não respondeu por exclusão quando o estímulo A2 foi ditado como modelo e os estímulos de comparação eram B1 e B2: ela permaneceu selecionando comparação B1 diante do modelo A2 por três tentativas consecutivas. Dirce acertou apenas as três últimas tentativas da relação A2B2.

Todas as participantes responderam por exclusão quando o estímulo modelo A3 foi apresentado pela primeira vez juntamente com os estímulos de comparação B1, B2 e B3. Entretanto, na sequência de tentativas de ensino da relação A3B3, Ana foi a única que acertou as cinco tentativas restantes: Adélia, Dirce, Julia e Paula cometeram um erro, sendo que Adélia errou a terceira tentativa, Dirce e Julia erraram a quarta tentativa e Paula errou a sexta tentativa. Bete, por sua vez, errou três tentativas (a terceira, quarta e a quinta).

Quando o estímulo A4 foi ditado pela primeira vez juntamente com os estímulos de comparação B1, B2, B3 e B4, as participantes Adélia e Paula foram as únicas que não demonstraram resposta por exclusão. Além de não responder por exclusão diante da inserção de A4, Adélia errou mais quatro tentativas, tendo acertado, portanto, apenas duas de sete tentativas de ensino dessa relação. Paula, além de não responder por exclusão, errou as tentativas quatro e cinco. Dirce, apesar de ter respondido por exclusão, errou a quinta tentativa de ensino. As demais participantes, Ana, Bete e Julia acertaram todas as tentativas.

Portanto, de modo geral, todas as participantes apresentaram responder por exclusão em pelo menos duas das três tentativas apresentadas; Dirce errou na tentativa de exclusão da relação A2B2 e Paula e Adélia na tentativa da relação A4B4. Apesar 
desse bom resultado, porém, cinco, das seis participantes, apresentaram algum erro na sequência de tentativas de ensino das quatro relações $\mathrm{AB}$. Esses erros se concentraram, principalmente, nas relações A3B3 e A4B4. Apenas Ana, além de responder por exclusão em todas as tentativas desse tipo, não apresentou nenhum erro nas tentativas de ensino subsequentes.

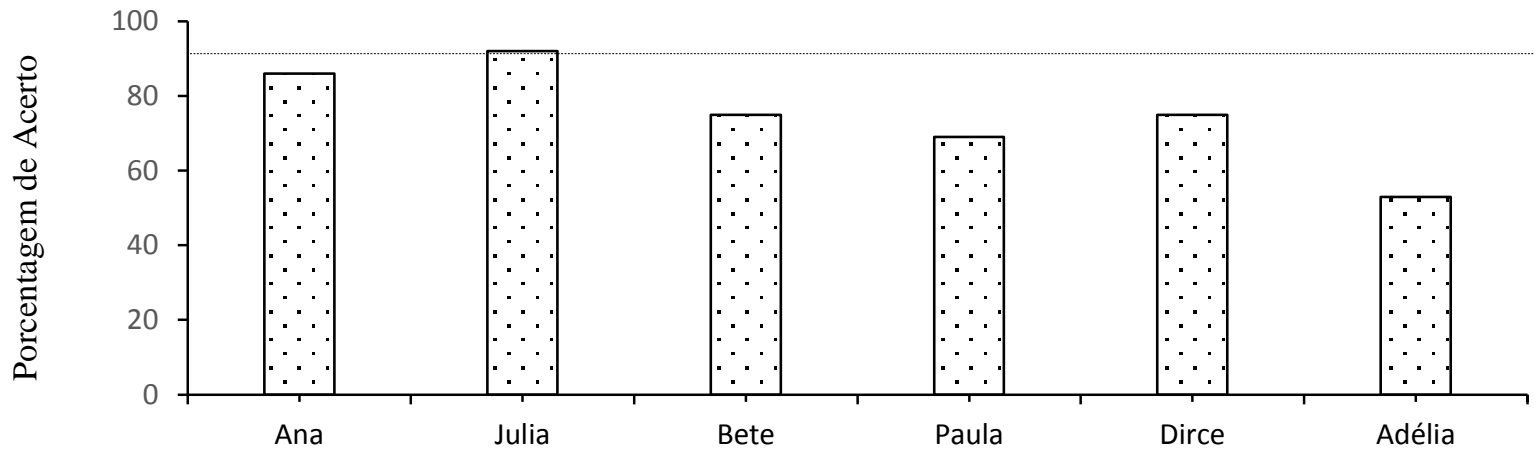

Figura 3: Porcentagem de acertos dos participantes no ensino relação AB.

A Figura 3 apresenta o desempenho das participantes em todas as tentativas dos blocos 1 e 2. Observa-se que a única participante que atingiu o critério de passagem para o bloco de LBCR foi a participante Julia. As demais participantes foram reexpostas ao ensino das relações $\mathrm{AB}$, porém não atingiram o critério de passagem de bloco e o experimento foi encerrado para elas.

A participante Júlia posteriormente foi exposta a LBCR e atingiu o critério de passagem para LBCE, porém neste bloco, ela não atingiu critério de aprendizagem, pois acertou apenas $85 \%$ das tentativas, retornando a LBCR (atingindo $95 \%$ de acerto) e sendo submetida mais uma vez a LBCE (acertando 90\% do teste). No teste de nomeação, Júlia acertou seis das oito tentativas. Os dois erros cometidos foram referentes à mesma foto. 


\section{Discussão}

O objetivo deste estudo foi investigar se idosos com comprometimento cognitivo e/ou com diagnóstico de DA demonstrariam responder por exclusão e aprenderiam um conjunto de quatro relações condicionais auditivo-visuais entre nomes ditados de pessoas e suas fotos.

O responder por exclusão é um desempenho emergente, observado quando um estímulo modelo novo é relacionado com um estímulo de comparação também novo, sem ensino prévio (McIlvane, et al., 2000). Estudos realizados com diferentes populações, desde não humanos (e.g., Freitas, et al, 2012; Souza \& Schmidt, no prelo), até crianças e adolescentes com desenvolvimento típico e atípico (e.g., Domeniconi, et al, 2007; Oshiro, de Souza, \& Costa, 2006; Dixon, 1977) e adultos (e.g., Strommer, 1989) demonstraram este desempenho. O Estudo 1 deste trabalho mostrou que idosos sem comprometimento cognitivo também são capazes de demonstrar este comportamento.

Os resultados do Estudo 2 indicam claramente que os idosos com CCL e DA na fase inicial, participantes deste estudo, também demonstram responder por exclusão: todos os participantes demonstraram desempenho por exclusão em pelo menos uma das tentativas em que esse desempenho era esperado; três participantes - Ana, Bete e Julia demonstraram respostas por exclusão quando havia dois, três e quatro estímulos de comparação disponíveis; duas participantes - Adélia e Paula - demonstraram respostas por exclusão quando havia dois e três estímulos de comparação disponíveis; e uma participante - Dirce - demonstrou este comportamento emergente quando havia, na tentativa, três e quatro estímulos de comparação disponíveis. Esses dados replicam e ampliam os de Souza (2011), que mostrou responder por exclusão em idosos com 
demência senil, mas em tentativas com apenas dois estímulos de comparação disponíveis.

Entretanto, é preciso considerar que a não demonstração de exclusão em algumas tentativas, especialmente na da relação A4B4, assim como a dificuldade demonstrada pelas idosas em manter os acertos nas tentativas consecutivas de ensino das relações A3B3 e A4B4 sugere que, talvez, o número de estímulos de comparação apresentados pode ocasionar uma dificuldade nos idosos de rastrear os estímulos na tela do computador. Souza (2011), ao trabalhar com uma idosa com demência senil, afirma que notou que a participante respondia nas tentativas iniciais do procedimento (também de ensino por exclusão), sob controle da posição dos estímulos, uma vez que a participante escolhia os estímulos de forma aleatória e rápida. Como procedimento remediativo, a pesquisadora interviu pedindo para que a participante olhasse e apontasse cada estímulo de comparação para depois escolher sua alternativa. Em todas as tentativas, esta instrução foi fornecida. Tal instrução pareceu ter sido eficiente já que a participante demonstrou um desempenho acima de $70 \%$ durante o ensino das relações condicionais. Assim, pode-se supor que a DA na fase inicial, apesar de não prejudicar o desempenho por exclusão, pode interferir no rastreamento dos estímulos de comparação, o que é essencial em tarefas de matching e em atividades cotidianas do indivíduo.

Hutton, Nagel e Loewenson (1984) verificaram dificuldades de idosos com DA para rastrear estímulos, em um trabalho com 19 idosos diagnosticado com DA, 17 diagnosticados com "pseudemência" (pacientes com depressão que apresentavam sintomas parecidos com os sintomas de demência) e 17 idosos controles, em uma tarefa de rastreamento de estímulos luminosos. Primeiramente os idosos foram posicionados frente a um computador, usando um eyetracker (um par de óculos com a capacidade de 
rastrear o movimento dos olhos). A tarefa consistia em seguir, com os olhos, um ponto de luz apresentado na tela do computador. Os resultados mostraram que idosos com DA tinham maior dificuldade em seguir o estímulo luminoso do que os demais participantes, principalmente se o estímulo se movimentasse de forma mais rápida. $\mathrm{O}$ estudo de Hutton et al. (1984), sugere que a demência pode interferir no comportamento de rastrear estímulos em uma situação controlada, mas são necessárias pesquisas específicas para verificar em que medida essa dificuldade ocorre em tarefas em que seja necessário o rastreamento estímulos mais complexos (como na tarefa proposta nesse estudo, em que fotos, por exemplo, apresentam várias dimensões como cor, forma, brilho, etc.), ou em situações cotidianas.

Outro fator que pode ter contribuído para a dificuldade na manutenção das relações após as tentativas de exclusão é a fonte de controle dessas respostas. Apesar das idosas com CCL terem apresentado respostas por exclusão, é difícil definir se essas respostas foram controladas pela seleção do estímulo novo ou pela rejeição dos estímulos conhecidos. A seleção do estímulo novo (controle por S+) ocorre quando, sem ensino prévio, um estímulo modelo novo é relacionado a um estímulo de comparação também novo que se encontra junto a outros estímulos de comparação que já são conhecidos. Já o controle por rejeição dos estímulos ensinados na linha de base (controle por S-) é evidenciado quando, diante do estímulo modelo novo, os estímulos de comparação já conhecidos são rejeitados, restando apenas o estímulo de comparação novo (Dixon, 1977; Mcllvane, et al, 2000; Wilkinson \& McIlvane, 1997). Alguns estudos (e.g., Arantes, 2012; Jonhson, \& Sidman, 1993) buscaram estruturar um procedimento de ensino de relações arbitrárias de tal forma que as respostas ocorressem por rejeição (controle por S-). Para isto, um dos métodos mais comuns é o procedimento de máscara (ou blank comparison - Wilkinson \& McIlvane, 1997; mas, ver outros 
métodos em Pérez \& Tomanari, 2013). Nesse procedimento, um quadrado preto é introduzido gradualmente sobre um dos estímulos de comparação ao longo de tentativas sucessivas, de forma a impedir a visualização do estímulo (em algumas tentativas a máscara encobre o $\mathrm{S}+$ e em outras o $\mathrm{S}$-). Dessa forma, o arranjo das tentativas é capaz de verificar se a escolha dos participantes ocorre por seleção ou por rejeição, avaliando os efeitos deste controle na aprendizagem de relações condicionais e classes de equivalência. Os estudos sobre exclusão indicam que a aprendizagem por exclusão envolve os dois tipos de controle (Wilkinson \& McIlvane, 1997; McIlvane et al., 2000) mas a literatura relata, também, que o controle exclusivo por rejeição pode ter efeitos deletérios sobre a aprendizagem de relações condicionais e sobre a formação de classes de equivalência (Pérez \& Tomanari, 2014). O presente estudo não controlou essa variável, mas é preciso considerar que a manutenção das relações estabelecidas entre os estímulos modelo e comparação nas tentativas de exclusão pode ter sido afetada pelo tipo de controle presente nessas tentativas.

Sobre o segundo objetivo do estudo, que foi avaliar o desempenho das idosas no ensino de relações condicionais $\mathrm{AB}$, o melhor desempenho foi o de Julia, a única participante que, apesar de apresentar CCL segundo o MEEM, não tinha diagnóstico de DA. Possivelmente, a despeito do ensino por exclusão se mostrar uma forma efetiva de ensino de relações condicionais, na presente pesquisa aparentemente outros fatores dificultaram o desempenho das participantes, como uma eventual dificuldade no rastreamento de estímulos, especialmente quando havia três ou quatro comparações disponíveis (Hutton et al., 1984). Saunders, Chaney e Marquis (2005), em estudo sobre formação de classes de equivalência com idosos sem comprometimento cognitivo em diferentes estruturas de treino e com diferentes números de estímulos de comparação, verificaram não haver diferenças importantes na formação de classes de equivalência 
pelos participantes quando o número de comparações nas tentativas de ensino era dois, três ou quatro. No entanto, os dados do presente Estudo indicam que o aumento de número de comparações pode ter dificultado a manutenção das relações estabelecidas nas tentativas de exclusão ao longo das tentativas de ensino. É preciso considerar, portanto, que um procedimento de ensino de relações condicionais para idosos com comprometimento cognitivo deve ser testado com no máximo três comparações, para evitar que essa variável interfira dos resultados de forma negativa.

Como os idosos com DA demonstraram responder por exclusão, mas não a aprendizagem das relações arbitrárias propostas pelo ensino por exclusão, parece que propor um procedimento de ensino de relações arbitrárias pautado apenas no procedimento de exclusão não é suficiente para esta população. Assim, foi proposto um terceiro estudo neste trabalho com o objetivo de avaliar se um procedimento de ensino por exclusão, associado a um procedimento de dica atrasada em um procedimento com estrutura "um-para-muitos" poderia favorecer o ensino de relações arbitrárias e a formação de classes equivalentes.

O Estudo 3 manipulou variáveis que pudessem facilitar a aprendizagem de relações condicionais e a formação de classes equivalentes. Por isto, foi utilizada (a) uma estrutura de ensino "um-para-muitos", já que tal estrutura não é considerada a mais difícil para o ensino de relações arbitrárias (Saunders, Chaney, \& Marquis, 2005), juntamente com o (b) procedimento de exclusão e (c) procedimento de dica atrasada, que são procedimentos que favorecem a aprendizagem com um número menor de erros (Browder, Ahlgrim-Delzell, Spooner, Mims, \& Baker, 2009; Melo, Hanna, \& Carmo, 2014; Souza, \& de Rose, 2006), (d) um número de menor de classes de estímulos e (e) de estímulos por classe (quando comparadas ao Estudo 2), (f) a apresentação dos estímulos de comparação na parte inferior da tela, e, finalmente, (e) o requerimento de 
resposta de observação, para garantir que os participantes estivessem olhando para o estímulo modelo, antes dos estímulos de comparação serem apresentados.

A hipótese que embasa o Estudo 3 é que o controle de tais variáveis poderia favorecer a aprendizagem de relações condicionais e sua manutenção, assim como a formação imediata de classes de equivalência. De modo geral, os estudos sobre equivalência promovem o ensino das relações condicionais que compõem as diferentes classes e, em seguida, apresentam aos participantes uma série de blocos de ensino em que todas as relações ensinadas são apresentadas juntas; em seguida, essas mesmas relações são apresentadas em extinção ou com a redução da frequência do reforço (reforço em esquemas de razão, por exemplo), para, então, expor o participante aos testes de equivalência. Esses testes também são apresentados em sequência, até que se atinja uma estabilidade no desempenho dos sujeitos nos blocos de testes (Aggio, \& Domeniconi, 2012; Eilifsen, \& Arntzen, 2009; Moss-Lourenco, \& Fields, 2011). Como estudos sobre equivalência de estímulos com participantes com DA e CCL são em número ainda muito reduzido na literatura, não se sabe os efeitos imediatos do ensino de relações condicionais sobre a manutenção dessas relações e sobre a emergência imediata de equivalência. O Estudo 3, então, pretende verificar se os procedimentos empregados no protocolo são capazes de produzir a manutenção das relações condicionais ensinadas, em blocos de linha de base cheia em extinção, e a formação imediata de classes de equivalência. 


\section{ESTUDO 3}

O Estudo 3 teve como objetivo investigar: (a) o efeito de um procedimento de ensino de relações condicionais com saída dos estímulos de comparação incorretos (Delayed-cue Procedure) (Sidman, 1994) para idosos com indicativos de CCL e DA e (b) o efeito desse mesmo procedimento na formação e manutenção de classes de equivalência por idosos com indicativos de comprometimento cognitivo.

\section{Método}

\section{Participantes}

Participaram deste estudo quatro mulheres, com idade entre 75 e 85 anos, residentes em uma ILPI na cidade de Ribeirão Preto. Todas apresentaram comprometimento cognitivo, segundo o MEEM. A Tabela 10 apresenta as características das participantes (com nomes fictícios), idade, escolaridade, os resultados do MEEM, do MoCA, do M1-Alpha, a medicação utilizada e diagnósticos fornecidos pela ILPI.

O critério de inclusão na amostra foi a presença de indicativos de comprometimento cognitivo segundo o MEEM (pontuação máxima de 16 pontos). Os critérios de exclusão foram: (1) o uso de medicamentos que pudessem alterar o estado de vigília do participante e (2) problemas visuais que impedissem o participante de observar os estímulos visuais apresentados. Esses critérios de exclusão foram verificados por meio de entrevista realizada com os responsáveis pela instituição. 
Tabela 10 .

Caracterização dos participantes (nomes fictícios), idade, grau de escolaridade, resultado do MEEM, MoCA, M1-Alpha, tempo de institucionalização, medicação utilizada no início do procedimento e diagnósticos fornecidos pelas ILPIs. FI: fundamental incompleto; AA: afasia ausente; DA: demência de Alzheimer; CCL: Comprometimento Cognitivo Leve; SD: sem diagnóstico.

\begin{tabular}{|c|c|c|c|c|c|c|c|c|}
\hline Participantes & Idade & Escolaridade & MEEM & MoCA & M1-Alpha & Institucionalizaçãa & Medicação & Diagnóstico \\
\hline Izilda & 80 & FI & 14 & 7 & AA & 3 meses & Alois, Bromazepam, Tegretol, Sinvastatina & DA \\
\hline Linda & 85 & FI & 14 & 8 & AA & 3 anos & Não faz uso diário de medicação & DA \\
\hline Mafalda & 75 & FI & 16 & 8 & AA & 2 meses & Risperidona e Rivotril & CCL \\
\hline Marta & 85 & FI & 16 & 5 & AA & 2 meses & Rivotril e Sinvastatina & SD \\
\hline
\end{tabular}




\section{Local}

A coleta de dados ocorreu em uma ILPI da cidade de Ribeirão Preto. O computador foi instalado diariamente na sala de refeição da instituição, que continha uma mesa e cadeiras de madeira. As participantes foram posicionadas em frente ao computador, e a pesquisadora permanecia ao lado, junto à filmadora.

\section{Instrumentos}

Para a execução desta pesquisa foram utilizados alguns dos instrumentos descrito e empregados no Estudo 1: Entrevista Semi-Estruturada com Participante e Responsável da Instituição, MEEM, MoCA e M1-Alpha.

\section{Equipamentos}

Os equipamentos utilizados para este procedimento foram os mesmo utilizados no Estudo 1.

\section{Estímulos}

Os estímulos usados foram distribuídos em três conjuntos, de três estímulos cada. Todos os estímulos utilizados foram visuais. O conjunto A foi composto por fotos de três funcionários da instituição, o conjunto B foi composto pelos nomes das pessoas representadas nas fotos e o conjunto $\mathrm{C}$ pelo nome escrito da profissão exercida pelas pessoas das fotos, conforme Tabela 11. 
Tabela 11.

Estímulos empregados no procedimento do Estudo 3.

Conjuntos de estímulos

\begin{tabular}{cccc} 
Classes & A & B & C \\
& Foto & $\begin{array}{c}\text { Nome } \\
\text { (palavras impressas) }\end{array}$ & $\begin{array}{c}\text { Profissão } \\
\text { (palavras impressas) }\end{array}$ \\
\cline { 2 - 4 } 1 & A1 & Isabel & Cozinheira \\
3 & A2 & Iara & Gerente \\
& A3 & Clarice & Enfermeira
\end{tabular}

\section{Concordância entre Observadores}

$\mathrm{O}$ acordo entre observadores seguiu os mesmo critérios descritos no Estudo $1 \mathrm{e}$ foi de $93 \%$.

\section{Procedimento de coleta de dados}

Após aprovação do projeto no Comitê de Ética em Pesquisa, foi realizada a aplicação dos seguintes instrumentos nas participantes: entrevista com as participantes e/ou seus responsáveis, aplicação do MEEM, MoCA e M1-Alpha. Após a seleção dos participantes, o procedimento foi iniciado. $\mathrm{O}$ procedimento de ensino das discriminações condicionais foi baseado em tarefas de matching to sample, com estrutura de ensino um-para-muitos e dica atrasada. Um resumo dos procedimentos adotados pode ser visualizado na Tabela 12. As sessões ocorreram diariamente (cinco vezes por semana), com duração aproximada de 20 minutos. 
Fase 1: Pré-teste de nomeação de figuras: foram apresentadas às participantes na tela do computador, individualmente, as fotos que poderiam ser utilizadas no procedimento, com o intuito de verificar se as participantes realmente não conseguiam nomear tais fotos. Cada imagem permaneceu na tela por 10 segundos e a pesquisadora perguntava “Você está vendo esta foto? Você sabe qual é o nome desta pessoa?". Se a participante não conseguisse nomear a foto no tempo estipulado, a foto seria considerada apropriada para ser incluída no procedimento. As fotos selecionadas foram aquelas que nenhuma participante conseguiu nomear.

Fase 2: Estabelecimento de Linha de Base: O objetivo dessa Fase foi ensinar as relações condicionais entre estímulos visuais (fotos e palavras escritas). Tal Fase foi composta por duas etapas. 


\section{Tabela 12}

Resumo das Fases e Etapas do procedimento de ensino e teste de relações condicionais.

\begin{tabular}{|c|c|c|c|c|c|c|c|c|c|}
\hline Fase & Etapa & Procedimento & Relação & Modelo & Comparação & Bloco & Tentativas & Permanência do S- & $\begin{array}{c}\text { Critério } \\
\text { Passagem } \\
\text { de Bloco }\end{array}$ \\
\hline $\begin{array}{c}1 \\
\text { Pré- } \\
\text { Teste }\end{array}$ & 1 & --- & --- & $\begin{array}{c}\text { A1-A2- } \\
\text { A3 }\end{array}$ & --- & --- & 3 & --- & --- \\
\hline \multirow{9}{*}{ 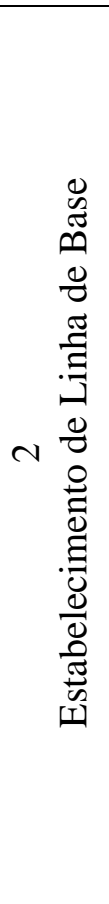 } & \multirow{8}{*}{1} & Ensino & $\mathrm{AB}$ & A1 & B1 & \multirow{3}{*}{1} & 10 & --- & \multirow{3}{*}{27 acertos } \\
\hline & & Ensino & $\mathrm{AB}$ & $\mathrm{A} 2$ & B1-B2 & & 10 & $\begin{array}{c}\text { tt } 1 \text { e } 2: 1 \mathrm{~s} \\
\text { tt } 3 \text { e } 4: 3 \mathrm{~s} \\
\text { tt } 5 \text { e } 6: 5 \mathrm{~s} \\
\text { tt 7-10: tempo total da tt }\end{array}$ & \\
\hline & & Ensino & $\mathrm{AB}$ & A1-A2 & B1-B2 & & 10 & Tempo total da tt & \\
\hline & & Ensino & $\mathrm{AB}$ & A3 & B1-B2-B3 & \multirow[t]{2}{*}{2} & 10 & $\begin{array}{c}\text { tt } 1 \text { e } 2: 1 \mathrm{~s} \\
\text { tt } 3 \text { e } 4: 3 \mathrm{~s} \\
\text { tt } 5 \text { e } 6: 5 \mathrm{~s} \\
\text { tt 7-10: Tempo total da tt }\end{array}$ & \multirow[t]{2}{*}{27 acertos } \\
\hline & & Ensino & $\mathrm{AB}$ & $\begin{array}{c}\text { A1-A2- } \\
\text { A3 }\end{array}$ & B1-B2-B3 & & 20 & Tempo total da tt & \\
\hline & & LBCR & $\mathrm{AB}$ & $\begin{array}{c}\text { A1-A2- } \\
\text { A3 }\end{array}$ & B1-B2-B3 & 3 & 15 & Tempo total da tt & 13 acertos \\
\hline & & LBCE & $\mathrm{AB}$ & $\begin{array}{c}\text { A1-A2- } \\
\text { A3 }\end{array}$ & B1-B2-B3 & 4 & 15 & Tempo total da tt & 13 acertos \\
\hline & & Simetria & BA & $\begin{array}{c}\text { B1-B2- } \\
\text { B3 }\end{array}$ & A1-A1-A3 & 5 & 15 & Tempo total da tt & 13 acertos \\
\hline & 2 & Ensino & $\mathrm{AC}$ & A1 & $\mathrm{C} 1$ & 6 & 10 & Tempo total da tt & 27 acertos \\
\hline
\end{tabular}




\begin{tabular}{|c|c|c|c|c|c|c|c|c|c|}
\hline & & Ensino & $\mathrm{AC}$ & $\mathrm{A} 2$ & $\mathrm{C} 1-\mathrm{C} 2$ & & 10 & $\begin{array}{c}\mathrm{tt} 1 \text { e } 2: 1 \mathrm{~s} \\
\mathrm{tt} 3 \text { e } 4: 3 \mathrm{~s} \\
\mathrm{tt} 5 \text { e } 6: 5 \mathrm{~s} \\
-10: \text { Tempo total da tt }\end{array}$ & \\
\hline & & Ensino & $\mathrm{AC}$ & A1-A2 & $\mathrm{C} 1-\mathrm{C} 2$ & & 10 & --- & \\
\hline & & Ensino & $\mathrm{AC}$ & A3 & $\mathrm{C} 1-\mathrm{C} 2-\mathrm{C} 3$ & 7 & 10 & $\begin{array}{c}\text { tt } 1 \text { e } 2: 1 \mathrm{~s} \\
\text { tt } 3 \text { e } 4: 3 \mathrm{~s} \\
\text { tt } 5 \text { e } 6: 5 \mathrm{~s} \\
-10: \text { Tempo total da tt }\end{array}$ & 27 acertos \\
\hline & & Ensino & $\mathrm{AC}$ & $\begin{array}{c}\text { A1-A2- } \\
\text { A3 }\end{array}$ & $\mathrm{C} 1-\mathrm{C} 2-\mathrm{C} 3$ & & 20 & Tempo total da tt & \\
\hline & & LBCR & $\mathrm{AC}$ & $\begin{array}{c}\text { A1-A2- } \\
\text { A3 }\end{array}$ & $\mathrm{C} 1-\mathrm{C} 2-\mathrm{C} 3$ & 8 & 15 & Tempo total da tt & 13 acertos \\
\hline & & LBCE & $\mathrm{AC}$ & $\begin{array}{c}\text { A1-A2- } \\
\text { A3 }\end{array}$ & $\mathrm{C} 1-\mathrm{C} 2-\mathrm{C} 3$ & 9 & 15 & Tempo total da tt & 13 acertos \\
\hline & & Simetria & $\mathrm{CA}$ & $\begin{array}{c}\mathrm{C} 1-\mathrm{C} 2- \\
\mathrm{C} 3\end{array}$ & $\mathrm{~A} 1-\mathrm{A} 2-\mathrm{A} 3$ & 10 & 15 & Tempo total da tt & 13 acertos \\
\hline \multirow[b]{2}{*}{ 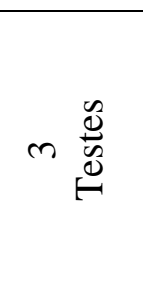 } & \multirow[b]{2}{*}{1} & LBCE & $\begin{array}{l}\mathrm{AB} \\
\mathrm{AC}\end{array}$ & $\begin{array}{c}\text { A1-A2- } \\
\text { A3 }\end{array}$ & $\begin{array}{l}\text { B1-B2-B3 } \\
\text { C1-C2-C3 }\end{array}$ & 11 & 30 & Tempo total da tt & --- \\
\hline & & $\begin{array}{c}\text { Teste de } \\
\text { Equivalência }\end{array}$ & $\begin{array}{l}\mathrm{BC} \\
\mathrm{CD}\end{array}$ & $\begin{array}{c}\text { B1-B2- } \\
\text { B3 } \\
\text { C1-C2- } \\
\text { C3 }\end{array}$ & $\begin{array}{l}\mathrm{C} 1-\mathrm{C} 2-\mathrm{C} 3 \\
\mathrm{~B} 1-\mathrm{B} 2-\mathrm{B} 3\end{array}$ & 12 & 30 & Tempo total da tt & --- \\
\hline \multirow{2}{*}{ 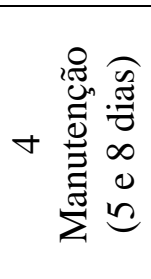 } & \multirow[b]{2}{*}{1} & LBCE & $\begin{array}{l}\mathrm{AB} \\
\mathrm{AC}\end{array}$ & $\begin{array}{c}\text { A1-A2- } \\
\text { A3 }\end{array}$ & $\begin{array}{l}\text { B1-B2-B3 } \\
\text { C1-C2-C3 }\end{array}$ & 11 & 30 & Tempo total da tt & --- \\
\hline & & $\begin{array}{c}\text { Teste de } \\
\text { Equivalência }\end{array}$ & $\begin{array}{l}\mathrm{BC} \\
\mathrm{CD}\end{array}$ & $\begin{array}{c}\text { B1-B2- } \\
\text { B3 } \\
\text { C1-C2- } \\
\text { C3 }\end{array}$ & $\begin{array}{l}\text { C1-C2-C3 } \\
\text { B1-B2-B3 }\end{array}$ & 12 & 30 & Tempo total da tt & --- \\
\hline
\end{tabular}


Etapa 1: Ensino de Discriminações Visuais-Visuais AB (foto - nome escrito)

$\mathrm{O}$ ensino das relações $\mathrm{AB}$ foi dividido em cinco blocos. Em todos os blocos, cada tentativa era iniciada com a apresentação do estímulo modelo visual no centro da tela; a pesquisadora apontava para o estímulo modelo, e perguntava à participante se ela estava vendo a foto. Se a participante afirmasse que estava vendo a foto, os estímulos de comparação eram apresentados. Tais estímulos apareciam sempre na parte inferior da tela, em três posições distintas: no centro, no canto direito ou no canto esquerdo. Após a participante colocar o dedo sobre o estímulo de comparação que julgava ser o correto, uma nova tentativa era iniciada, 1 s após o encerramento da anterior. Respostas corretas, ao longo de todas as tentativas de ensino (mas não nas tentativas de teste) tinham como consequência a frase falada pela pesquisadora "Parabéns! Você acertou!" e respostas incorretas tinham como consequência a frase "Está errado." E o início de nova tentativa.

No primeiro bloco, o estímulo modelo A1 foi apresentado em 10 tentativas consecutivas e apenas o estímulo de comparação B1 era apresentado. Na sequência, (11 a tentativa) o estímulo modelo A2 era apresentado, e os estímulos de comparações eram B1 e B2. Foram realizadas 10 tentativas consecutivas da relação A2B2, entretanto, o estímulo de comparação incorreto B1 (S-) foi introduzido gradualmente: nas duas primeiras tentativas, B1 permanecia disponível por apenas 1s na tela; nas tentativas três e quatro, o S- permanecia disponível por 3s; nas tentativas cinco e seis, o S- permanecia disponível por $5 \mathrm{~s} \mathrm{e}$, nas quatro últimas tentativas, ele permanecia na tela durante toda a duração da tentativa. Em seguida, o participante passava por 10 tentativas em que os modelos A1 e A2 (cinco vezes cada um) se alternavam de forma quase aleatória e os dois estímulos de comparação eram apresentados, em posições alternadas ao longo das tentativas. Se o participante não acertasse 27 das 30 tentativas, o bloco era 
reapresentado por até três vezes, até que o critério fosse atingido. Caso o participante atingisse o critério de acerto de 27 tentativas, ele passava para o segundo bloco de ensino.

No segundo bloco, inicialmente o estímulo modelo A3 foi apresentado 10 vezes consecutivas, juntamente com os estímulos de comparação B1, B2 e B3. Os estímulos de comparação incorretos permaneciam disponíveis por $1 \mathrm{~s}$ nas duas primeiras tentativas, por $3 \mathrm{~s}$ nas tentativas três e quatro, e por $5 \mathrm{~s}$ nas tentativas cinco e seis. Nas tentativas de sete a 10, os estímulos incorretos permaneciam na tela por todo o tempo de duração da tentativa. Em seguida, apresentava-se ao participante um conjunto de 20 tentativas, sendo cinco da relação A1B1, cinco da relação A2B2 e 10 da relação A3B3. Os modelos, nesse conjunto de tentativas, alternavam-se de forma quase aleatória. Nessas tentativas, nenhum estímulo de comparação incorreto desaparecia da tela antes do final da tentativa. Se o participante acertasse 27 tentativas, ele passava para o terceiro bloco, caso contrário, o bloco era reapresentado por até três vezes.

O terceiro bloco, LBCR, foi composto por 15 tentativas, cinco de cada relação (A1B1, A2B2 e A3B3). Os estímulos modelos eram apresentados de forma alternada e quase aleatória, com os 3 estímulos de comparação, que permaneciam na tela todo o tempo. O participante deveria acertar no mínimo 13 tentativas para passar para o bloco seguinte, caso contrário, era reexposto ao bloco. O bloco poderia ser repetido por até três vezes.

O quarto bloco, LBCE, seguia a mesma estrutura do terceiro bloco (número de tentativas, relações testadas, critério de passagem para o bloco seguinte e critério de repetição de bloco), porém, as respostas, certas ou erradas, não tinham consequências específicas (extinção). A instrução dada as participantes era: "Neste bloco de tentativas, a senhora deverá relacionar as fotos que aparecerão no centro da tela do computador 
com os nomes ou profissões que aparecerão na parte inferior da tela do computador. Eu não irei dizer se a senhora acertou ou errou.".

No quinto bloco, Teste de Simetria, foram testadas as relações simétricas BA. O bloco era composto por 15 tentativas, sendo cinco de cada relação (B1A1, B2A2 e B3A3). O estímulo modelo era apresentado ao centro da tela e os estímulos de comparação só ficaram disponíveis após o participante emitir a resposta de observação, que era ler o nome apresentado. Todos os estímulos ficavam presentes até o participante tocar no estímulo de comparação que julgava ser correto, porém não havia consequências para as respostas corretas ou incorretas. Em seguida, uma nova tentativa era iniciada. $\mathrm{O}$ participante deveria emitir pelo menos 13 respostas corretas para ser passar para a Etapa 2, caso contrário, o teste de simetria era reapresentado por até três vezes, mas nessas reapresentações as tentativas eram consequenciadas. Quando o participante atingisse o critério de 13 acertos no bloco de relações simétricas consequenciado, era realizado um novo teste de simetria, porém sem consequências para acertos ou erros.

Etapa 2: Ensino de Discriminações Visuais-Visuais AC (foto - profissão)

A Etapa 2 seguiu a mesma estrutura da Etapa 1: ensino da relação A1C1, depois A2C2, com a introdução gradual do S-, em seguida conjunto de tentativas A1C1 e A2C2, ensino da relação A3C3, LBCR, LBCE, e testes de simetria CA. Tentativas de ensino foram consequenciadas e os critérios de aprendizagem e passagem entre os blocos foram os mesmos da Etapa 1. O acerto de 13 das 15 tentativas de simetria CA foi definido como critério de encerramento da Etapa 2 e passagem para a Fase 3. 
Fase 3: LBCE das relações AB e AC, Testes de Equivalência e Teste de Nomeação: esta fase foi dividida em três blocos. O primeiro bloco era de LBCE, formado por 30 tentativas, sendo cinco tentativas de cada relação (A1B1, A2B2, A3B3, A1C1, A2C2 e A3C3). O objetivo desse teste era verificar se as relações ensinadas na fase anterior se manteriam quando apresentadas juntas e sem consequenciação específica. Nesse bloco, as tentativas se alternavam de forma quase aleatória e, independente do desempenho dos participantes, sua finalização conduzia para o bloco seguinte. O segundo bloco, de testes de equivalência, também era formado por 30 tentativas, que apresentavam as relações $\mathrm{BC}$ e $\mathrm{CB}: \mathrm{B} 1 \mathrm{C} 1, \mathrm{~B} 2 \mathrm{C} 2, \mathrm{~B} 3 \mathrm{C} 3, \mathrm{C} 1 \mathrm{~B} 1, \mathrm{C} 2 \mathrm{~B} 2$ e $\mathrm{C} 3 \mathrm{~B} 3$ (cinco tentativas para cada relação). Nenhuma resposta teve consequência. As participantes passavam por apenas um bloco de testes de equivalência para verificar se ocorreria emergência imediata (ou não) das relações não diretamente ensinadas entre os estímulos. Independentemente do número de acertos das participantes, a Fase 3 era encerrada após a conclusão de um bloco de testes de equivalência. O terceiro bloco tinha como objetivo verificar se o participante conseguia nomear as fotos que foram usadas no procedimento de ensino. Para tanto, era apresentado no meio da tela, as fotos (A1, A2 e A3) e era dada a seguinte instrução ao participante: "Você sabe qual o nome da pessoa da foto?”. Cada foto foi apresentada apenas uma vez e o bloco se encerrava após a apresentação de todas as fotos, independente do desempenho das participantes

Fase 4: Manutenção: esta fase teve como objetivo verificar a manutenção das relações aprendidas após cinco e oito dias da conclusão da Fase 3. Para tanto, a LBCE das relações $\mathrm{AB}$ e $\mathrm{AC}$, os Testes de Equivalência e os testes de Nomeação foram reaplicados nos períodos previstos. 


\section{Resultados}

A Figura 4 apresenta os resultados gerais do desempenho das participantes no ensino das relações $\mathrm{AB}$ e $\mathrm{AC}$, assim como LBCR, nos testes de $\mathrm{LBCE}$, simetria e Equivalência das Fases 3, 4 e de Manutenção.

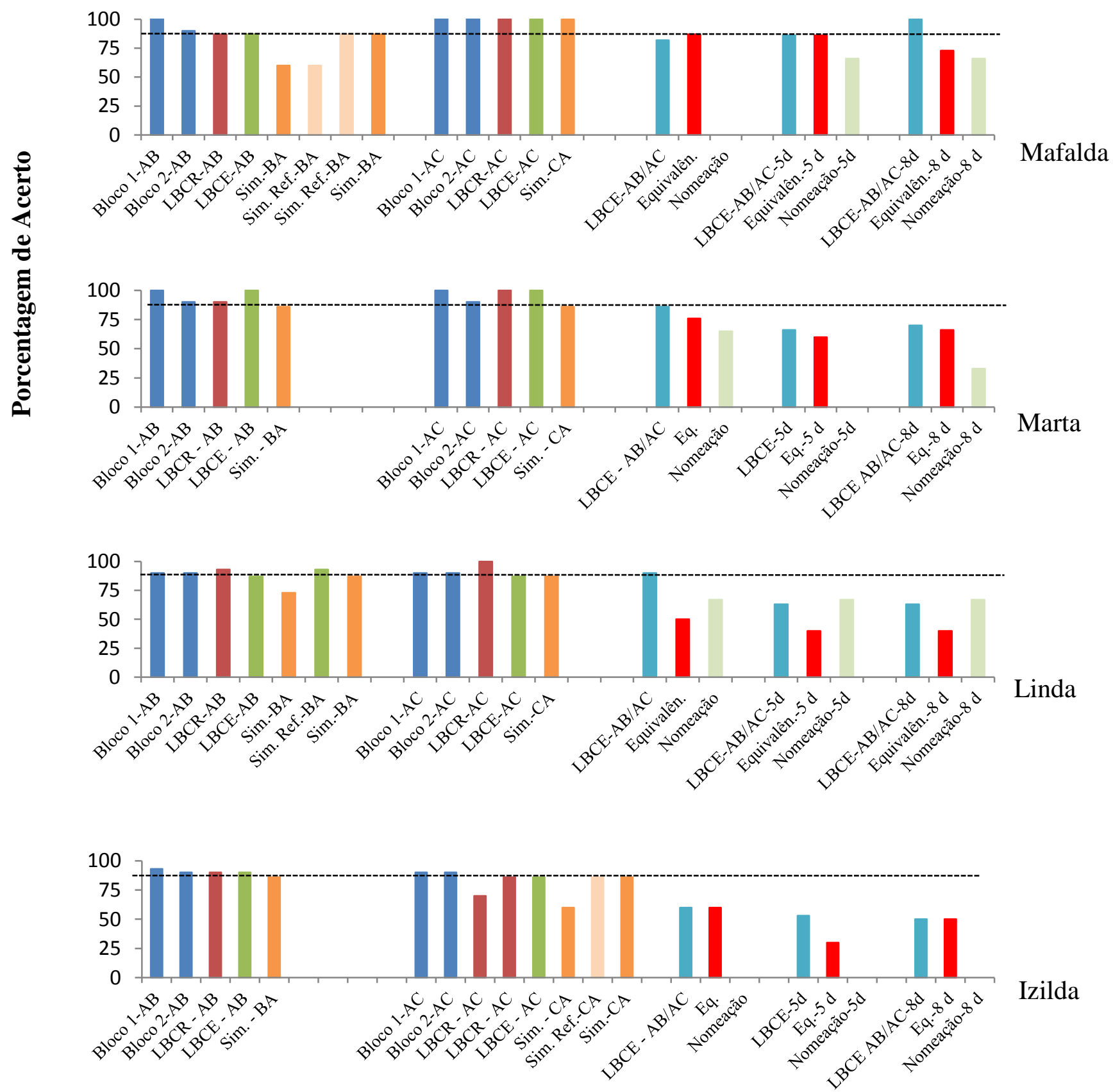

Figura 4: resultados das participantes no ensino das relações condicionais e testes de equivalência

Observa-se na Figura 4 que no ensino das relações $A B$, todas as participantes atingiram o critério estabelecido para aprendizagem com apenas uma única 
apresentação do bloco de ensino AB, LBCR AB e LBCE AB. As participantes Marta e Izilda apresentaram emergência imediata de simetria BA. Porém, Linda e Mafalda necessitaram fazer o bloco de simetria reforçado por uma e duas vezes, respectivamente, antes de atingirem o critério de passagem para o bloco de ensino seguinte.

No ensino das relações AC, observa-se que todas as participantes atingiram os critérios de acertos estabelecidos para a aprendizagem na primeira vez em que foram submetidas aos blocos de ensino AC, LBCR AC e LBCE AC. A exceção foi Izilda, que precisou passar duas vezes pelo bloco de LBCR AC para atender ao critério de aprendizagem proposto. A mesma participante também passou pelo bloco de simetria CA por três vezes (uma vez com reforço e duas em extinção). As demais participantes demonstraram emergência das relações CA na primeira vez em que foram submetidas ao teste.

No teste que de LBCE que ocorreu após a Fase de Ensino observa-se que o melhor desempenho foi o de Linda, com $90 \%$ de acertos, seguida por Marta com $86 \%$, Mafalda com $82 \%$ e Izilda com $60 \%$ de acertos. O desempenho das participantes nesta LBCE, conduzida logo após a Fase de Ensino, e nas LBCE's aplicadas no período de manutenção, serão apresentadas de forma detalhada na Figura 5.

Ainda na Figura 4, observa-se que no Teste de Equivalência que ocorreu após a Fase de Ensino, o melhor desempenho foi o de Mafalda com $86 \%$ de relações corretas, seguido por Marta com 76\%, Izilda com $60 \%$ e Linda com $50 \%$ de acertos. Linda, portanto, apesar de ter apresentado o melhor desempenho na LBCE, não apresentou emergência de equivalência. As outras três participantes tiveram desempenhos parecidos na LBCE e na equivalência, mas pode-se considerar que apenas Mafalda e Marta apresentaram um desempenho que pode indicar emergência de relações de equivalência. 
Na Fase de Manutenção de cinco dias, observa-se que o desempenho de todas as participantes piorou, com exceção de Mafalda que manteve seu desempenho, tanto na LBCE, quanto nos testes de equivalência: $86 \%$ de acerto em ambas as sondas. As demais apresentaram queda no desempenho (Marta com 66\% de acerto, Linda com 63\% de acerto e Izilda com $53 \%$ de acerto). A deterioração mais importante verificada foi no desempenho de Linda, cujo desempenho caiu de $90 \%$ para $63 \%$ após cinco dias. No teste de equivalência após cinco dias, observa-se que Marta, Linda e Izilda apresentaram piora no desempenho: $60 \%, 40 \%$ e $30 \%$ de acertos, respectivamente.

Por fim, nos testes de manutenção de oito dias, observa-se que os desempenhos de Marta, Izilda e Linda se mantiveram estáveis em relação ao Teste de Manutenção anterior: tanto na LBCE quanto nos Testes de Equivalência, as três participantes apresentaram praticamente os mesmos níveis de acerto. Mafalda apresentou $100 \%$ de acertos na LBCE, mas apresentou mais erros no Teste de Equivalência, com $73 \%$ de acertos nesse bloco de testes. Ainda assim, Mafalda manteve-se como a participante com melhor desempenho. O número de acertos das participantes em cada relação dos Testes de Equivalência será apresentado na Figura 6. 

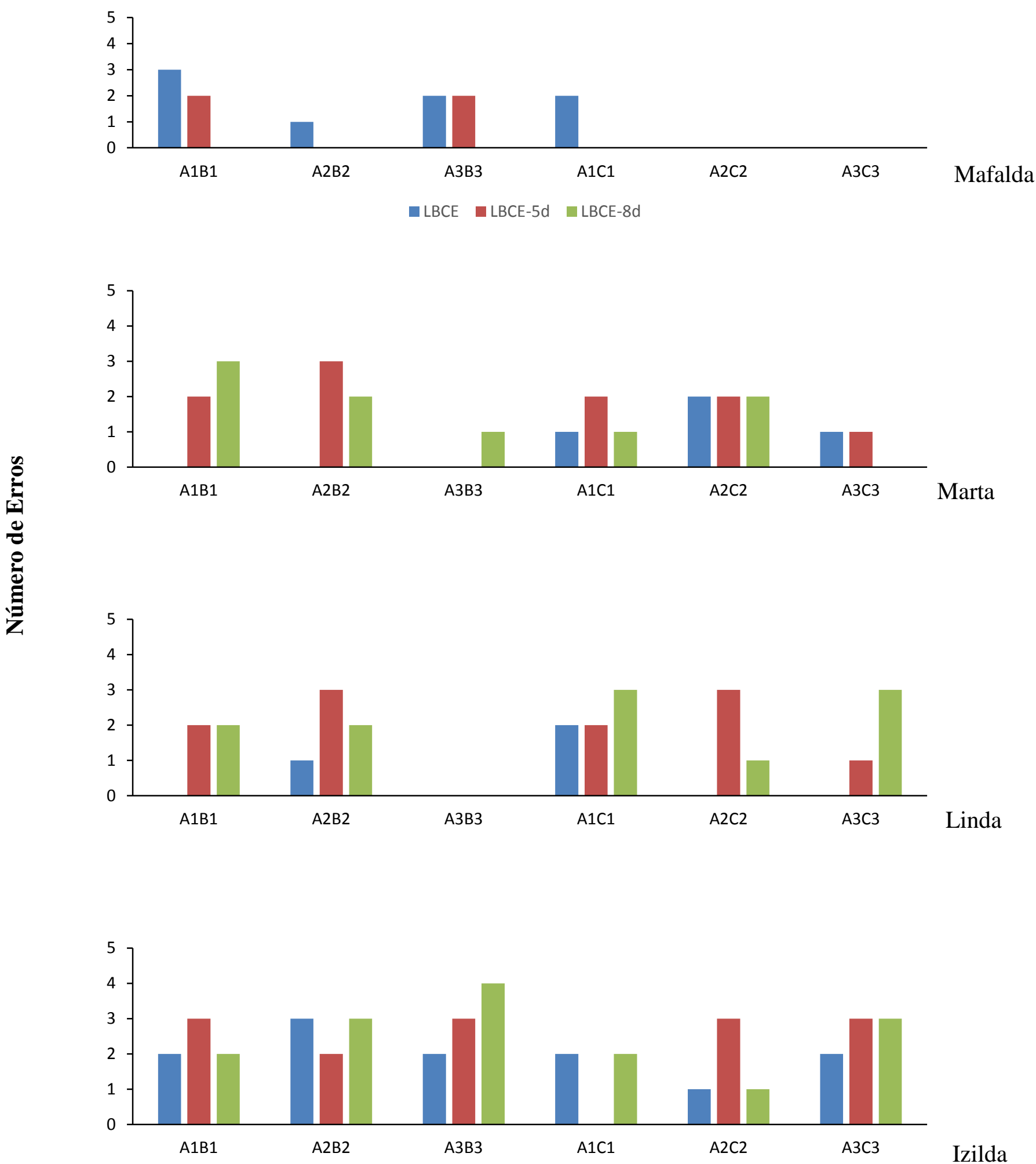

Figura 5: Número de erros cometidos pelas participantes individuais em cada relação da LBCE, quando aplicado pela primeira vez na Fase 2, posteriormente no primeiro e segundo Teste de Manutenção.

Analisando o número de erros cometidos pelas participantes nos blocos de LBCE, observa-se que Mafalda, a participante que apresentou o melhor desempenho, 
cometeu erros apenas nas relações $\mathrm{AB}$ (A1B1, $\mathrm{A} 2 \mathrm{~B} 2$, e $\mathrm{A} 3 \mathrm{~B} 3)$, que foram as primeiras relações ensinadas. Esses erros ocorreram em maior número no bloco de tentativas apresentado logo após a Fase de Ensino, diminuindo na Manutenção de cinco dias. As participantes Marta e Linda apresentaram um desempenho semelhante: um número menor de erros na LBCE apresentada na sequência da Fase de Ensino (quatro e três erros, respectivamente), um aumento nesse número na Manutenção de cinco dias (10 e 11 erros) e a estabilização desse número na Manutenção de oito dias (nove e 11 erros). Ambas apresentaram mais erros nas tentativas das relações AC (A1C1, A2C2 e A3C3). Para ambas, também, a relação A3B3 pareceu ser a melhor estabelecida ao longo de todas as apresentações do bloco de LBCE: Linda não errou nenhuma tentativa dessa relação e Marta apresentou apenas um erro, na Manutenção de 8 dias . Izilda foi a participante que demonstrou o pior desempenho, pois cometeu o maior número de erros, que se distribuíram de forma quase uniforme ao longo de todas as apresentações do bloco. Izilda apresentou erros em todas as relações, mas em maior número nas relações AB (A1B1, A2B2 e A3B3).

A Figura 6 apresentará o número de acerto em cada relação do Teste de Equivalência (B1C1, B2C2, B3C3, C1B1, C2B2 e C3B3) que foi aplicado na primeira vez após a finalização da Fase de Ensino e por duas vezes durante os Testes de Manutenção (cinco e oito dias, respectivamente). 


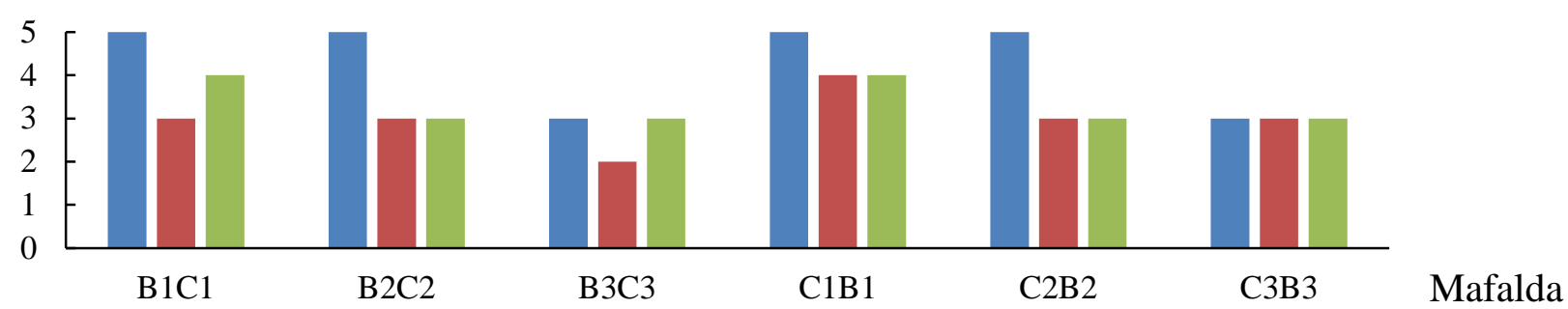

Eq.-Fase3 $\quad$ Eq.-5 dias $\square$ Eq.-8 dias
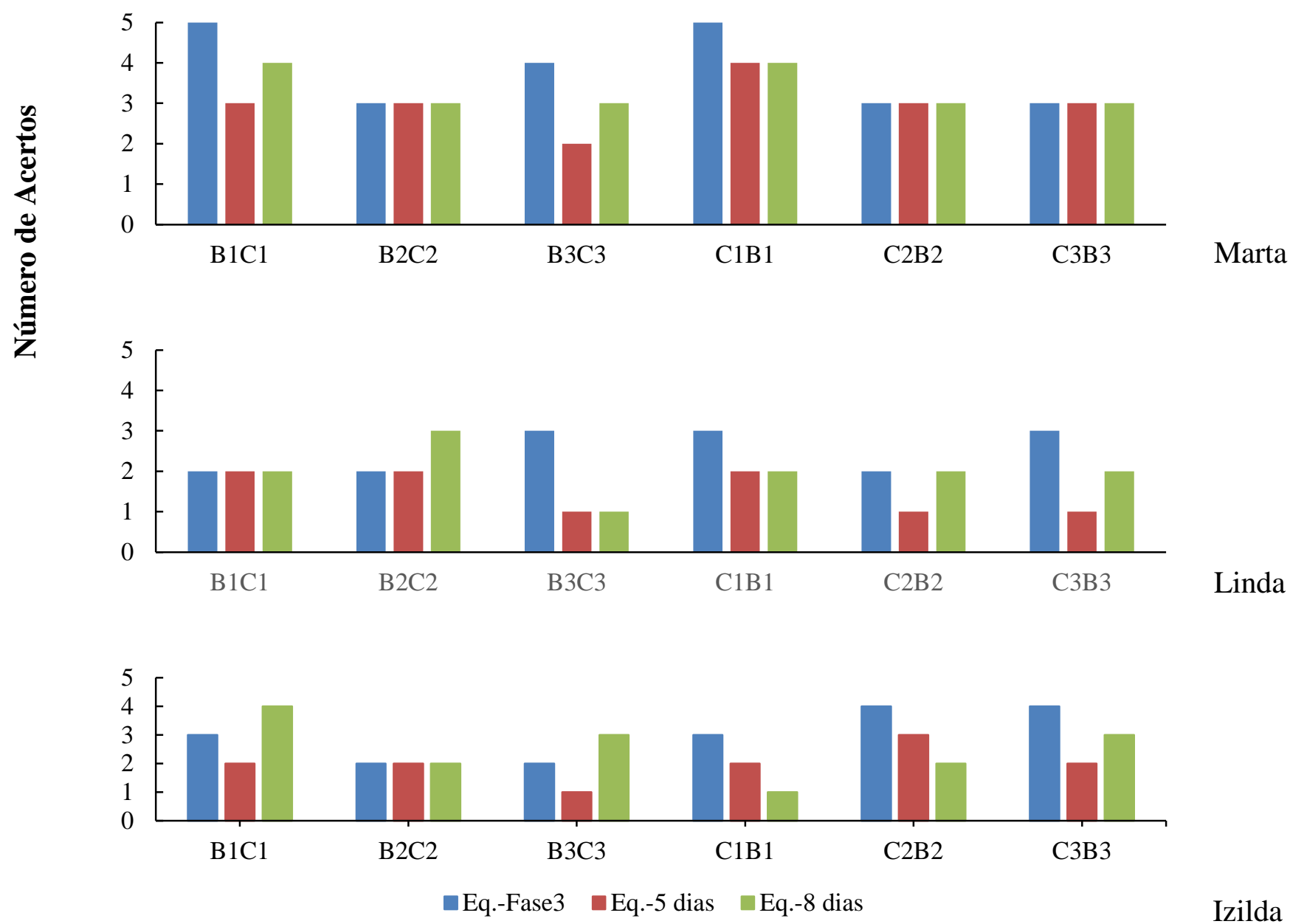

Figura 6: Número de acertos dos participantes individuais em cada relação do Teste de Equivalência, quando aplicado pela primeira vez na Fase 2, e posteriormente no primeiro e segundo Teste de Manutenção, respectivamente.

Os resultados da Figura 6 mostram que a participante Mafalda, na primeira apresentação dos Testes de Equivalência, acertou todas as tentativas referentes às relações B1C1, B2C2, C1B1 e C2B2 - portanto, os estímulos ensinados por último (B3 e C3) foram aqueles cuja relação se apresentou menos consistente, ao menos nessa 
primeira apresentação do Teste. Nas apresentações seguintes (cinco e oito dias), observa-se que essa participante apresentou o mesmo número de acertos (entre dois e três) para todas as relações, com exceção da relação C1B1, que se manteve mais estabelecida. A participante Marta, também apresentou melhor desempenho na primeira apresentação do Teste de Equivalência, também presentou maior número de acertos nas relações $\mathrm{C} 1 \mathrm{~B} 1$ e $\mathrm{B} 1 \mathrm{C} 1$. Os menores números de acertos no primeiro Teste de Equivalência foram nas relações B2C2, C2B2 e C3B3. Observa-se que no Testes de Equivalência aplicado na Fase de Manutenção de cinco dias o desempenho da participante caiu um todas as relações em comparação ao primeiro Teste de Equivalência, porém no Teste de Equivalência de 8 dias, o desempenho da participante manteve-se igual ao Teste de Equivalência de 5 dias nas relações B2C2, C1B1, C2B2 e C3B3.

As participantes Linda e Izilda apresentaram um baixo desempenho em todas as relações (entre um e dois acertos, na maioria das relações, ao longo dos três testes apresentados). Pelos dados apresentados não é possível dizer que essas participantes apresentaram desempenho acima do nível do acaso de maneira consistente para qualquer uma das relações testadas.

Nos Testes de Nomeação, também apresentados em três momentos distintos (após da finalização da Fase de Ensino e nos Testes de Manutenção de cinco e oito dias), as participantes tiveram desempenhos distintos. Tais dados podem ser visto na Tabela 13, que apresenta o número de acertos nos Testes de Nomeação. 


\section{Tabela 13.}

Número de acertos para cada apresentação de foto do teste de nomeação, nos três momentos em que foi aplicado: um, cinco e oito dias após a finalização do ensino das relações arbitrárias.

\begin{tabular}{cccccccccc}
\hline & \multicolumn{3}{c}{ Após 1 dia } & \multicolumn{3}{c}{ Após 5 dias } & \multicolumn{3}{c}{ Após 8 dias } \\
\cline { 2 - 9 } & Isabel & Iara & Clarisse & Isabel & Iara & Clarisse & Isabel & Iara & Clarisse \\
\cline { 2 - 9 } Izilda & 0 & 0 & 0 & 0 & 0 & 0 & 0 & 0 & 0 \\
Marta & 1 & 0 & 1 & 0 & 0 & 0 & 1 & 0 & 0 \\
Linda & 1 & 1 & 0 & 1 & 1 & 0 & 1 & 1 & 0 \\
Mafalda & 0 & 0 & 0 & 0 & 1 & 1 & 0 & 1 & 1 \\
\hline
\end{tabular}

A participante Linda foi a que apresentou maior número de nomeações (e de forma consistente) nas três apresentações do teste: soube nomear duas fotos nos três momentos em que o teste foi aplicado, acertando sempre os mesmos nomes: Isabel e Clarice. Marta, no primeiro Teste de Nomeação, soube nomear as fotos de Isabel e a de Clarice, porém, no segundo teste de nomeação, não soube nomear nenhuma foto e no terceiro Teste de Nomeação acertou apenas o nome da Isabel. Mafalda não soube nomear nenhuma foto no primeiro teste de nomeação, porém no segundo e no terceiro testes, soube nomear as fotos da Clarice e de Iara. Izilda não soube nomear nenhuma das fotos em nenhum dos três testes. Entretanto, com exceção de Izilda, as demais participantes, souberam dizer a profissão de todas as pessoas representadas nas fotos (relação AC). 


\section{Discussão}

O objetivo deste estudo foi investigar o efeito de um procedimento de ensino de relações condicionais por exclusão, com dica atrasada de estímulos de comparação incorretos, para idosos com CCL ou DA. Pretendia-se verificar se esse treino seria eficiente para ensinar relações condicionais entre fotos, nomes escritos das pessoas retratadas nas fotos e suas ocupações na ILPI onde as participantes residiam. Além disso, pretendia-se verificar se, a partir do protocolo de treino proposto, as participantes seriam capazes de manter as relações aprendidas na fase de treino em blocos de linha de base cheia de tentativas não consequenciadas, formar classes de estímulos equivalentes a partir das relações aprendidas e de manter essa aprendizagem (e as classes eventualmente formadas), em sondas não reforçadas, por períodos de tempo distintos em seguida à Fase de Ensino e após 5 dias e 8 dias desta Fase.

De modo geral, os resultados apontaram que o método de ensino foi eficiente, uma vez que as participantes demonstraram aprendizagem das relações ensinadas com um número reduzido de erros. Porém, os dados de equivalência e manutenção apresentaram maior variabilidade entre as participantes. Esses resultados serão discutidos na sequência.

O procedimento de ensino de relações condicionais proposto mostrou-se eficiente, a despeito das condições de declínio cognitivo das participantes. Esse dado é importante por demonstrar que idosos com diagnóstico de CCL ou DA podem aprender (ou reaprender) relações entre estímulos a partir de condições planejadas de ensino. Ainda que as participantes Linda e Mafalda tenham necessitado da repetição de alguns blocos das relações de simetria $\mathrm{AB}$, todas as idosas demonstraram um bom desempenho nos blocos de ensino das relações condicionais a partir de poucas tentativas de ensino, $\mathrm{o}$ que pode ter sido favorecido pelo número de comparações disponíveis, pela estrutura do 
treino um-para-muitos (Saunders \& Green, 1999; Arntzen, 2012), pelo procedimento de dica atrasada do estímulo de comparação incorreto durante o ensino (Sidman, 1977) e pelo procedimento de ensino por exclusão (de Souza \& de Rose, 2006). Tais variáveis (menor número de estímulos de comparação, estrutura de treino, procedimento de dica atrasada e procedimento de exclusão) foram propostas e controladas no Estudo 3, pois o procedimento proposto no Estudo 2, que foi planejado a partir do ensino por exclusão e continha quatro estímulos de comparação, não favoreceu condições para o ensino das relações $\mathrm{AB}$ (som-foto). Assim, as modificações no procedimento do Estudo 3 certamente favoreceram a aprendizagem das participantes.

A redução do número de estímulos de comparação, de quatro no Estudo 2 para 3 no presente Estudo, foi planejada em função de dados de observação de que as participantes do Estudo 2, no ensino da relação A4B4, tendiam a responder de forma rápida, sem olhar para os quatro cantos da tela (onde os estímulos estavam localizados). Essa aparente dificuldade em olhar para todos os locais em que os estímulos estavam localizados e o fato de que três, das seis participantes, apresentaram erros no conjunto de tentativas de ensino da relação A4B4, indicaram a necessidade de alterações nessa variável. Saunders et al. (2005), em estudo com idosos sem comprometimento cognitivo, não encontraram diferenças no desempenho dos participantes em função do número de comparações nas tentativas. Por outro lado, Steingrimsdottir e Arntzen (2011), em estudo com o objetivo de avaliar se o número de estímulos de comparação e a forma de apresentação destes estímulos (com ou sem atraso) poderiam interferir na aprendizagem de matching de identidade de uma idosa de 84, com DA, encontraram dados que sugerem que o número de comparações interfere negativamente no desempenho em discriminações condicionais. Os autores expuseram a participante a quatro condições que se diferenciavam pelo número de estímulos de comparação e o 
tempo de apresentação do modelo. Nas duas primeiras condições havia três estímulos de comparações apresentados de forma simultânea, porém na segunda condição, uma dica foi oferecida (um quadrado vermelho brilhava em torno do estímulo de comparação correto). Nas demais condições foram usados dois estímulos de comparação, sendo que na última condição foi aplicado um atraso de 0 segundos. Os resultados mostraram que o desempenho da participante foi melhor nas condições em que havia um número menor de estímulos de comparação (dois). Apesar de Steingrimsdottir e Arntzen (2011) consideraram que o número reduzido de estímulos foi uma das limitações do trabalho, parece que idosos com DA necessitam de procedimentos de ensino com poucos estímulos de comparação.

No presente estudo, além da redução do número de comparações, optou-se pela apresentação destes na parte inferior da tela, diferente do Estudo 2 em que os estímulos foram apresentados nos quatro cantos da tela. Essa modificação tentou melhorar as condições de visualização dos comparações, facilitando o rastreamento dos estímulos (Hutton et al., 1984).

Outro fator controlado no presente protocolo foi a estrutura de treino empregada. No Estudo 1, a estrutura de treino empregada foi a linear, que mostrou-se favorável para a aprendizagem dos idosos sem comprometimento cognitivo e a emergência de classes de equivalência, mas que tem sido referida na literatura como a mais difícil para a formação de classes de equivalência em função da distância nodal inerente ao procedimento (Arntzen \& Holth, 1997, 2000; Saunders \& Green, 1999). Como o objetivo do Estudo 3 era preparar um protocolo que favorecesse a aprendizagem de relações condicionais e a emergência de equivalência, optou-se pela estrutura um-paramuitos. Saunders e Green (1999) afirmam que o tipo de estrutura de treino mais favorável para a emergência de equivalência é a "muitos-para-um", por proporcionar o 
treino de todas as discriminações simples necessárias como pré-requisito para os testes subsequentes das propriedades de equivalência, seguida da "um-para-muitos" e por fim, a estrutura linear.

No entanto, Arntzen e Holth (2000), em uma série de três experimentos comparando as estruturas de treino um-para-muitos, muitos-para-um e estrutura linear, apontaram a superioridade da estrutura um-para-muitos sobre as demais na probabilidade de emergência de equivalência. Esses resultados replicaram outros produzidos pelos mesmos autores (Arntzen \& Holth, 1997), indicando, também, a superioridade da estrutura um-para muitos na probabilidade de produção de formação de equivalência. De acordo com os autores, é possível que a vantagem da estrutura umpara-muitos, ao contrário do previsto por Saunders e Green (1999), resida no fato de que a estrutura um-para-muitos requeira um número elevado de discriminações simultâneas nas tentativas de treino (em contraste com as discriminações sucessivas requeridas pela estrutura muitos-para-um). Além disso, na estrutura um-para-muitos, um mesmo modelo, durante o treino, é relacionado a mais de uma comparação, enquanto que na estrutura muitos-para-um, durante cada fase de treino, um mesmo comparação é correto diante de muitos modelos, o que poderia levar os participantes a "prever" o comparação correto com base um uma rápida inspeção no modelo, sem a necessidade de um rastreamento completo das alternativas disponíveis. Esses fatores produziriam a necessidade de um menor número de tentativas na fase de ensino para que os critérios de aprendizagem fossem atingidos (um-para-muitos) e gerariam um tempo de reação menor nas tentativas de teste.

Resultados demonstrando a superioridade da estrutura muitos-para-um sobre a um-para-muitos foram obtidos, em geral, com crianças (e.g., Saunders, Drake, \& Spradlin, 1999) e pessoas com deficiência intelectual (e.g., Saunders, Wachter, \& 
Spradlin, 1988), o que, de acordo com Arntzen e Holth (2000) pode ser um fator a ser ponderado na análise dos resultados. Em função dessa discussão e da variabilidade de resultados apresentados na literatura sobre a melhor estrutura para produzir a formação de classes de equivalência, optou-se, no presente estudo, pelo uso da estrutura um-paramuitos.

Aliado à estrutura de treino um-para-muitos, foi empregado o procedimento de ensino por exclusão. Esse procedimento é referido na literatura como facilitador da aprendizagem de relações arbitrárias por ser considerado uma forma de "aprendizagem sem erro" (Melo et al., 2014). De Souza e de Rose (2006) afirmam que o procedimento de ensino por exclusão é eficaz porque os estímulos definidos são usados como "dicas" para a seleção do estímulo indefinido. Além disto, o ensino por exclusão minimiza a ocorrência de erros porque os estímulos de comparação novos são inseridos gradualmente e sempre após a garantia de que a relação anterior foi estabelecida (de Souza, \& de Rose, 2006; Wilkinson et al., 2000). O responder por exclusão já foi demonstrado em várias populações, inclusive em idosos com DA (conformo visto no Estudo 2) e, como procedimento de ensino, favorece a aprendizagem de relações arbitrárias (Dixon, 1977; Ferrari, de Rose, \& McIlvane, 2008). Contudo para idosos com DA o procedimento de ensino por exclusão sozinho não pareceu suficiente para o ensino de relações arbitrárias (cf. Estudo 2).

Os dados do Estudo 2 mostraram que idosos com DA demonstram responder por exclusão, mas não mantêm a aprendizagem das relações ensinadas. Assim, o fato de idosos com DA demonstrarem respostas por exclusão fez com que o procedimento de ensino por exclusão fosse mantido no Estudo 3, mas como não houve manutenção das relações ensinadas aparentemente sozinho, o procedimento de ensino por exclusão não é eficiente para esta população, por isto, este foi aliado ao procedimento de dica atrasada. 
De acordo com Melo, Hanna e Carmo (2014), a remoção gradual de estímulos em situações distintas é denominada dica atrasada. Esses autores exemplificam este procedimento relatando que a dica atrasada ocorre quando os estímulos de comparação corretos e incorretos são apresentados ao mesmo tempo, porém, após um curto intervalo (e.g., 1s), o estímulo de comparação incorreto é retirado. Ao longo das tentativas seguintes, o estímulo de comparação incorreto também é retirado, porém o intervalo de permanência do estímulo também aumenta. Tal procedimento parece favorecer a aprendizagem, uma vez que diminui a probabilidade de erros, pois com a saída do estímulo de comparação incorreto, o participante tem apenas como opção de resposta o estímulo de comparação correto, o que favorece o estabelecimento de uma linha de base. No Estudo 3, o procedimento de dica atrasada provavelmente ajudou as participantes idosas, pois quando a Fase de Ensino foi iniciada, o desempenho das participantes foi reforçado sempre que elas selecionavam o estímulo de comparação B1; assim, provavelmente, quando a relação A2-B2 fosse inserida, as participantes responderiam por exclusão, mas depois, nas tentativas seguintes de A2B2, poderiam selecionar o estímulo incorreto (B1), pelo fato deste ter sido anteriormente reforçado por várias tentativas seguidas. Isto ficou evidente nos dados do Estudo 2. Assim, a retirada do estímulo incorreto parece ter favorecido o estabelecimento da relação A2B2 por forçar a escolha do estímulo de comparação correto sem, contudo, deixar de apresentar o comparação incorreto.

O conjunto das condições de ensino reunidas no procedimento aqui apresentado pareceu ser eficaz para o ensino das relações por evitar a ocorrência de erros, o que parece ser importante para as técnicas de ensino para idosos com CCL ou DA. Sartori (2008) e Souza (2011), por exemplo, também investigaram procedimentos de ensino de 
relações condicionais para idosos com comprometimento cognitivo e DA, porém, não obtiveram os mesmos resultados do presente estudo.

Sartori (2008) com o objetivo verificar se idosos com DA aprendiam discriminações condicionais entre estímulos arbitrários por meio de tarefas de matchingto-sample simultâneo e com atraso, expôs seis idosos com possível diagnóstico de DA, oito idosos sem CCL e sete adultos jovens a um procedimento de ensino de relações condicionais por identidade e relações arbitrárias. Os idosos com DA passaram, primeiramente, por um procedimento de ensino de identidade (a) simultâneo com estímulos unitários, (b) com atraso e estímulos unitários e (c) simultâneo e com estímulos compostos de sequências. Caso eles não atingissem critério de aprendizagem (100\% de acerto), eram submetidos a um procedimento de discriminação simples. No procedimento de discriminação simples havia 20 tentativas, sendo que nas cinco primeiras era apresentado apenas o estímulo considerado correto e a resposta era tocar sobre o estímulo. Nas demais tentativas, o estímulo incorreto foi retirado (dica atrasada). O critério de acerto era de $100 \%$ e após o alcance deste critério, o participante era submetido a um bloco sem a retira do S-. No procedimento de matching-to-sample ocorreu na condição com atraso e simultâneo. O ensino das relações se deu através da estrutura um-para-muitos e foram utilizado três conjuntos com três estímulos em cada conjunto. Por fim, foram testadas as relações de simetria e equivalência. Os resultados mostraram que os idosos com DA aprenderam apenas as relações de identidade e discriminação simples, e não as relações arbitrárias entre os estímulos, independente do ensino ser simultâneo ou com atraso. Os demais participantes aprenderam todas as relações condicionais e formaram classes de equivalência (Sartori, 2008). A não aprendizagem dos idosos por DA nas relações condicionais pode ter ocorrido porque, além da condição atraso, os estímulos utilizados não eram familiares. 
Souza (2011), com o objetivo de ensinar relações condicionais de estímulos referentes a dados biográficos (foto, nome, profissão, lazer, objeto e animal de estimação) e verificar se isto proporcionaria a formação de classes equivalentes, expôs uma participante com DA a um procedimento de ensino de relação condicional formado por estrutura linear, de três classes com seis estímulos em cada classe. Entre o ensino de cada relação condicional, havia testes de linha de base e simetria. E após o estabelecimento das primeiras relações, foto-nome e nome-profissão, foi realizado testes de linha de base destas relações, como também simetria e equivalência. Em seguida foi ensinada a relação profissão-lazer e feito teste de linha de base e simetria desta relação. Posteriormente foi feito teste de linha de base, simetria e equivalência de todas as relações ensinadas até o momento. Esta mesma estrutura de ensino e teste seguido por todo o procedimento, até que todas as relações fossem ensinadas e pudesse ser realizado um teste de equivalência todas as relações. Os resultados mostraram que a idosa apresentou um desempenho variável na Fase de Ensino, LB e simetria, com um bom desempenho em algumas relações (e.g., DE e ED), mas um desempenho fraco em outras relações. Nos Testes de Equivalência, foram testadas 40 relações e a participante demonstrou um desempenho acima de $90 \%$ em apenas 11 relações, o que demonstra que o ensino não foi eficaz para a formação de classes equivalentes.

Pode-se supor que os idosos com DA do trabalho de Sartori (2008) não aprenderam as relações com estímulos arbitrários, pois o critério de passagem entre os blocos de ensino eram altos, porque foram utilizados estímulos não familiares (letras gregas) e pelo procedimento de atraso na apresentação dos estímulos de comparação. Já a participante do trabalho de Souza (2011), assim como as participantes do presente estudo, demonstraram um desempenho regular no ensino das relações condicionais, possivelmente pelo tipo de estímulos utilizados (estímulos familiares) e pelo emprego 
do procedimento de ensino por exclusão. No entanto, a participante de Souza (2011) não obteve um bom resultado nos testes de equivalência, possivelmente devido ao ensino das relações condicionais ter ocorrido pela estrutura linear, com muitos nódulos e um número grande de estímulos em cada classe. Em comparação, todas as participantes do presente estudo foram expostas a um treino de estrutura um-paramuitos, o que possivelmente favoreceu a aprendizagem das relações arbitrárias, uma vez que os estímulos de comparação foram sempre relacionados ao mesmo modelo, além do procedimento ter ocorrido por exclusão e com dica atrasada, prevenindo erros e favorecendo a aprendizagem das relações.

Além de investigar a aprendizagem de relações condicionais por idosos com CCL e DA, pretendia-se verificar o protocolo de ensino proposto seria eficiente para promover a manutenção das relações aprendidas na fase de treino em blocos de linha de base cheia de tentativas não consequenciadas, a formação de classes de equivalência e a manutenção dessa aprendizagem (e das classes eventualmente formadas), após diferentes períodos de tempo. Esses testes foram realizados uma única vez em cada situação (após a finalização da Fase de Ensino, e em dois momentos nos Teste de Manutenção), pois o intuito foi verificar a ocorrência desses desempenhos a partir da fase de ensino, cumpridos os critérios de aprendizagem a ela designados. Apesar dos resultados de Linha de Base Cheia em Extinção terem sido mais consistentes (para pelo menos três das quatro participantes), os dados de equivalência foram mais variáveis e, de forma geral, todas as participantes demonstraram uma queda no desempenho de equivalência ao longo dos testes.

As participantes Marta e Mafalda foram as que apresentaram o melhor desempenho nos testes de equivalência. Essas participantes também obtiveram a melhor pontuação no MEEM (16 pontos), indicando menor comprometimento cognitivo dentre 
as quatro participantes do Estudo 3. Entretanto, mesmo com o melhor desempenho nos testes de equivalência (em relação ao restante do grupo), tal resultado quando comparado com os dos idosos sem CCL do Estudo 1, com os idosos do trabalho de Aggio e Domeniconi (2012) e Haydu e Morais (20009), foi inferior, indicando que a condição de comprometimento cognitivo tem um impacto na formação de classes de equivalência (caso de Marta, Linda e Izilda) e na sua manutenção (caso das duas participantes que aparentemente formaram classes de equivalência).

No Estudo 1, o procedimento de ensino para os idosos sem comprometimento cognitivo foi mais complexo que o procedimento do Estudo 3, uma vez que a estrutura de treino utilizada foi a linear, o número de classes e o número de estímulos por classes foi maior (quarto classes com quatro estímulos em cada classe) e os estímulos de comparação estavam nos quatro cantos da tela do computador. Porém, apesar do procedimento do Estudo 1 ter sido mais difícil, os idosos deste estudo, com exceção de Cássia, demonstraram manutenção das classes ensinadas por um período mais longo de tempo (30 dias). Assim, observa-se que as características do treino são relevantes para a formação e manutenção de classes equivalência, mas o comprometimento cognitivo também é um favor importante.

Gallagher e Kennan (2009) afirmaram que pode haver uma relação entre o desempenho do indivíduo no MEEM e o seu desempenho em testes de equivalência. Esses autores ensinaram a 18 idosos (67 a 94 anos - Experimento 1) que viviam em uma instituição residencial, relações condicionais de duas classes de três membros, e também os avaliaram por meio do MEEM. Apenas os idosos que pontuaram acima de 27 pontos no MEEM demonstraram indicativos de formação de equivalência, enquanto que nenhum dos idosos que pontuaram abaixo de 25 pontos no MEEM demonstraram indícios de formação de classes. Em uma replicação do estudo (Experimento 2) com 12 
idosos (57 a 92 anos), os autores verificaram que os participantes com escores entre 21 e 16 não conseguiram atingir os critérios de aprendizagem das relações $A B$ ou $B C$, enquanto que todos os participantes com escores entre 28 e 30 pontos (Experimento 3) demonstraram formação de equivalência. Esse trabalho foi realizado com uma amostra pequena e é possível fazer objeções em relação a alguns aspectos do procedimento que podem ter afetado negativamente o desempenho dos participantes (e.g., natureza dos estímulos empregados). Apesar disso, os autores encontraram evidências de que, no procedimento de ensino específico empregado, foi possível encontrar uma correlação entre o desempenho no MEEM e o desempenho nos testes de equivalência. No presente estudo, apesar de terem sido encontrados resultados melhores do que os apresentados por Gallagher e Kennan (2009) (especialmente no que diz respeito à aprendizagem de relações condicionais), as participantes que apresentaram o melhor desempenho nos testes de equivalência foram as participantes que tiveram uma pontuação melhor no MEEM. Da mesma forma, no Estudo 1 os participantes que obtiveram um escore mais alto no MEEM também apresentaram um desempenho melhor nos testes de equivalência.

Com isto, é possível concluir que o CCL e a DA na fase inicial não prejudicam a aprendizagem de relações condicionais, porém tais diagnósticos são variáveis que influenciam de forma negativa na formação de classes equivalentes e manutenção dessas novas classes. A literatura reporta que a DA e o CCL implicam em dificuldades de memória e de linguagem, além de agnosia (DSM IV, 2008). No entanto, o número reduzido de estudos específicos sobre equivalência de estímulos com idosos com DA dificulta o entendimento sobre em que medida esse diagnóstico impacta a formação de classes entre estímulos. A formação de outros tipos de classes (classes funcionais ou classes por semelhança física) também seria afetada por essa patologia? Essa e outras 
questões relativas ao funcionamento simbólico demandam pesquisas adicionais que contribuiriam para a compreensão de como o comprometimento cognitivo interfere na formação/manutenção de conceitos por idosos.

Finalmente, é preciso considerar o desempenhos das participantes do Estudo 3 nos Testes de Nomeação. Durante a seleção das participantes, foi realizado um teste de nomeação das fotos que seriam utilizadas no procedimento, cujo intuito era verificar se a participante sabia ou não nomear tais fotos, uma vez que as fotos eram das funcionárias da instituição. As fotos eram apresentadas na tela do computador e perguntava-se à participante se ela sabia o nome da pessoa da foto. Esse teste foi reapresentado depois de cada teste de equivalência, sempre com a mesma instrução: “Olhe para esta foto. Qual o nome da pessoa da foto?”.

Os dados de nomeação obtidos foram variáveis. Linda acertou $67 \%$ das tentativas nos três momentos em que o teste foi reaplicado, enquanto Izilda não acertou nenhuma tentativa sob as mesmas condições. As demais participantes apresentaram desempenhos irregulares ao longo dos testes: Mafalda melhorou seu desempenho ou contrário de Marta que teve um declínio em seu desempenho. Não é possível correlacionar os dados do MEEM com os dados do teste de nomeação, uma vez que Linda e Izilda apresentaram o mesmo resultado no MEEM, ambas com 14 pontos, porém Linda demonstrou um desempenho superior o de Izilda no teste de nomeação. Mafalta e Marta também apresentaram o mesmo escore no MEEM - 16 pontos - porém a primeira obteve um resultado melhor no teste de nomeação quando comparada a segunda.

Porém, é preciso ressaltar que Linda era a participante que tinha o maior tempo de institucionalização e a que mais tempo permanecia na casa durante a semana. Isto pode, de alguma forma, ter contribuído para o seu melhor desempenho no teste da 
nomeação, uma vez que ela foi a participante mais exposta às funcionárias da casa. Talvez, por ficar mais tempo na instituição, a participante possa ter se beneficiado mais do procedimento de ensino proposto: ficar mais tempo na casa e ser exposta aos funcionários e, eventualmente, aos seus nomes, pode ter tido um efeito positivo somado ao procedimento realizado, melhorando seu desempenho nos testes de nomeação. Outro dado relevante é que, Mafalda e Marta, apesar de terem dificuldade na nomeação, souberam dizer a profissão das pessoas das fotos, principalmente da foto que era representada pela gerente, que era a responsável pela ILPI - por exemplo, quando apresentadas às fotos e perguntadas sobre o nome das pessoas ali retratadas, essas participantes diziam: "É a gerente", ou "é a enfermeira”, demonstrando manutenção de uma relação ensinada na Fase de Ensino.

A nomeação é definida por Catania (1999) como uma "expansão do vocabulário" e que apresenta relação com o comportamento de lembrar. Entretanto, é preciso considerar que idosos com DA possam apresentar uma maior dificuldade na expansão de seu vocabulário, uma vez que um dos sintomas desta demência é a afasia, que prejudica a comunicação e os déficits na memória (DSM-IV, 2008), que certamente interferem de forma negativa no comportamento de lembrar.

A emergência de nomeação a partir do ensino de relações condicionais e de formação de classes de equivalência já foi investigada em vários estudos. Sidman, (1971), por exemplo, ao submeter um adolescente com deficiência intelectual a um procedimento de ensino de relações arbitrárias e testes de equivalência, verificou a ocorrência de nomeação das figuras pelo adolescente sem ensino direto. O presente estudo não investigou de forma sistemática a nomeação derivada do procedimento de ensino e nem teve como objetivo controlar condições que pudessem favorecê-la. No entanto, os dados aqui descritos sugerem que esse é um tópico de grande relevância para 
estudo, e que merece investigações adicionais, uma vez que esse desempenho é fundamental no repertório social dos indivíduos e pode favorecer o funcionamento social de idosos com DA. 


\section{Conclusão}

Os objetivos gerais deste trabalho foram investigar se idosos com e sem CCL e/ou DA demonstram responder por exclusão e formam classes de equivalência. Os dados apresentados indicam que idosos, com CCL, DA na fase inicial ou com nenhuma perda cognitiva, demonstram desempenho por exclusão, o que comprova que este fenômeno emergente não deixa de ocorrer com o avanço da idade e com as mudanças biológicas e cognitivas causadas pelo próprio envelhecimento. Contudo ainda não há evidências que demonstram se idosos com DA na fase moderada ou avançada demonstram respostas por exclusão, o que indica a necessidade de estudos que avaliem se o processo de neurodegeneração causada pela DA interfere nesse desempenho.

No entanto, a análise dos resultados indica que, apesar de os idosos com DA responderem por exclusão, a aprendizagem de relações via exclusão é menos evidente, quando se compara os dados dos Estudos 1 com os dados do Estudo 2. No Estudo 1, o ensino das relações condicionais (som-foto, foto-nome escrito, nome escrito-grau de parentesco e grau de parentesco-profissão) ocorreram por exclusão e nenhum dos idosos errou a tentativa de exclusão: quase todos mantiveram as relações apresentadas na tentativa de exclusão ao longo do procedimento de ensino. No Estudo 2, o ensino das relações "som-nome" também ocorreu por exclusão e o procedimento proporcionou três tentativa de exclusão, porém, apenas uma participante acertou as três tentativas. Isto pode ter ocorrido (a) pelo fato do comprometimento cognitivo interferir de forma negativa em tarefas de relações condicionais, (b) pela linha de base não ter sido estabelecida de forma eficaz, ou (c) pela dificuldade em rastrear os estímulos de comparação, especialmente quando havia três ou quatro alternativas. Porém, são necessários estudos que avaliem tais conjecturas para posterior conclusão, pois uma das 
limitações deste estudo foi não identificar como idosos com DA rastreiam informações visuais.

Sobre o ensino de relações arbitrárias e formação de classes de equivalência de estímulos conclui-se que, de modo geral, os idosos sem comprometimento cognitivo não demonstraram dificuldade na aprendizagem das relações condicionais, além de demonstrarem um desempenho positivo nos Testes de Equivalência. Assim, observa-se que o processo normal de envelhecimento não interfere na aprendizagem de novas relações arbitrárias.

Idosos com DA na fase inicial também são capazes de aprender relações condicionais se o procedimento de ensino estiver estruturado de uma forma que auxilie a aprendizagem. O procedimento proposto no Estudo 3 mostrou-se eficaz para produzir a aprendizagem das relações condicionais propostas, aliando o ensino por exclusão com o procedimento de dica atrasada com a retirada dos estímulos de comparação incorretos, em uma estrutura de treino um-para-muitos, utilizando estímulos familiares e três estímulos de comparação. Contudo, tal procedimento não foi eficaz para a formação de classes equivalentes que, apesar de presentes em alguns dos participantes, não se mantiveram de forma comparável a dos idosos sem comprometimento cognitivo.

Outra limitação deste estudo para a verificação da emergência de classes de equivalência em idosos com DA foi a não repetição de blocos de linha de base cheia em extinção até um critério específico de aprendizagem e dos blocos de Testes de Equivalência até que se obtivesse uma estabilidade do responder. É provável que essa repetição (reexposição) afetasse positivamente o desempenho das idosas com DA, pois seria uma tentativa de garantir a aprendizagem das relações condicionais de forma mais confiável e um melhor desempenho no Teste de Equivalência. No entanto, o objetivo inicial da presente pesquisa era verificar se os procedimentos de ensino adotados 
promoveriam a manutenção das relações ensinadas e emergência de classes de equivalência, o que não foi confirmado. Estudos futuros devem promover modificações no procedimento proposto, de tal forma que se garanta uma linha de base consistente antes de se promover os testes de equivalência, a fim de investigar outras variáveis que podem interferir na formação de classes por esses participantes.

Conclui-se também que, apesar de todos os idosos participantes deste trabalho serem residentes de ILPI's, tais instituições não prejudicaram o seu desempenho na aprendizagem de relações condicionais e formação de classes equivalentes, o que indica que as instituições não proporcionam prejuízos cognitivos para os idosos, apesar de colaborarem com o isolamento familiar. No entanto, apenas um estudo de seguimento com idosos residentes em ILPI's poderá fornecer indícios confiáveis de que, de fato, a institucionalização em si não prejudica o funcionamento cognitivo desses indivíduos.

Apesar dos achados destes estudos, são necessárias mais investigações sobre o modo como idosos com DA aprendem relações condicionais. Os pesquisadores de Análise do Comportamento muito têm feito por outras populações, mas as investigações com idosos com DA ainda são escassas. Há muito que se investigar em idosos como DA, como o seu desempenho em tarefas de discriminações simples, em tarefas que investiguem a relações de estímulos funcionais e não funcionais para a aprendizagem de idosos, em procedimentos de transferência de função, como também em tarefas que tenham como objetivo produzir ou melhorar o discurso desta população. Este trabalho pode ser um estímulo a outros pesquisadores interessados no tema. 


\section{Referências}

Aggio, N. M., \& Domeniconi, C. (2012). Formação e manutenção de classes de estímulos equivalentes: um estudo com participantes da terceira idade. Acta Comportamentalia, 20, 29-43

Almeida-Verdu, A. C., Bevilacqua, M.C., de Souza, D. G., \& de Souza, F. C. (2009). Imitação vocal e nomeação de figuras em deficientes auditivos usuários de implante coclear: estudo exploratório. Revista Brasileira de Análise do Comportamento, 5(1), 63-78.

Antoniazzi, M., Domeniconi, C., \& Schmidt, A. (2014). Efeito da pré-exposição ao objeto no desempenho por exclusão e na aprendizagem da relação nome-objeto. Acta Comportamentalia, 22(1), 23-36

ANVISA. Resolução da Diretoria Colegiada, 283, de 26 de setembro de 2005. Disponível em: <www.portalsaude.gov.br>.

Arantes, Ana Karina Leme. Topografias de controle de estímulos e equivalência de estímulos: variações paramétricas do procedimento de máscaras. Tese de Doutorado, São Carlos.

Arntzen, E. (2006). Delayedmatchingtosample: probabilityofresponding in accord with equivalence as a function of different delays. The PsychologicalRecord, 56, 135167.

Arntzen, E. (2012). Training and testing parameters in formation of stimulus equivalence: methodological issues. European Journal of Behavior Analysis, 13, 123-135.

Arntzen, E., \& Holth, P. (2000). Equivalence outcome in single subjects as a function of training structure. The Psychological Record, 50, 603-628.

Arntzen, E., \& Holth, P. (1997). Probability of stimulus equivalence as a function of training design. The Psychological Record, 47, 309-320.

Brasil, Lei no 10.741 , de $1^{\circ}$ de outubro de 2003. Estatuto do Idoso. Brasília.

Bischkopf, J.,Busse, A., \&Angermeyer, M.C. (2002). Mild cognitive impairment: a review of prevalence, incidence and outcome according to current approaches. Acta PsychiatricaScandinavica, 106, 403-414.

Bottino, C. M. C., Carvalho, I. A. M., Alvarez, A. M. M. A., \& et al (2002). Reabilitação cognitiva em pacientes com doença de Alzheimer. Arquivos de neuropsiquiatria,60, 70-79.

Browder, D., Ahlgrim-Delzell, L., Spooner, F., Mims, P. J., \& Baker, J. N. (2009). Using time delay to teach literacy to students with severe developmental disabilities. Exceptional Children, 75,343-364. 
Camaro, A. M. \&Kanso, S. (2010). As instituições de longa permanência para idosos no Brasil. Revista Brasileira de Estatística e População, 27 (1), 233-235.

Catania, C. A. (1999). Aprendizagem: comportamento, linguagem e cognição. Porto Alegre: Artes Médicas Sul.

Caxieta, L. (2012) Evolução do conceito de doença de Alzheimer. In L. Caxieta, \& cols. (Eds.), Doença de Alzheimer (pp. 21-29). Artmed: Porto Alegre.

Costa, A. R. A. da, \& Domeniconi, C. (2009). Análise do responder por exclusão em um cão treinado em tarefas de discriminação simples. Revista Brasileira de Análise do Comportamento, 5, 49-62.

Costa, A. R. A., McIlvane, J. W., Wilkinson, K. M., \& de Souza, D. G. (2001). Emergent word-object mapping by children: Further studies using the blank comparison technique. The PsychologicalRecord, 51, 343-355.

Costa, A. R. A., de Rose, J. C. \& de Souza, D. G. (2009). Interferência de variáveis de contexto em sondas de exclusão com substantivos e verbos novos. Acta Comportamentalia, 18(1), 35-54.

da Silva, S. L., Pereira, D. A., Veloso, F., Satlher, C.E., Arantes, A. \& Guimarães, R. M. (2011) Programa de reabilitação neuropsicológica da memória aplicada à demência: um estudo não controlado intrasujeitos. Estudos de Psicologia, 28, 229240.

de Rose, J. C. (1993) Classes de estímulos: implicações para uma análise comportamental da cognição. Psicologia: Teoria e Pesquisa, 9, 283-303.

de Rose, J. C., de Souza, D. G. \& Hanna, E. S. (1996). Teaching reading and spelling: exclusion and stimulus equivalence. Journal of Applied Behavior Analysis, 29(4), 451-469.

de Rose, J. C., Kato, O. M., Thé, A. P. G., \& Kledaras, J. B. (1997). Variáveis que afetam a formação de classes de estímulos: estudos sobre efeitos do arranjo do treino. Acta comportamentalia, 5(2), 143-163.

de Rose, J. C., \& Bortoloti, R. (2007). A equivalência de estímulos como modelo do significado. Acta comportamentalia., 15, 83-102.

de Souza, D. G., \& de Rose, J. C. (2006). Desenvolvendo programa individualizado para o ensino de leitura. ActaComportamentalia, 14(1), 77-98.

Dixon, L. S. (1977). The nature of control by spoken words over visual stimulus selection. Journal of the Experimental Analysis of Behavior, 27, 433-442.

Dixon, M., Becker, J. C., \& Sadowski, K. A. (2011).Applying Skinner's analysis of verbal behavior to persons with dementia.BehaviorTherapy, 42, 120-126. 
Domeniconi, C., Costa, A. R. A., de Souza, D. G. \& de Rose, J. C. (2007). Responder por exclusão em crianças de 2 e 3 anos em uma situação e brincadeira. Psicologia: Reflexão e Crítica, 20(2), 342-350.

Enhelhardt, E.,Brucki, S. M. T., Cavalcanti, J. L. S. \& Cols. (2005) Tratamento da doença de alzheimer: recomendações e sugestões do departamento científico de neurologia cognitiva e do envelhecimento da academia brasileira de neurologia. Arquivos de Neuro-Psiquiatria, 63, 1104-1112.

Eilifsen, C., \& Arntezen, E. (2009). On the role of trial types in tests for stimulus equivalence. European Journal of Behavior Analysis, 2, 187-202.

Ferrari, C., de Rose, J. C. \& McIlvane, W. J. (1993). Exclusion vs. Selection Training of Auditory-Visual Conditional Relations.Journal of Experimental Child Psychology, $56,49-63$.

Ferrari, C., de Rose, J. C., Mcllvane, W. J. (2008). A comparison of exclusion and trialand-error procedures: primary and secondy effects. Experimental Analysis og Human Behavior Bulletin, 29, 9-16.

Freitas, M. C., Reis, T. S., Mizael, T. M. \& Domeniconi, C. (2012).Responder de cães por exclusão em tarefas de discriminação condicional. Interação em Psicologia, 16(2), 173-183.

Folstein, M. F., Folstein, S. E., \& McHugh. (1975). Mini-Mental State: a practical method for grading the cognitive state of patients for the clinician. Journal Psychiatric, 12, 189-198.

Forlenza, O. V. (2005) Tratamento farmacológico da doença de Alzheimer. Revista de PsiquiatriaClínica, 32, 137-148.

Gallagher, S. M. \& Keenan, M. (2009).Stimulus equivalence and the mini mental status examination in the elderly.European Journal of Behavior Analysis, 10, 159-165.

Garcia, F. C. (2007). Exame de afasia M1-Alpha: uma proposta para readequação ao português. Tese, Universidade de São Paulo, Ribeirão Preto.

Goyos, C., Rossit, R. A. S., Elias, N. C., Escobal, G. \&Chereguini, P. (2009).Análise do comportamento e o estudo do envelhecimento humano: revisão dos estudos de aplicação. Revista Brasileira de Análise do Comportamento, 5(2), 1-20.

Haydu, V. B., \& Morais, L. P. (2009). Formação, manutenção e recuperação de relações equivalentes em adultos da terceira idade. Psicologia Argumento, 27 (59), 323-336.

Haydu, V. B., \& Miura, P. O. (2012). Manutenção de relações de equivalência e a recordação de nomes. Psicologia: Teoria e Prática, 12(1), 16-31.

Haydu, V. B., Omote, L. C. F., Vicente, P., Aggio, N. M., \& Paula, J. B. C. de (2009). Efeitos do tamanho da classe na manutenção de relações de equivalência em um delineamento intra-grupo. Interação em Psicologia, 13(2), 179-193. 
Haydu, V. B., \& Paula, J. B. C. de (2008). Efeitos do tamanho da classe na manutenção de relações equivalentes. Psicologia, Reflexão e Critica, 21 (2), 233-251.

Hutton, J. T., Nagel, J. A., \& Loewenson, R. T. (1984). Eye tracking disfunction in Alzheimer-type dementia. Neurolgy, 34 (1), 99-102.

Instituto Brasileiro de Geografia e Estatística [IBGE]. (2000). Perfil dos idosos responsáveis pelos domicílios no Brasil. Estudos \& Pesquisa: informações demográficas e socioeconômicas. Rio de Janeiro.

Jackson, O. (2011). Demência senil e comprometimento cognitivo. In T. L. Kauffman (Ed.), Manual de reabilitação geriátrica (pp. 112-116). Guanabara, 2011.

Johnson, C., \& Sidman, M. (1993). Conditional discrimination and equivalence relations: Control by negative stimulus. Journal of the Experimental Analysis of Behavior, 59, 333-347.

Jorm, A. F., Korten, A. E., \& Henderson, A. S (1987). The prevalence of dementia: A quantitative integration of the literature. Acta PsychiatricaScandinavica, 76, 465479

Kane, R. L., Ouslander, J. G., \& Abrass, T. B. (2004). O paciente geriátrico: demografia, epidemiologia e utilização dos serviços de saúde. In R. L. Kane, J. G. Ouslander, \& T. B. Abrass (Eds), Geriatria Clínica. Rio de Janeiro.

Kazdin, A. E. (1982). Single case research designs: methods for clinical and applied settings. New York: Oxford.

Lebrão, M. L., Duarte, Y. A. O., Santos, J. L. F., \&Laurenti, R. (2008) Evolução nas condições de vida e saúde da população idosa do Município de São Paulo. São Paulo em Perspectiva, 22, 30-45.

Manual diagnóstico e estatístico de transtornos mentais [DSM-IV]. (2008). Porto Alegre, Ed. Artes Médicas.

McIlvane, W. J., \& Dube, W. V. (1992). On terms. Stimulus control shaping and stimulus control topographies. The Behavior Analyst, 15, 89-94.

McIlvane, W. J., Wilkinson, K., \& de Souza, D. G. (2000). As origens da exclusão. Temas em Psicologia, 2, 195-203.

Melchiori, L. E., de Souza, D. G., \& de Rose, J. C. (2000). Reading, equivalence, and recombination of units: A replication with students with different learning histories. Journal of Applied Behavior Analysis, 33, 97-100.

Medeiros, J. G., Monteiro, G. \& Silva, K. Z. (1997). O ensino da leitura e escrita a um sujeito adulto. Temas em Psicologia, 1, 65-78. 
Melo, R. M. do., Hanna, E. S., \& Carmo, J. dos. S. (2014). Ensino sem erro e aprendizagem de discriminação. Temas em Psicologia, 22(1), 207-222.

Moreira, M. M. (1998). O envelhecimento da população brasileira: intensidade, feminização e dependência. Revista Brasileira de Estudos Populacionais, 15 (1), 79-94.

Moss-Loureco, P., \& Fields, L. (2011). Nodal structure and stimulus relatedness in equivalence classes: post-class formation preference tests. Journal of the Experimental Analysis of Behavior, 95, 343-368.

Nunes, V. M. de A., Menezes, R. M. P. de, \& Alchieri, J. C. (2010). Avaliação da qualidade de vida em idosos institucionalizados no município de Natal, Estado do Rio Grade do Norte. Acta Scientiarum, 32, 119-126.

O’Connor, J., Rafferty, A., Barnes-Holmes, D., \& Barnes-Holmes, Y. (2009). The role of verbal behavior, stimulus nameability, and familiarity on the equivalence performaces of autistic and normally developing children. The Psychological Record, 56, 53-74.

Olchick, M. R., Mattos, D., Maineri, N. S., Farina, J., Oliveira, A., \&Yassuda, M. S. (2012). Revisão: efeitos do treino de memória em idosos normais e em idosos com comprometimento cognitivo leve. Temas em Psicologia, 20(1), 235-245.

Oliveira, S. R. (2012). Avaliação de fala de usuários de implante coclear após ensino de relações modelo articulatório/figura e palavra falada/figura. (Dissertação). Universidade Federal de São Carlos.

Omote, L. C. F., Vicente, P., Aggio, N. M., \& Haydu, V. B. (2009). Manutenção de classes de estímulos equivalentes. Psicologia: Teoria e Prática, 11(1), 18-34.

Oshiro, C. K. B, de Souza, D. G., \& Costa, A. R. A. (2006). Responder por exclusão a partir de uma linha de base de discriminações condicionais visuais. Revista Brasileira de Análise do Comportamento, 2(2), 251-276.

Papaléo Netto, M. (2007). Gerontologia: a velhice e o envelhecimento em visão globalizada. Atheneu. São Paulo.

Perez, W. F. ; Tomanari, G. Y. (2014). Indução de controles por seleção e por rejeição em tarefas de emparelhamento com o modelo: uma revisão metodológica. Acta Comportamentalia, v. 22, p. 227-242.

Perez, W. F. ; Tomanaria, G. Y. (2013). Inferindo a ocorrência dos controles por seleção e por rejeição em tarefas de emparelhamento com o modelo: uma revisão metodológica. Acta Comportamentalia, v. 21, p. 211-225.

Pérez-González, \& Moreno-Sierra, V. (1999). Equivalence class formation in elderly persons. Psicothema, 11(2), 325-336. 
Petersen, R. C., Smith, G. E.,Warin, S. C., Ivnik, R. J., Kokmem, E., \&Tangelos, E. R. (1997). Aging, memory, and mild cognitive impairment.International Psychogeriatrics, 9(1), 65-69.

Petersen, R. D., Stevens, J. C, Ganguli, M. D., \& et al (2001).Pratice parameter: early detection of dementia: mild cognitive impairment (an evidence-based review). American Academy of Neurology, 56, 1133-1142.

Ponte, L. M. M., \& Hübner, M. M. C. (2008).A reabilitação neuropsicológica sob a ótica da psicologia comportamental. Revista de Psiquiatria Clinica, 35(1), 6-12.

Rehfeldt, R. A., \& Hayes, L. J. (2000). The long-term retention of generalized equivalence classes.The PsychologicalRecord, 50, 405-428

Santos, S. S. C., Feliciani, A. M. \& Silva, B. T. (2007). Perfil de idosos residentes em instituições de longa permanência: proposta de ações de enfermagem/saúde. Revista RENE, 8 (3), 26-33.

Sartori, R. M. (2008). Aprendizagem discriminativa em jovens e em idosos com e sem doenças de Alzheimer. Dissertação, Universidade de São Carlos, São Carlos.

Saunders, R. R., Drake, K. M., \& Spradlin, J. E. (1999). Equivalence class development, expansion, and modification in preschool children. Journal of the Experimental Analysis of Behavior, 71, 195-214.

Saunders, R. R., Saunders, K. J., Kirby, K. C., \& Spradlin, J. E. (1988).The merger and development of equivalence classes by unreinforced selection of comparison stimuli. Journal of the Experimental Analysis of Behavior, 50, 145-161.

Saunders, R. R., Wachter, J.,\& Spradlin, J. E. (1988). Establishing auditory stimulus control over an eight-member equivalence class via conditional discrimination procedure. Journal of the Experimental Analysis of Behavior, 49, 95-115.

Saunders, R. S., \& Green, G. (1999). A discrimination analysis of training-structure effects on stimulus equivalence outcomes. Journal of the Experimental Analysis of Behavior, 72, 117-137.

Saunders, R. R., Chaney, L., \& Marquis, J. G. (2005).Equivalence class establishment with two, three, and four choice matching to sample by senior citizens. The Psychological Record, 55, 539-559.

Saunders, R. R., Wachter, J. A., \& Spradlin, J. E. (1988). Establishing auditory stimulus control over an eight-member equivalence class via conditional discrimination procedure. Journal of the Experimental Analysis of Behavior, 49, 95-115.

Sidman, M. (1994). Equivalence relations and behavior: a research story. Boston: Authors Cooperative.

Sidman, M. (1971) Reading and auditory-visual equivalence. Journal of Speech and Hearing Research. 14, 5-13. 
Sidman, M. \& Cresson, O. (1973) Reading and crosmodal transfer or estimulus equivalence in severe mental retardation.American Journal of Mental deficiency, $77,515-523$.

Sidman, M., \& Tailby, W. (1982). Conditional discrimination vs. matching-to-sample: An Expansion of the testing paradigm. Journal of the experimental Analysis of Behavior, 37, 261-273.

Skinner, F. B. (1957). Comportamento Verbal. São Paulo. Ed. Cultrix.

Souza, F. S. de. (2011). O ensino de discriminações condicionais para idosos com comprometimento cognitivo. Dissertação, Pontifícia Universidade Católica, São Paulo.

Stella, F. (2012). Comprometimento Cognitivo Leve. In L. Caxieta, L \& cols. (Eds), Doença de Alzheimer (pp. 251-264) Artmed: Porto Alegre.

Souza, M. F. de, \& Schmidt, A. (no prelo). Responding by exclusion in Wistar rats in a simultaneous visual discrimination task. Journal of the Experimental Analysis of Behavior.

Steingrimsdottir, H. S., \& Arntzen, E. (2011). Using conditional discrimination procedures to study remembering in an Alzheimer's patient.Behavior Intervention, 26, 179-192.

Steingrimsdottir, H. S., \& Arntzen, E. (2011b). Identity machting in a patient with Alzheimer's disease. American Journal of Alzheimer's Disease \& Other Dementias, 26(3), 247-253.

Stromer, R. (1989). Symmetry of control by exclusion in human's arbitrary maching to sample.PsychologicalReports, 64, 915-922.

United Nations Population Fund (2000).Setting the scene.In United Nations Population Fund.Aging in the Twenty-First Century: a celebration and a challenge.

Wilkinson, K. M., \& McIlvane, W. J. (1997). Blank comparison analysis of emergent symbolic mapping by young children.Journal of Experimental Child Psychology, 67, 115-130.

Wilkinson, K. M., Rosenquist, C., \& McIlvane, W. (2009).Exclusion learning and emergent symbolic category formation in individuals with severe language impairments and intellectual disabilities.The PsychologicalRecord, 59, 187-206.

World Health Organization (WHO). (2005). Envelhecimento Ativo: uma politica de saúde. Tradução de Suzana Gontijo. Brasilia: OPAS. 


\section{Anexos}

Anexo 1

Universidade de Săo Paulo

Faculdade de Filosofia, Ciências e Letras de Ribeiräo Preto

Comitê de Ética em Pesquisa

Campus de Ribeirão Preto

Of.CETPIFFCLRP-USP/022-js!

Ribeiräo Preto, 26 de março de 2013

Prezada Pesquisadora

Comunicamos a V. Sa. que o projeto de pesquisa intitulado "Equivaléncia de estimulos e responder por exclusāo em idosos com e sem COMPROMETIMENTo cognitivo" foi reanalisado pelo Comitê de Ética em Pesquisa da FFCLRP-USP, e enquadrado na categoria: APROVADO (CAAE 12939513.8.0000.5407).

Solicitamos que eventuais modificaçoes ou emendas ao projeto de pesquisa sejam apresentadas ao CEP, de forma sucinta, identificando a parte do projeto a ser modificada e suas justificativas, e que, ao término do estudo, um relatório final seja entregue, via Plataforma Brasil.

Atenciosamente,

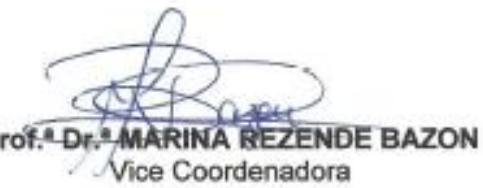

A Senhora

Mariana Ducatti Almeida

Programa de Pós-graduaçâo em Psicobiologia da FFCLRP USP

a/c:

Profa. Dra. Andréla Schmidt

Departamento de Psicologra da FFCLRP USP

CEP - Camis de Elica em PBequisa da FFCLRP

Fone: (16) $36002-4811$

Fax (16) 3633-2060 (droto) ou 3633-501s

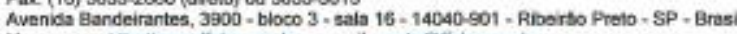

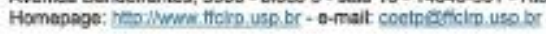


Anexo 2

\section{Mini Exame do Estado Mental}

1. Orientação espacial (0-5 pontos):

Em que dia estamos?

Ano:

Semestre:

Mês:

Dia:

Dia da Semana:

\section{Orientação espacial (0-5 pontos):}

Onde estamos?

Estado:

Cidade:

Bairro:

Rua:

Local:

\section{Repita as palavras ( $(0-3$ pontos):}

Caneca; Tijolo; Tapete

\section{Cálculo (0-5 pontos):}

4.a Se de 100 fossem tirados 7 quanto restaria? E se tirarmos mais 7?

(Repetir o procedimento por cinco vezes)

4b. Soletre a palavra MUNDO de trás pra frente.

O-D-N-U-M

\section{Memorização (0-3 pontos):}

Falar as palavras ditadas anteriormente (Caneca; Tipojo; Tapete).

\section{Linguagem ( $0-2$ pontos):}

Mostrar um relógio e uma caneta e pedir para o entrevistador nomeá-los.

\section{Linguagem (1 ponto):}

Repetir a frase: "Nem aqui, nem ali, nem lá."

\section{Linguagem ( $0-3$ pontos):}

Siga a ordem:

(1) Pegue esse papel com a mão direita.

(2) Dobre-o no meio.

(3) Coloque-o no chão.

\section{Linguagem (1 ponto):}

Escrever num papel a ordem "Feche os Olhos" e pedir para o participante ler e executar.

\section{Linguagem (1 ponto):}

Pedir para o entrevistador escrever uma frase completa.

\section{Linguagem (1 ponto):}

Cópia do desenho:

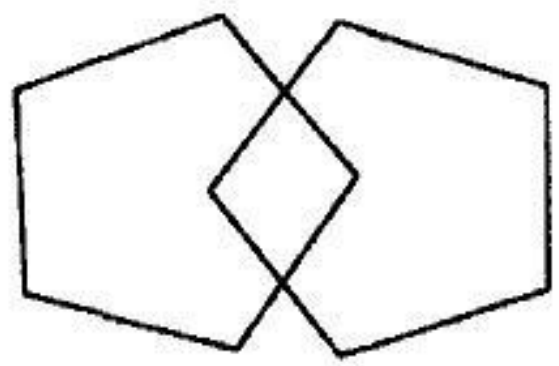

Verificar se todos os lados estão preservados e se os lados da intersecção formam um quadrilátero. Tremor $\mathrm{e}$ rotação podem ser ignorados. 
Anexo 3

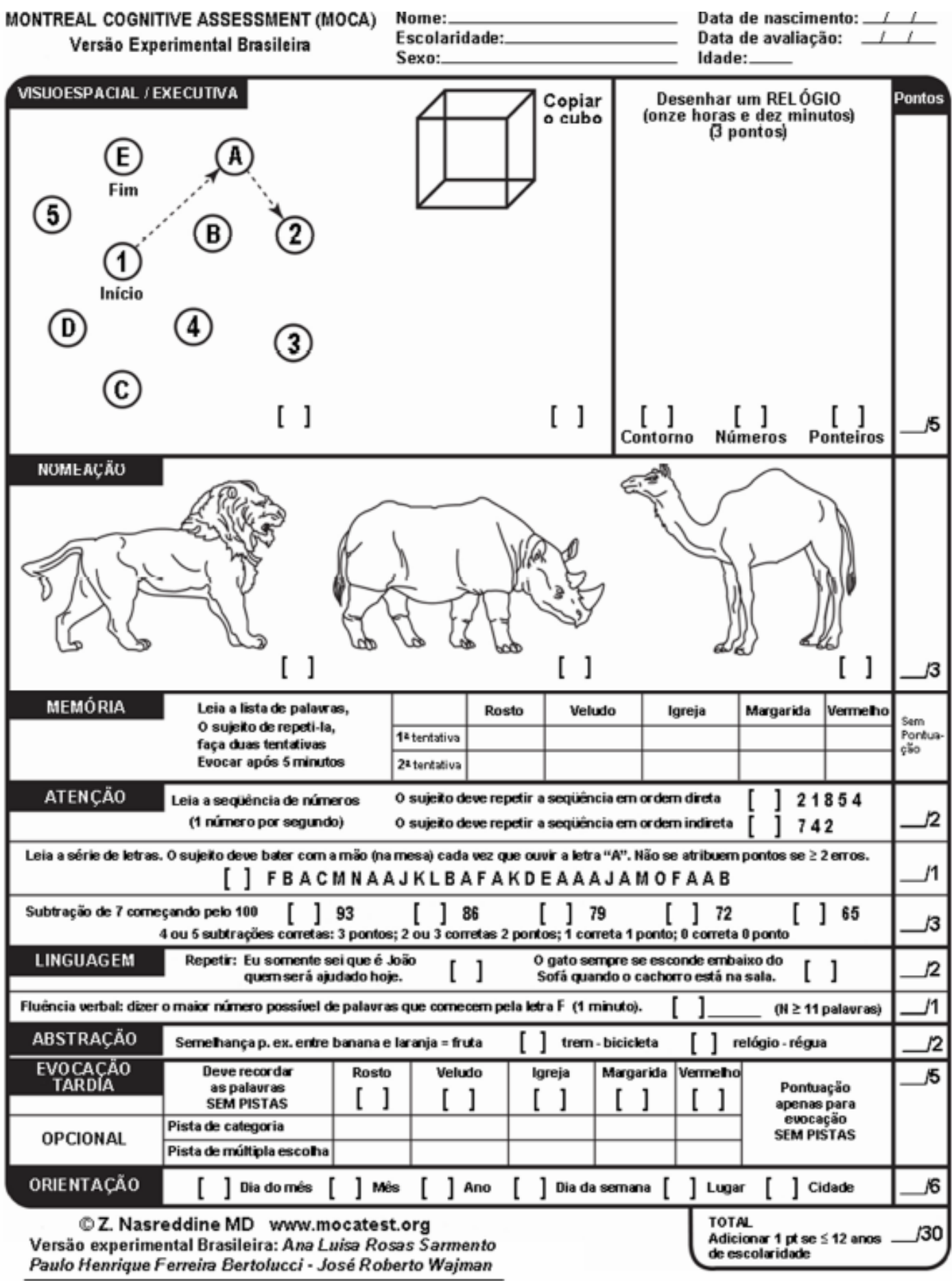




\section{Anexo 4}

PROTOCOLO M1 ALPHA - FOLHA DE ANOTAÇÃO

Nome:

Notaçăo da Entrevista Dirigida (primeira parte)

\begin{tabular}{|c|c|c|}
\hline Estímulos & & Compreensăo \\
\hline 1 & Bom dia. & $\mathrm{N}+?$ \\
\hline 2 & Comoé a seu nome? & $N+?$ \\
\hline 3 & Quantos anos você tem? & $\mathrm{N}+?$ \\
\hline \multirow{2}{*}{4} & Vacếmora em Bauru? & $\mathrm{N}+?$ \\
\hline & Dndevocê nasceu? & $\mathrm{N}+?$ \\
\hline \multirow{2}{*}{5} & Há quanto tempo você está na clínica? & $\mathrm{N}+?$ \\
\hline & (Caso necessário) Desde an o passado? Etc & $\mathrm{N}+?$ \\
\hline \multirow{2}{*}{6} & Como é que vacê está se sentin do? & $\mathrm{N}+?$ \\
\hline & Conte-me o que lhe aconteceu? & $\mathrm{N}+?$ \\
\hline \multirow{2}{*}{7} & Qual o seu trabalho? & $N+?$ \\
\hline & Ah! Bom. Explique um pouco. & $\mathrm{N}+$ ? \\
\hline \multirow{2}{*}{8} & Vocé tem bom apetite? & $\mathrm{N}+?$ \\
\hline & Oque é que vocé costuma comer? & $\mathrm{N}+$ ? \\
\hline \multirow{2}{*}{9} & Como é que o tempo está hoje? & $N+?$ \\
\hline & (Caso necessário): O tempo está. & $\mathrm{N}+$ ? \\
\hline
\end{tabular}

Notaçâo da Entrevista Dirigida (segunda parte)

\begin{tabular}{|l|l|}
\hline Reduçăo (quantitativa) & $\mathrm{N}+++\mathrm{S}$ \\
\hline Agramatismo & $\mathrm{N}+++\mathrm{S}$ \\
\hline Falta de Palavra & $\mathrm{N}+++\mathrm{S}$ \\
\hline Desvios Fonéticos & $\mathrm{N}+++\mathrm{S}$ \\
\hline Desvios Fon émicos (e/ou Neologismos) & $\mathrm{N}+++\mathrm{S}$ \\
\hline Desvios Vocabulares & $\mathrm{N}+++\mathrm{S}$ \\
\hline
\end{tabular}

2. Compreen sầo Oral das Palavras

\begin{tabular}{|l|c|c|c|c|c|}
\hline A canalizaçãonãofoi obtida( ) \\
\hline $1^{a}$ prancha & MALA & BOLSA & BALA & MACO & OUTRA \\
\hline $2^{\mathrm{a}}$ prancha & ESPADA & REVOLVER & ESCADA & LAPIS & OUTRA \\
\hline $3^{\circ}$ prancha & MAOO & PE & PĀO & FOLHA & OUTRA \\
\hline $4^{\circ}$ prancha & PENTE & CABELO & PONTE & ANCINHO & OUTRA \\
\hline $5^{\circ}$ prancha & FACA & PRATO & VACA & FOSSFORO & OUTRA \\
\hline
\end{tabular}


7. Compreensão Escrita des Frases Simples

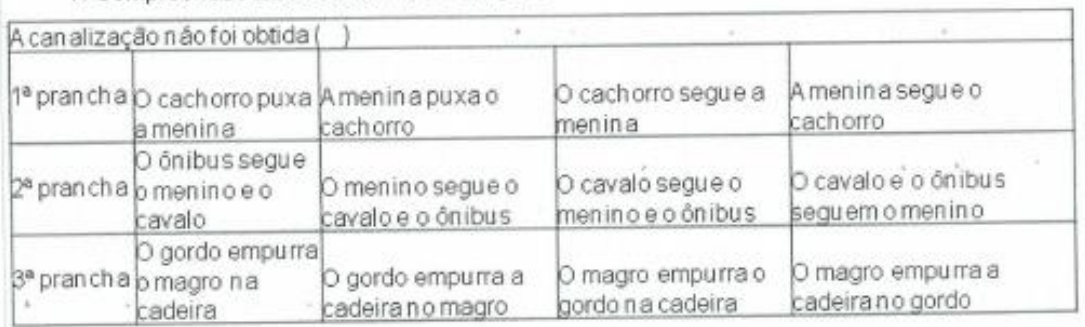

8. Provas de Cópia $\theta$ Ditado

Supressăo da escrita (ou esterotipia) ( )
O sujeito escreve com a mäu direita ( ) ou esquerda( )

\section{O TREME VELOZ}

Cópia

\begin{tabular}{|c|c|c|}
\hline \multicolumn{3}{|c|}{ A canalizaçăo năo foi obtida ( ) } \\
\hline \multicolumn{3}{|c|}{ Acópla eservil () } \\
\hline \multicolumn{2}{|c|}{ Avaliaçâo do grafismo } & $\mathrm{N}+++$ \\
\hline 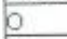 & $\mathrm{N}+$ & Dis \\
\hline rem & $\mathrm{N}+$ & Dis \\
\hline 8 & $\mathrm{~N}+$ & Dis \\
\hline veloz & $\mathrm{N}+$ & Dis \\
\hline
\end{tabular}

Ditado

\begin{tabular}{|c|c|c|}
\hline \multicolumn{3}{|c|}{ A can alizaçăo năo foi obtida ( ) } \\
\hline \multicolumn{3}{|c|}{ Acópia é servil ( ) } \\
\hline \multicolumn{2}{|c|}{ Avaliaça o do grafismo } & $\mathrm{N}+++$ \\
\hline 1. Quintal & $\mathrm{N}+$ & Dis \\
\hline 2. Trovão & $\mathrm{N}+$ & Dis \\
\hline 3. Mancha & $N+$ & Dis \\
\hline 4. As & $N+$ & Dis \\
\hline pêras & $\mathrm{N}+$ & Dis \\
\hline sáo & $\mathrm{N}+$ & Dis \\
\hline verdes & $\mathrm{N}+$ & Dis \\
\hline
\end{tabular}

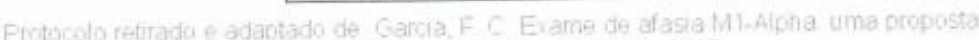

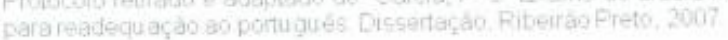


3. Compreensâo Oral das Frases Simples

\begin{tabular}{|c|c|c|c|c|}
\hline & náoto & & & \\
\hline "prancha & O homem com & O homem bebe & Amulhercome & ebe \\
\hline 2 prancha & Ame & Ameninacorre & Omenino anda & ocorre \\
\hline oranche & & brin & gato dorme & gato brinca \\
\hline
\end{tabular}

4. Compreen sáo Oral das Frases Complexas

\begin{tabular}{|c|c|c|c|c|}
\hline analiz & ắn âo foi obtic & 1 & & \\
\hline $1^{13}$ prancha & $\begin{array}{l}\text { D cavalo puxa o } \\
\text { menino }\end{array}$ & $\begin{array}{l}\text { P menino segueo } \\
\text { cavelu }\end{array}$ & $\begin{array}{l}\text { G menino puxao } \\
\text { cavalo }\end{array}$ & a caralo segue o monino \\
\hline $2^{a}$ prancha & $\begin{array}{l}\text { O cach orro } \\
\text { segue a mulher } \\
\text { go carro }\end{array}$ & $\begin{array}{l}\text { A mulher segue o } \\
\text { cachorro e o carro }\end{array}$ & $\begin{array}{l}\text { O carro segue a } \\
\text { mulher e o cachorro }\end{array}$ & $\begin{array}{l}\text { A mulher e o cach orro } \\
\text { seguem o carro }\end{array}$ \\
\hline$\beta^{\circ}$ prancha & $\begin{array}{l}\text { Opequeno } \\
\text { mpurra o } \\
\text { grandena } \\
\text { cadeira }\end{array}$ & $\begin{array}{l}\text { D pequeno empurra } \\
\text { acadeira no arande }\end{array}$ & $\begin{array}{l}\text { O gran de empurra } 0 \\
\text { pequeno na cadeira }\end{array}$ & $\begin{array}{l}6 \text { grande empurre a } \\
\text { cadeira no pequeno }\end{array}$ \\
\hline
\end{tabular}

5. Compreen sâo Oral das Palevras

\begin{tabular}{|c|c|c|c|c|c|}
\hline \multicolumn{6}{|c|}{ Acanalizaçãonáo foi obtida ( ) } \\
\hline $1^{3 \mathrm{p} p r a n c h s}$ & LATA & VASILHA & GATA & BARRIL & OUTRA \\
\hline $2{ }^{\circ}$ prancha & BOLO & SORVETE & ROLO & PNEU & OUTRA \\
\hline $3^{\mathrm{s}}$ prancha & ovo & GALINHA & osso & BOLADE TENIS & QUTRA \\
\hline $4^{\circ}$ prancha & ROSA & OUTRAFLOR & RODA & SINO & OUTRA \\
\hline $5^{5}$ prancha & BOLA & REDE & MOLA & NOVELO & OUTRA \\
\hline
\end{tabular}

6. Compreensão Escrita das Frases Simples

\begin{tabular}{|c|c|c|c|}
\hline A canalizaçāo nâo foi obtidal & & & \\
\hline 13 prancha A mulher escreve & Ohomemle & Amulnerles & Ö homem escreve \\
\hline 2 pranch a 0 cach orro brinca & D cach orro dorme & 0 gato brinca & O gato dorme \\
\hline
\end{tabular}

$3^{3}$ prancha $O$ caminháo desce $D$ caminhảo sobe $O$ trem desce $O$ trem sobe 
9. Prova de Leitura em Voz Alta

\begin{tabular}{|c|c|c|}
\hline \multicolumn{3}{|l|}{ A canalizaçẫo não foi obtida( ) } \\
\hline Avaliaçăo da realizaçâo fonética &. & $\mathrm{N}+++$ \\
\hline 1. $\mathrm{Pe}$ & $N+\cdots$ & $\mathrm{Pm}$ \\
\hline 2. Cruz & $N+$ & $\mathrm{Pm}$ \\
\hline 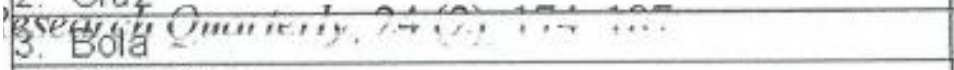 & $\mathrm{N}+$ & $\mathrm{Pm}$ \\
\hline 4. Colchäo & $\mathrm{N}+$ & $\mathrm{Pm}$ \\
\hline 5. Cinema & $\mathrm{N}+$ & $\mathrm{Pm}$ \\
\hline 6. Cónstruçắo & $\mathrm{N}+{ }^{\prime}$ & $\mathrm{Pm}$ \\
\hline 7. Gasolina & $N+$ & $\mathrm{Pm}$ \\
\hline 8. Complicaçăo & $N+$ & $\mathrm{Pm}$ \\
\hline 9. O aviâo foi embora & $N+$ & $\mathrm{Pm}$ \\
\hline 10. Aquele gato branco do moinho qu ebrou a lâmpada & $N+$ & $\mathrm{Pm}$ \\
\hline 11. Nós vamos vê-la se você permitir & $\mathrm{N}+$ & $\mathrm{Pm}$ \\
\hline
\end{tabular}

10. Prova de repetiçấo

\begin{tabular}{|c|c|c|}
\hline \multicolumn{3}{|l|}{ Acanalização nāo foi obtida( ) } \\
\hline Avaliaçăo da realizaçâo fon ética & $+\ldots \ldots$ & $\mathrm{N}+++$ \\
\hline 1. $\mathrm{Pa}$ & $\mathrm{N}+$ & $\mathrm{Pm}$ \\
\hline 2. Trem & $\mathrm{N}+$ & Pm \\
\hline 3. Bato & $\mathrm{N}+$ & $\mathrm{Pm}$ \\
\hline 4. Pratos & $\mathrm{N}+$ & $\mathrm{Pm}$ \\
\hline 5. Cavalo & $\mathrm{N}+$ & $\mathrm{Pm}$ \\
\hline 6. Cruzeiros & $N+$ & $\mathrm{Pm}$, \\
\hline 7.:Sabonetes. & $\mathrm{N}+$ & $\mathrm{Pm}$. \\
\hline 8. Embarcaçăo & $N+$ & $\mathrm{Pm}$, \\
\hline 9. O céu está azul & $\mathrm{N}+$ & $\mathrm{Pm}$ ! \\
\hline 10. - cachorro preto grande da vizinha mordeu o menino & $\mathrm{N}+$ & $P_{R 1}$ \\
\hline 11. Nós lhe daremos desde que ela reclame & $\mathrm{N}+$ & $\mathrm{Pm}$ \\
\hline
\end{tabular}


11. Prova de Denominação

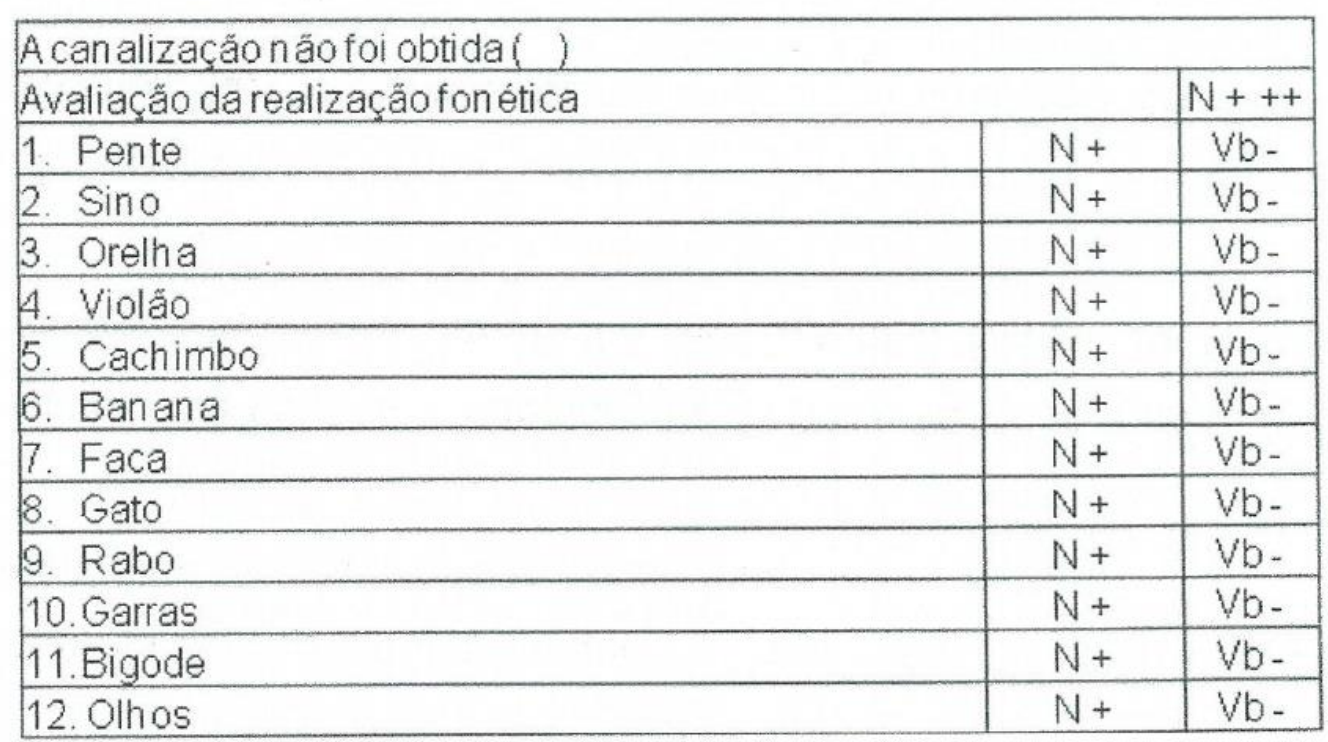


Anexo 5

ESCALA GERIÁTRICA DE DEPRESSÃO ${ }^{1}$

(Yesavage, 1983)

PACIENTE:

DATA DA AVALIAÇÃO: AVALIADOR:

1. Você está satisfeito com sua vida?

2. Abandonou muitos de seus interesses e atividades?

3. Sente que sua vida está vazia?

4. Sente-se frequientemente aborrecido?

5. Você tem muita fé no futuro?

6. Tem pensamentos negativos?

7. Na maioria do tempo está de bom humor?

8. Tem medo de que algo de mal vá lhe acontecer?

9. Sente-se feliz na maioria do tempo?

10. Sente-se freqüentemente desamparado, adoentado?

11. Sente-se freqüentementeintranqüilo?

12. Prefere ficar em casa em vez de sair?

13. Preocupa-se muito com o futuro?

14. Acha que tem mais probl de memória que os outros?

15. Acha bom estar vivo?

16. Fica freqüentemente triste?

17. Sente-se inútil?

18. Preocupa-se muito com o passado?

19. Acha a vida muito interessante?

20. Para você é difícil começar novos projetos?

21. Sente-se cheio de energia?

22. Sente-se sem esperança?

23. Acha que os outros têm mais sorte que você?

24. Preocupa-se com coisas sem importância?

25. Sente frequientemente vontade de chorar?

26. É difícil para você concentrar-se?

27. Sente-se bem ao despertar?

28. Prefere evitar as reuniões sociais?

29. É fácil para você tomar decisões?

30. O seu raciocínio está tão claro quanto antigamente?

\begin{tabular}{|c|c|c|}
\hline Sim & ( & ) Não \\
\hline ) $\operatorname{Sim}($ & ) Nã & \\
\hline ) Sim & ( & ) Não \\
\hline ) Sim & ( & ) Não \\
\hline Sim & ( & ) Não \\
\hline ) Sim & ( & ) Não \\
\hline ) $\mathrm{Sim}$ & ( & ) Não \\
\hline ) Sim & ( & ) Não \\
\hline ) $\mathrm{Sim}$ & ( & ) Não \\
\hline \multicolumn{3}{|c|}{ ) $\operatorname{Sim}($ ) Não } \\
\hline Sim & ( & ) Não \\
\hline Sim & ( & ) Não \\
\hline $\mathrm{Sim}$ & ( & ) Não \\
\hline \multicolumn{3}{|c|}{ ()Sim ( ) Não } \\
\hline ) $\mathrm{Sim}$ & ( & ) Não \\
\hline Sim & ( & ) Não \\
\hline ) Sim & ( & ) Não \\
\hline ) Sim & ( & ) Não \\
\hline ) $\mathrm{Sim}$ & ( & ) Não \\
\hline ) Sim & ( & ) Não \\
\hline ) $\mathrm{Sim}$ & 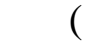 & ) Não \\
\hline ) Sim & ( & ) Não \\
\hline ) Sim & ( & ) Não \\
\hline ) Sim & ( & ) Não \\
\hline ) Sim & ( & ) Não \\
\hline ) Sim & ( & ) Não \\
\hline \multicolumn{3}{|c|}{ ) Sim ( ) Não } \\
\hline ) Sim & ( & ) Não \\
\hline ) $\mathrm{Sim}$ & ( & ) Não \\
\hline ) $\mathrm{Sim}$ & ( & ) Não \\
\hline
\end{tabular}

\footnotetext{
${ }^{1}$ Pontuação: 0 quando for diferente da resposta em negrito 1 quando for igual à resposta em negrito Total $>10=$ suspeita de depressão
} 


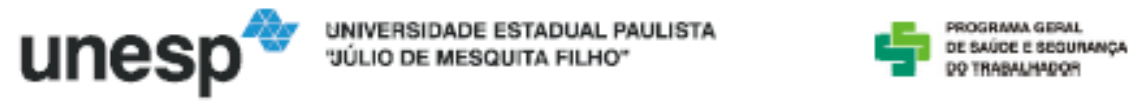

ESCALA HAD - AV ALIAÇÃO DO NIVEL DE ANSIEDADE E DEPRESSĀO

\begin{tabular}{|c|c|c|c|}
\hline \multicolumn{4}{|l|}{ DADOS PESSOAIS } \\
\hline \multicolumn{4}{|l|}{\begin{tabular}{|l|l|} 
NOME & \\
\end{tabular}} \\
\hline \multicolumn{4}{|c|}{ ORIENTAÇOES PARA REALIZACAAO DO TESTE } \\
\hline \multicolumn{4}{|c|}{ Assinale com "X" a alternativa que melhor descreve sua resposta a cada questäo. } \\
\hline \multicolumn{4}{|c|}{ 1. Eu me sinto tensa (o) ou contraida (o): } \\
\hline $\begin{array}{l}\text { ( ) a maior parte do } \\
\text { tempo[3] }\end{array}$ & $\begin{array}{l}\text { ( ) boa parte do } \\
\text { tempo[2] }\end{array}$ & ( ) devez em quando[1] & ( ) nunca $[0]$ \\
\hline \multicolumn{4}{|c|}{2 Eu ainda sinto que gosto das mesmas coisas de antes: } \\
\hline $\begin{array}{l}\text { ( ) sim, do mesmo jeito } \\
\text { que antes [0] }\end{array}$ & $\begin{array}{l}\text { ( ) não tanto quanto } \\
\text { antes [1] }\end{array}$ & ( ) só um pouco [2] & $\begin{array}{l}\text { ( ) já não consigo ter } \\
\text { prazzer em nada [3] }\end{array}$ \\
\hline \multicolumn{4}{|c|}{3 Eu sinto uma espécie de medo, como se alguma coisa ruim fosse acontecer } \\
\hline $\begin{array}{l}\text { ( ) sim, de jeito muito } \\
\text { forte [3] }\end{array}$ & $\begin{array}{l}\text { ( ) sim, mas năo tăo } \\
\text { forte [2] }\end{array}$ & $\begin{array}{l}\text { ( ) um pouco, mas isso } \\
\text { näo me preccupa [1] }\end{array}$ & $\begin{array}{l}\text { ( ) näo sinto nada } \\
\text { disso[1] }\end{array}$ \\
\hline \multicolumn{4}{|c|}{ 4. Dou risada e me divirto quando ve jo coisas engraçadas } \\
\hline $\begin{array}{c}(\text { ) do mesmo jeito que } \\
\text { antesion }\end{array}$ & $\begin{array}{l}\text { ( ) atualmente um pouco } \\
\text { menos[1] }\end{array}$ & $\begin{array}{l}\text { ( ) ahualmente bem } \\
\text { menos[2] }\end{array}$ & ( ) năo consigo mais[3] \\
\hline \multicolumn{4}{|c|}{ 5. Estou com a cabeça cheia de preocupaçoes } \\
\hline $\begin{array}{l}\text { ( ) a maior parte do } \\
\text { tempo[3] }\end{array}$ & ( ) boa parte do tempo[2] & ( ) de vez em quando[1] & ( ) raramente[0] \\
\hline \multicolumn{4}{|l|}{ 6. Eu me sinto alegre } \\
\hline ( ) nunca[3] & ( ) poucas vezes[2] & ( ) muitas vezes[1] & $\begin{array}{l}\text { ( ) a malor parte do } \\
\text { tempo[0] }\end{array}$ \\
\hline \multicolumn{4}{|c|}{ 7. Consigo ficar sentado à vontade e me sentir relaxado: } \\
\hline ( ) sim, quase sempre[0] & ( ) multas veres[1] & ( ) poucas vezes[2] & ( ) nunc:[3] \\
\hline \multicolumn{4}{|c|}{ 8. Eu estou lenta (o) para pensar e fazer coisas: } \\
\hline ( ) quase sempre[3] & ( ) multas veres[2] & ( ) poucas vezes[1] & $(\mathrm{l})$ nunca[0] \\
\hline \multicolumn{4}{|c|}{ 9. Eu tenho uma sensaçāo ruim de medo, como um frio na barriga ou um aperto no estômago: } \\
\hline \multicolumn{4}{|c|}{ 10. Eu perdi o interesse em cuidar da minha aparéncia: } \\
\hline ( ) completamente[3] & $\begin{array}{l}\text { ( ) náo estou mals me } \\
\text { culdando como eu deveria[2] }\end{array}$ & $\begin{array}{c}\text { ( ) tavez nao tanto quanto } \\
\text { antes[1] }\end{array}$ & $\begin{array}{l}\text { ( ) me cuido do mesmo } \\
\text { lelto que antes[o] }\end{array}$ \\
\hline \multicolumn{4}{|c|}{ 11. Eu me sinto inquieta (o), como se eu nāo pudesse ficar parada $(0)$ em lugar nenhum: } \\
\hline ( $)$ sim, demais[3] & ( ) bestante [2] & ( ) um pouco[1] & ( ) naso me sinto assim[0] \\
\hline \multicolumn{4}{|c|}{12 Fico animada (o) esperando animado as coisas boas que estäo por vir } \\
\hline $\begin{array}{c}\text { ( ) do mesmo jeito que } \\
\text { antes[0] }\end{array}$ & $\begin{array}{c}\text { ( ) um pouco menos que } \\
\text { antes[1] }\end{array}$ & $\begin{array}{l}\text { ( ) bem menos do que } \\
\text { gntes[2] }\end{array}$ & ( ) quase nunca[3] \\
\hline \multicolumn{4}{|c|}{ 13. De repente, tenho a sensação de entrar em pânico: } \\
\hline $\begin{array}{l}\text { ( ) a quase todo } \\
\text { momento[3] }\end{array}$ & ( ) varias vezes[2] & ( ) devez em quando[1] & ( ) napo senti isso[0] \\
\hline \multicolumn{4}{|c|}{$\begin{array}{l}\text { 14. Consigo sentir prazer quando assisto a um bom programa de televisão, de rádio ou quando leio alguma } \\
\text { coisa: }\end{array}$} \\
\hline ( ) quase sempre[0] & ( ) várias vezes[1] & $(1)$ poucas vezes[2] & ( ) quase nunca[3] \\
\hline \multicolumn{4}{|l|}{ RESULTADO DO TESTE } \\
\hline \multicolumn{4}{|l|}{ OBSERVACOES: } \\
\hline \multicolumn{2}{|c|}{ 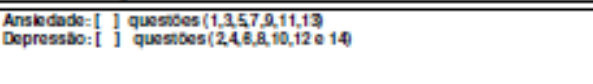 } & 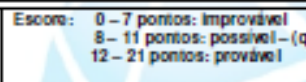 & Ulontwel ou duvidoss) \\
\hline \multicolumn{4}{|c|}{ NOME RESPONSAVEL PELA APLICACAAO DO TESTE } \\
\hline \multicolumn{4}{|l|}{$\overline{\text { DATA }}$} \\
\hline \multicolumn{4}{|c|}{ 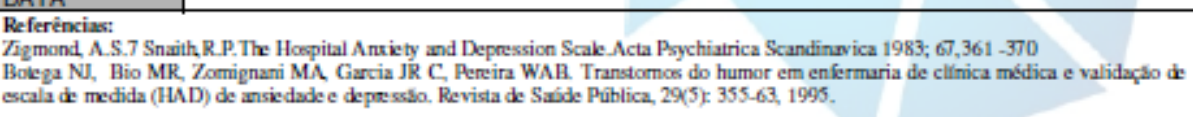 } \\
\hline
\end{tabular}


Apêndices

Apêndice 1

\section{TERMO DE AUTORIZAÇÃO}

Meu nome é Mariana Ducatti Almeida e estou realizando uma pesquisa de mestrado que tem como título "Equivalência de Estímulos e Responder por Exclusão em Idoso com Comprometimento Cognitivo”, sob orientação da profa. Dra. Andréia Schmidt, professora da Pós-Graduação em Psicobiologia da Universidade de São Paulo. Nessa pesquisa, estamos estudando maneiras de ajudar idosos que tenham diagnóstico de Doença de Alzheimer em estágio inicial a manter a lembrança de palavras, especialmente palavras relacionadas ao seu cotidiano, como nome de familiares, por exemplo. Para isso, desenvolvemos um método de ensino/recuperação dessas palavras, que é feito com a ajuda de um computador. Nesse procedimento, as palavras são apresentadas pelo computador e o participante deve tocar na tela, escolhendo a figura apresentada que corresponde à palavra que foi ditada. Esse procedimento é feito em passos, ao longo de vários dias. A duração total desse procedimento é de 4 meses aproximadamente, sendo que as sessões de ensino serão feitas de segunda a sexta-feira, por aproximadamente 30 minutos com cada idoso.

Para selecionar os idosos que participarão da pesquisa, precisaremos fazer em todos eles uma avaliação de memória e da cognição (a capacidade dele se localizar no tempo e no espaço e de responder algumas questões de raciocínio lógico), por meio de dois testes, chamados de Mini Exame do Estado Mental, do Montreal CognitiveAssessment (MOCA). Além disso, precisamos avaliar se esses idosos apresentam depressão, por meio do Teste "Inventário Beck de Depressão", e também avaliar se eles se lembram do nome de uma série de figuras, por meio do teste para Afasia M1-Alpha. Os resultados de todos esses testes serão disponibilizados para a instituição para serem anexados ao prontuário de cada residente.

A pesquisa não envolverá nenhum custo para a instituição assim como não haverá nenhuma remuneração, nem para o participante e nem para a instituição. Da mesma forma, não há riscos previsíveis para a participação dos idosos. A identidade de todos os participantes e da instituição não será divulgada e os resultados da pesquisa serão usados exclusivamente para fins científicos, ou seja, para o desenvolvimento de 
estratégias que possam ajudar pessoas idosas que apresentem problemas de memória e linguagem, a manter ou recuperar o vocabulário.

Garantimos que a instituição poderá ter acesso aos dados da pesquisa ou esclarecimentos sobre a mesma em qualquer momento que desejar, bastando, para isso, entrar em contato com as pesquisadoras por meio do telefone abaixo descrito, ou pessoalmente, uma vez que a coleta de dados ocorrerá nas dependências da própria instituição. Caso autorize o desenvolvimento dessa pesquisa em sua instituição, por gentileza assine o termo de autorização abaixo. Desde já, agradecemos a sua atenção e disponibilidade.

\begin{tabular}{l} 
(cargo) \\
\hline $\begin{array}{l}\text { instituição_ } \\
\text { documento, que sejam realizados neste local todos os procedimentos acima, sob } \\
\text { responsabilidade de Mariana Ducatti. Declaro que fui esclarecido(a) sobre esses } \\
\text { procedimentos e que tenho sob minha guarda uma cópia desse termo de autorização. }\end{array}$
\end{tabular}

Ribeirão Preto, de de 2013.

Assinatura do Responsável pela Instituição:

Pesquisadoras:

Mariana Ducatti Almeida

RG: 46.026.274 - 9

End: Rua Henrique Dumont, 1375, apt $^{\circ} 38$

Ribeirão Preto/SP

Telefone: (16) 3967 - 2659
Prof. Dr ${ }^{\mathrm{a}}$ Andréia Schmidt

RG: 2.243 .897

End. Av. Bandeirantes, 3900

Ribeirão Preto/SP

Telefone: $3602-3742$

Comitê de Ética em Pesquisa da Faculdade de Filosofia, Ciências e Letras de Ribeirão Preto - USP Avenida Bandeirantes, 3900 - bloco 3 - sala 16 - 14040-901 - Ribeirão Preto - SP - Brasil Fone: (16) 3602-4811 / Fax: (16) 3633-2660

E-mail: coetp@ffclrp.usp.br 
Apêndice 2

\section{TERMO DE CONSENTIMENTO LIVRE E ESCLARECIDO - Cuidador}

Meu nome é Mariana Ducatti Almeida e estou realizando uma pesquisa de mestrado que tem como título "Equivalência de Estímulos e Responder por Exclusão em Idoso com e sem Comprometimento Cognitivo”, sob orientação da profa. Dra. Andréia Schmidt, professora da Pós-Graduação em Psicobiologia da Universidade de São Paulo. Nessa pesquisa, estamos estudando maneiras de ajudar idosos que tenham problemas de memória ou dificuldades de recordar palavras, especialmente palavras relacionadas ao seu dia a dia, como nome de familiares, por exemplo. Para isso, desenvolvemos um método de ensino/recuperação dessas palavras, que é feito com a ajuda de um computador. Nesse método, as palavras são apresentadas pelo computador e o participante deve tocar na tela, escolhendo uma entre as figuras apresentadas na tela e que corresponde à palavra que foi ditada. Esse procedimento é feito em passos, ao longo de vários dias. A duração total desse procedimento é de 4 meses aproximadamente, sendo que as sessões de ensino serão feitas de segunda a sexta-feira, por aproximadamente 30 minutos com cada participante. Estamos estudando pessoas com mais de 60 anos que tenham problemas de memória, assim como pessoas dessa faixa de idade Para selecionar os idosos que participarão da pesquisa, precisaremos fazer uma avaliação de memória e da cognição (avaliando a capacidade dele se localizar no tempo e no espaço e de responder algumas questões de raciocínio lógico), por meio de dois testes, chamados de Mini Exame do Estado Mental, e Montreal CognitiveAssessment (MOCA). Além disso, precisamos avaliar se os possíveis participantes apresentam depressão, por meio do Teste "Inventário Beck de Depressão", e também avaliar se eles se lembram do nome de uma série de figuras, por meio do teste para Afasia M1-Alpha. Os resultados de todos esses testes serão disponibilizados para o participante (faremos uma entrevista com cada um, contando os resultados dos testes) e para a instituição com finalidade de serem anexados ao prontuário de cada residente.

A pesquisa não envolverá nenhum custo, assim como não haverá nenhuma remuneração, nem para o participante e nem para a instituição. Da mesma forma, não há riscos previsíveis para a participação dos idosos. O benefício esperado com a pesquisa é o desenvolvimento de novas formas de ajudar pessoas com perda de memória. Para o participante, especificamente, a pesquisa é uma espécie de exercício para a memória. 
A identidade de todos os participantes e da instituição não serão divulgadas e os resultados da pesquisa serão usados exclusivamente para fins científicos, ou seja, para o desenvolvimento de estratégias que possam ajudar pessoas idosas que apresentem problemas de memória e linguagem, a manter ou recuperar o vocabulário. Esses resultados serão apresentados em congressos científicos, mas ainda assim, a identidade dos participantes e da instituição não serão divulgados.

Garantimos que o participante, seu familiar e a instituição na qual reside poderá ter acesso aos dados da pesquisa ou esclarecimentos sobre a mesma em qualquer momento que desejar, bastando, para isso, entrar em contato com as pesquisadoras por meio do telefone abaixo descrito, ou pessoalmente, uma vez que a coleta de dados ocorrerá nas dependências da própria instituição. Caso autorize a participação de seu familiar neste trabalho, por gentileza assine o termo de consentimento abaixo. Desde já, agradecemos a sua atenção e disponibilidade.

$\mathrm{Eu}$,

portador do $\mathrm{RG} \quad \mathrm{n}^{\circ}$

(filho/filha/marido/esposa)

aceito

que

portador

do $\mathrm{RG} \mathrm{n}^{\circ}$ , através desse documento, participe da pesquisa acima descrita. Declaro que fui esclarecido(a) sobre esses procedimentos e que tenho sob minha guarda uma cópia desse termo de consenimento.

Ribeirão Preto, de de 2013

Assinatura do Participante:

Pesquisadoras:

Mariana Ducatti Almeida

RG: 46.026.274 - 9

End: Rua Henrique Dumont, 1375, $\mathrm{apt}^{\mathrm{o}} 38$

Ribeirão Preto/SP

Telefone: (16) 3967 - 2659
Prof. Dr ${ }^{\mathrm{a}}$ Andréia Schmidt

RG: 2.243 .897

End. Av. Bandeirantes, 3900

Ribeirão Preto/SP

Telefone: 3602-3742 
Apêndice 3

Entrevista Estruturada - Participante de Pesquisa/Cuidador

1. Dados Pessoais

Nome:

Data de nascimento:

Idade:

Endereço:

Telefone:

Escolaridade:

Profissão:

Estado Civil:

2. Reside com:

\begin{tabular}{|l|l|l|l|}
\hline Nome & Parentesco & Profissão & Idade \\
\hline & & & \\
\hline & & & \\
\hline & & & \\
\hline & & & \\
\hline
\end{tabular}

3. Informações sobre a rotina (atividades, funções na casa, etc...).

4. Realiza algum tratamento? Se sim, qual? Qual a medicação utilizada? 